\title{
WSRC-TR-2003-00254
}

SRT-RPP-2003-00120

\section{Integrated Sr/TRU Precipitation and Cs Ion Exchange Process Validation (U)}

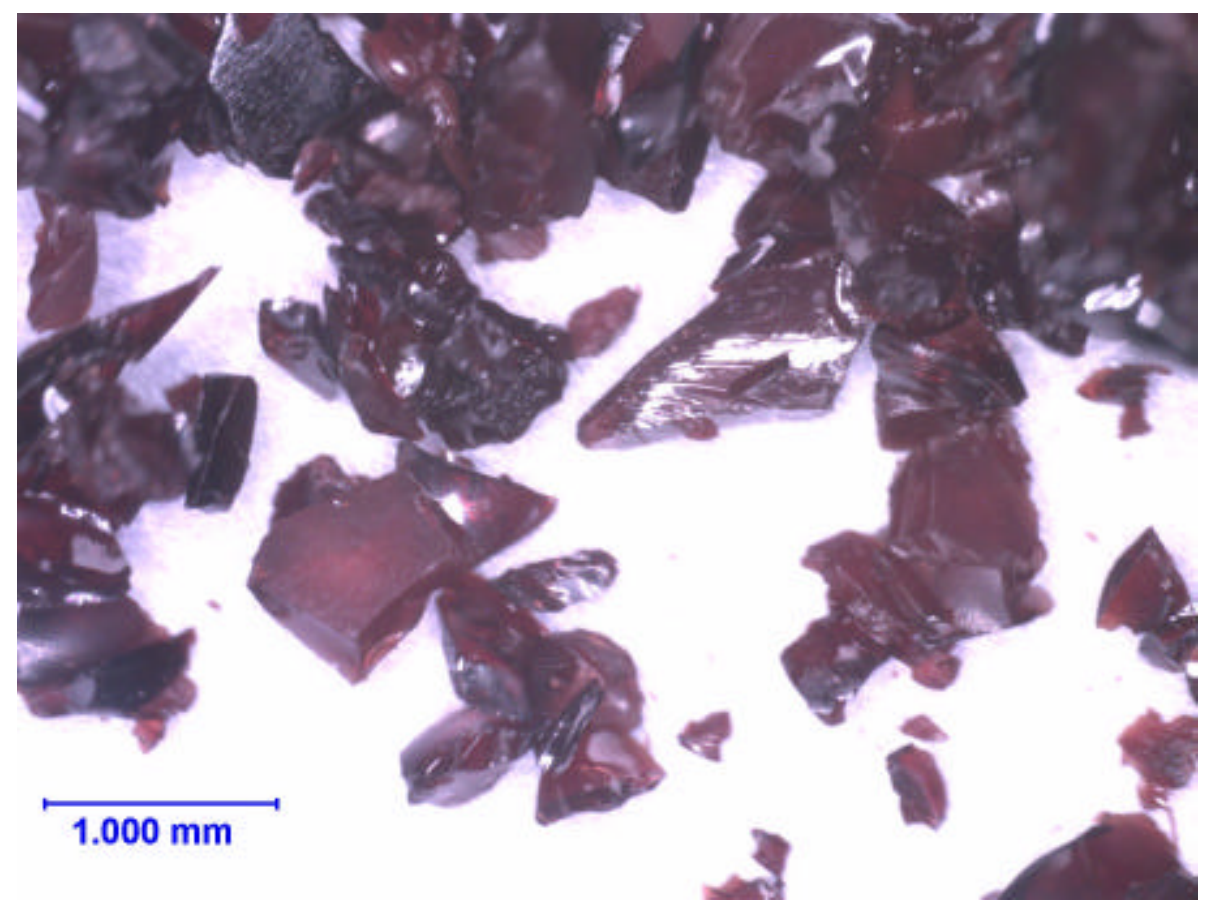

Westinghouse Savannah River Company

Savannah River Site

Aiken, SC 29808

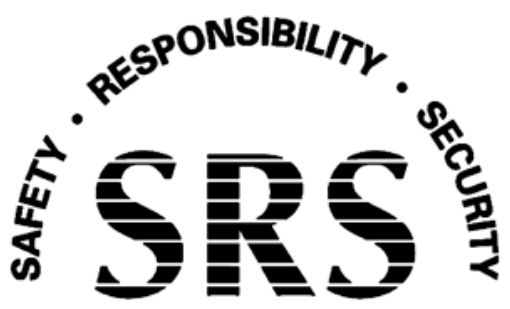

Prepared for the U.S. Department of Energy under Contract No. DE-AC09-96SR18500 
This document was prepared in conjunction with work accomplished under Contract No. DE-AC09-96SR18500 with the U. S. Department of Energy.

\section{DISCLAIMER}

This report was prepared as an account of work sponsored by an agency of the United States Government. Neither the United States Government nor any agency thereof, nor any of their employees, makes any warranty, express or implied, or assumes any legal liability or responsibility for the accuracy, completeness, or usefulness of any information, apparatus, product or process disclosed, or represents that its use would not infringe privately owned rights. Reference herein to any specific commercial product, process or service by trade name, trademark, manufacturer, or otherwise does not necessarily constitute or imply its endorsement, recommendation, or favoring by the United States Government or any agency thereof. The views and opinions of authors expressed herein do not necessarily state or reflect those of the United States Government or any agency thereof.

This report has been reproduced directly from the best available copy.

Available for sale to the public, in paper, from: U.S. Department of Commerce, National Technical Information Service, 5285 Port Royal Road, Springfield, VA 22161, phone: (800) 553-6847, fax: (703) 605-6900

email: orders@ntis.fedworld.gov

online ordering: http://www.ntis.gov/help/index.asp

Available electronically at http://www.osti.gov/bridge

Available for a processing fee to U.S. Department of Energy and its contractors, in paper, from: U.S. Department of Energy, Office of Scientific and Technical Information, P.O. Box 62, Oak Ridge, TN 37831-0062,

phone: (865)576-8401,

fax: (865)576-5728

email: $\underline{\text { reports@ adonis.osti.gov }}$ 


\section{WSRC-TR-2003-00254}

SRT-RPP-2003-00120

\section{KEYWORDS:}

River Protection Project

Ion Exchange

Cesium

Storage Effects

Precipitates

Sorption

AN-105

AN-107

Optical Microscopy

Surface Characterization

SEM

$E D X$

RETENTION - Permanent

\section{Integrated Sr/TRU Precipitation and Cs Ion Exchange Process Validation (U)}

Steven M. Serkiz, 773-A

Kimberly R. Powell, 773-43A

Adrian L. Pishko, 735-11 A

Publication Date: August 4, 2003

Westinghouse Savannah River Company

Savannah River Site

Aiken, SC 29808

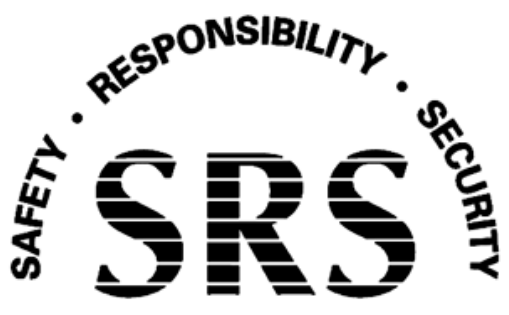

Prepared for the U.S. Department of Energy under Contract No. DE-AC09-96SR18500 
DOCUMENT: $\quad$ WSRC-TR-2003-00254 (SRT-RPP-2003-00120)

TITLE: Integrated Sr/TRU Precipitation and Cs Ion Exchange Process Validation (U)) 
WESTINGHOUSE SAVANNAH RIVER COMPANY

Integrated Sr/TRU Precipitation and

Cs Ion Exchange Process Validation (U)
Report:

WSRC-TR-2003-00254

SRP-RPP-2003-00120

Revision (Date): $\quad$ Rev. 0 (8/04/03)

Page:

\section{TABLE OF CONTENTS}

\section{EXECUTIVE SUMMARY}

7

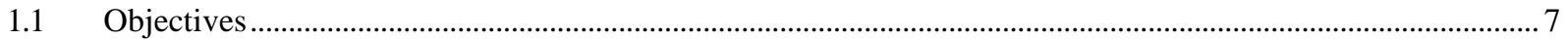

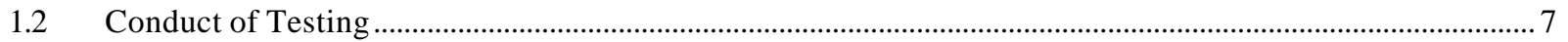

1.3 Results and Performance Against Objectives …………………………...................................................... 8

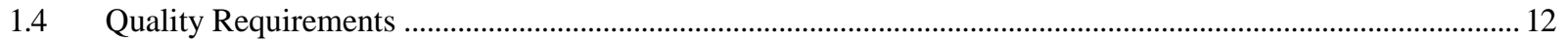

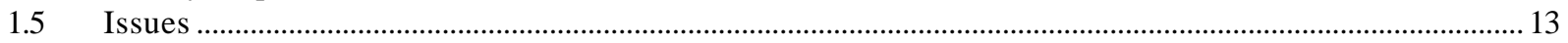

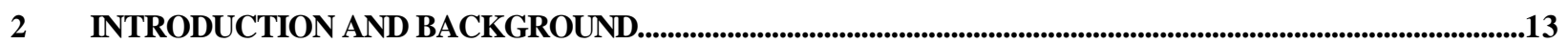

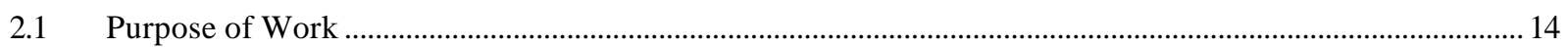

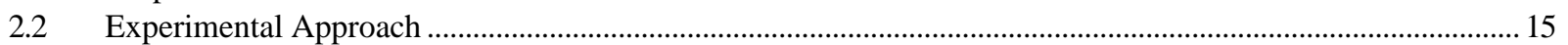

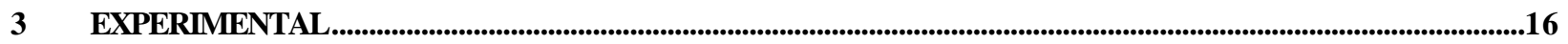

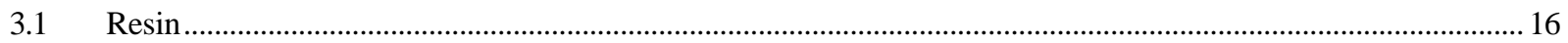

3.1.1 Characterization and Pretreatment …………...............................................................................

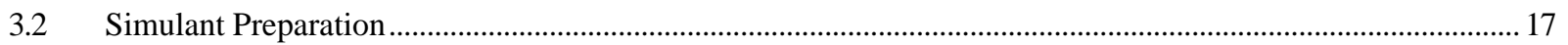

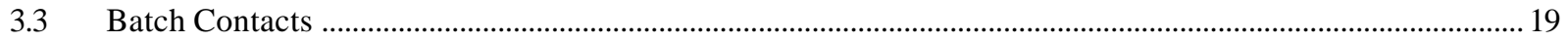

3.3.1 Analytical Techniques ................................................................................................................21

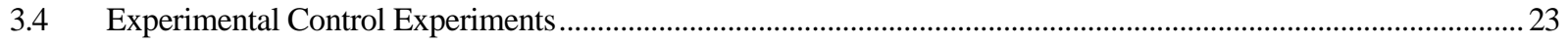

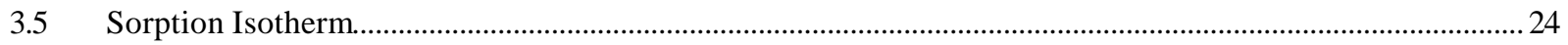

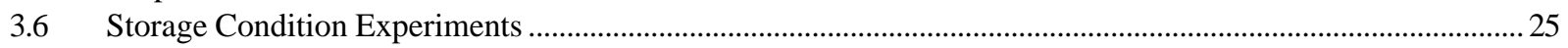

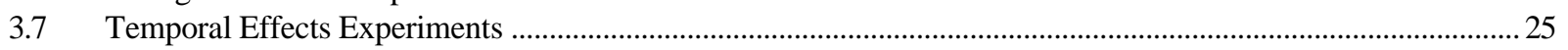

NOTES: OM = OPTICAL MICROSCOPY; SEM = SCANNING ELECTRON MICROSCOPY ......................................27

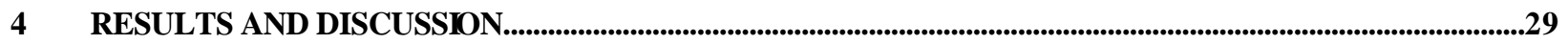

$4.1 \quad$ Unreacted Resin Characterization..............................................................................................................2 29

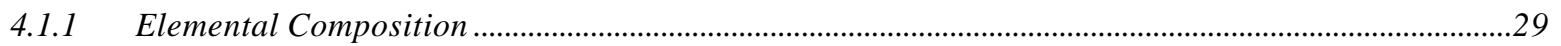

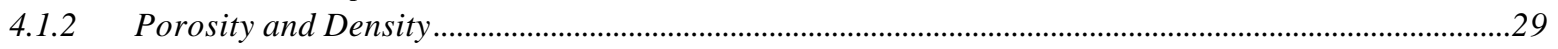

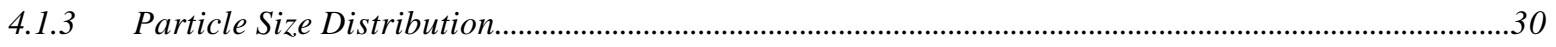

4.1.4 Optical Microscopy …………………………….......................................................................

4.1.5 Scanning Electron Microscopy

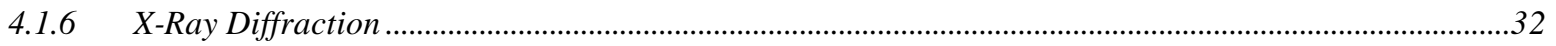

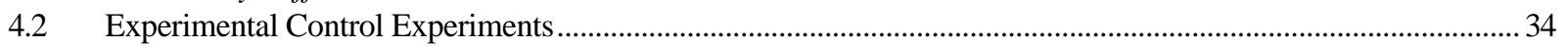

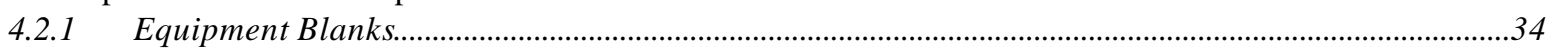

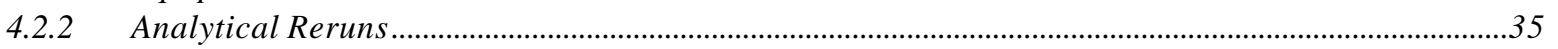

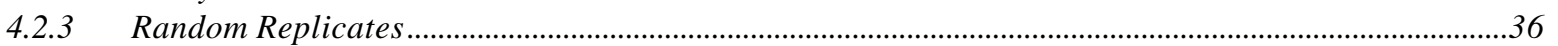

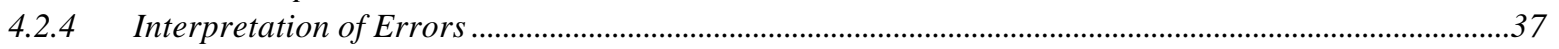

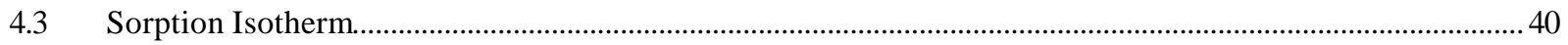

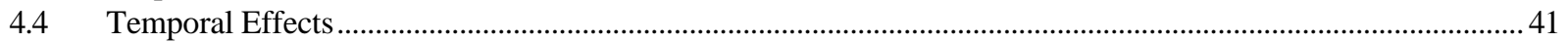

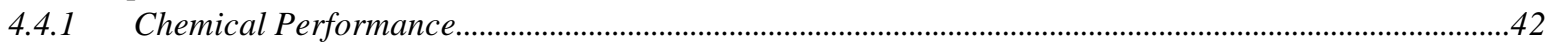

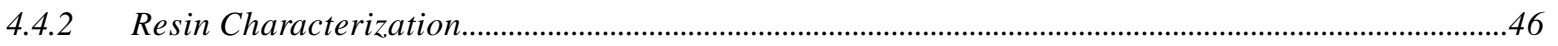

4.4.3 Temporal Effects Summary ……………………..........................................................................53

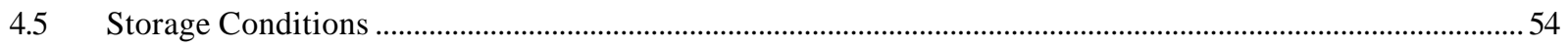

4.5.1 Chemical Performance..........................................................................................................................5

Storage Conditions Summary .............................................................................................................60

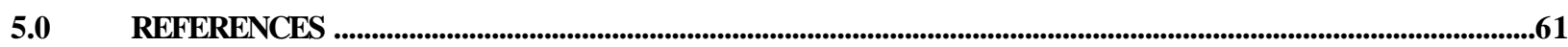

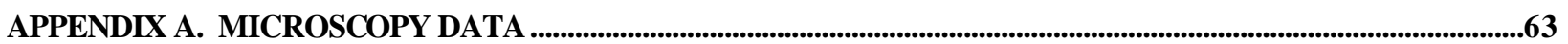




\section{LIST OF TABLES}

TABLE 3-1 EXPECTED CONCENTRATIONS OF SELECTED SPECIES IN ORIGINAL HANFORD SimUlANTS BASED ON

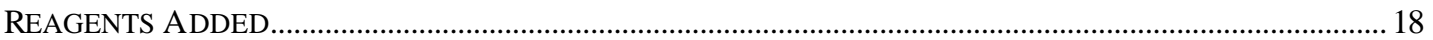

TABle 3-2 ICP-ES MEASURED MOlar CONCENTRATIONS (MOLE/L) OF SELECTED SPECIES IN EXPERIMENTAL

BLANKS OF HANFORD SIMULANTS USED FOR BATCH CONTACTS.......................................................... 19

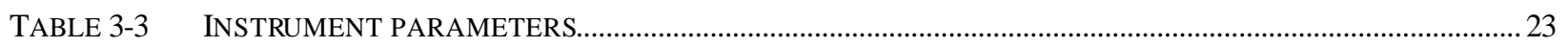

TABLE 3-4 EXPERIMENTAL MATRIX - EXPERIMENTAL CONTROLS .........................................................................26

TABLE 3-5 EXPERIMENTAL MATRIX - STORAGE CONDITIONS.................................................................................. 27

TABLE 3-6 EXPERIMENTAL MATRIX TEMPORAL EFFECTS........................................................................................2 28

TABLE 4-1 POROSITY AND DENSITY OF SUPERLIG® 644 ONE-GALLON BATCH RESIN MEASURED IN NACL

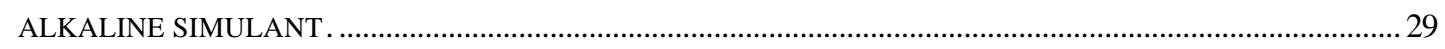

TABLE 4-2 SKELETAL DENSITY OF SUPERLIG® 644 ONE-GALLON BATCH RESIN MEASURED IN DE-IONIZED

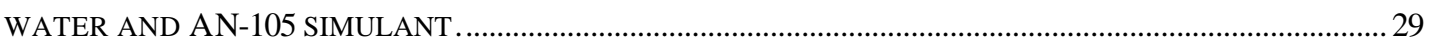

TABLE 4-3 PARTICLE SIZE DISTRIBUTION OF SUPERLIG® 644 ONE-GALLON BATCH RESIN BY WET SIEVE ANALYSIS. (2 REPLICATES) ............................................................................................................... 30

TABLE 4-4 EQUIPMENT BLANK SIMULANT CONCENTRATION RESULTS.................................................................. 35

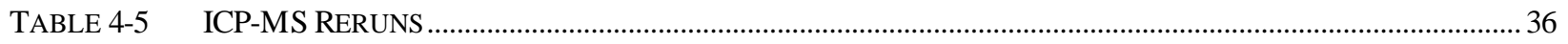

TABLE 4-6 RANDOM REPLICATE RESULTS........................................................................................................... 37

TABLE 4-7 RELATIVE ERROR OF Q AS A FUNCTION OF FINAL CS CONCENTRATION ...............................................40

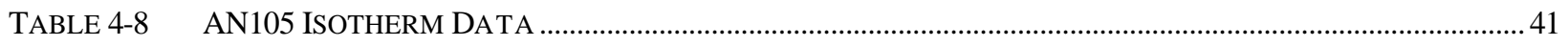

TABLE 4-9 AN105 TEMPORAL EFFECTS CS SORPTION RESULTS............................................................................ 42

TABLE 4-10 AN107 TEMPORAL EFFECTS CS SORPTION RESULTS.............................................................................. 43

TABLE 4-11 SUMMARY OF CHEMICAL PERFORMANCE FOR STORAGE CONDITION EXPERIMENTS WITH SIMPLE

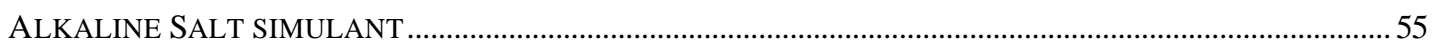




\section{LIST OF FIGURES}

FIGURE 1-1 CS K K VERSUS STORAGE DURATION IN ALL ST ORAGE CONDITIONS 30 ML SAMPLES................................... 9

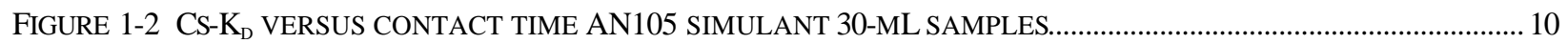

FIGURE 1-3 CS-K D $_{\mathrm{D}}$ VERSUS CONTACT TIME AN107 SIMULANT 30-ML SAMPLES.............................................................. 10

FIGURE 1-4 OPTICAL MICROSCOPY OF 1 GALLON SL644 CONTACTED WITH AN107.................................................. 11

FIGURE 1-5 AN105 AND AN107 CONTACTED CHORD-LENGTH DISTRIBUTION SUPERLIG ${ }^{\circledR} 644$ ONE GALLON BATCH

FIGURE 1-6 CS SORPTION ISOTHERM IN AN105 SIMULANT SL 644 (ONE GALLON BATCH) 30-ML SAMPLES.

FIGURE 4-1 AS-RECEIVED CHORD-LENGTH DISTRIBUTION SUPERLIG ${ }^{\circledR}$ 644 ONE GALLON BATCH.................................. 31

FIGURE 4-2 AS RECEIVED SL644 1 GALLON BATCH (LEFT). AS RECEIVED SL644 25 GALLON BATCH 1 SODIUM FORM

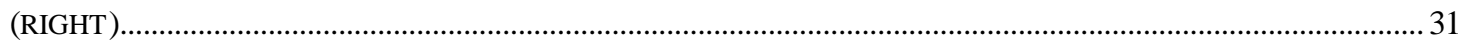

FIGURE 4-3 SL644 1 GALLON BATCH HYDROGEN FORM SEM UPPER STAGE IMAGE (15.3 X TOP LEFT . 305 X TOP RIGHT) SL644 25 GALLON BATCH 1 SODIUM FORM SEM BACKSCATTER IMAGE (19.0 X BOTTOM LEFT. 100X BOTTOM RIGHT).

FIGURE 4-4 SL644 1 GALLON BATCH HYDROGEN FORM (TOP). SL644 25 GALLON BATCH 1 SODIUM FORM (BOTTOM).

FIGURE 4-5 CS SORPTION ISOTHERM IN AN105 SIMULANT SL 644 (ONE GALLON BATCH) 30-ML SAMPLES .

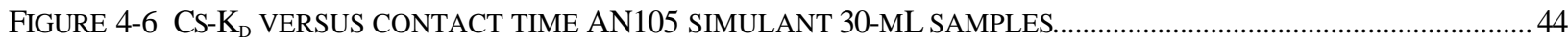

FIGURE 4-7 CS-K $\mathrm{K}_{\mathrm{D}}$ VERSUS CONTACT TIME AN107 SIMULANT 30-ML SAMPLES................................................................ 44

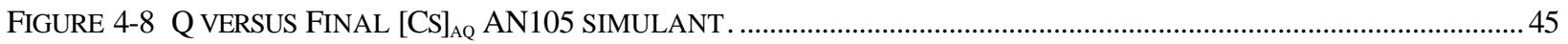

FIGURE 4-9 Q VERSUS FINAL [CS] $]_{\mathrm{AQ}}$ AN105 SIMULANT 30-ML SAMPLES......................................................................... 45

FigURE 4-10 SL644 25 GALLON BATCH 1(LEFT). AN105 1 WEEK (CENTER). AN105 STAGNANT A 8 WEEKS (RIGHT).

FIGURE 4-11 OPTICAL MICROSCOPY OF SL644 ONE-GALLON BATCH CONTACT WITH AN107 …………………………..... 47

FIGURE 4-12 OPTICAL MICROSCOPY OF SL644 ONE-GALLON BATCH CONT ACT WITH AN107 ....................................... 47

FigURE 4-13 SEM IMAGES OF SL644 AN105. 8 WEEKS STAGNANT A: 15.4 X (UPPER LEFT), 154 X (UPPER RIGHT), 2040 X (LOWER LEFT AND LOWER RIGHT) 49

FIGURE 4-14 SEM IMAGE OF SL644 ONE-GALLON BATCH CONTACT WITH AN105........................................................... 50

FIGURE 4-15 SEM IMAGE OF SL644 ONE-GALLON BATCH CONTACT WITH AN107..........................................................51

FIGURE 4-16 XRD PATTERNS OF SL644 ONE-GALLON BATCH CONTACT WITH AN107 …………................................52

FIGURE 4-17 AN105 AND AN107 CONTACTED CHORD-LENGTH DISTRIBUTION SUPERLIG ${ }^{\circledR} 644$ ONE GALLON BATCH

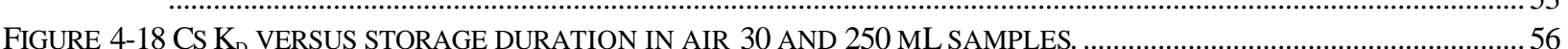

FIGURE 4-19 CS $K_{D}$ VERSUS STORAGE DURATION IN ALL STORAGE CONDITIONS 30 ML SAMPLES..................................56

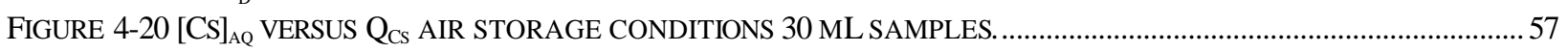

FIGURE 4-21 [CS $]_{A Q}$ VERSUS Q

FIGURE 4-22 [CS $]_{A Q}$ VERSUS Q

FIGURE 4-23 SL644 25 GALLON BATCH 1(LEFT). NACL-0 WEEKS STORAGE (CENTER). NACL-5 WEEKS-AIR (RIGHT) 59

FIGURE 4-24 NACL-5 WEEKS-H $\mathrm{H}_{2} \mathrm{O}$. SECONDARY ELECTRON (LEFT). BACKSCATTER IMAGE (RIGHT) ...........................59

FIGURE 4-25 NACL-5 WEEKS-H $\mathrm{H}_{2} \mathrm{O}$ (INSET) AND REPRESENTATIVE EDX SPECTRUM FOR SPOT 2..................................60 


\section{TABLE OF NOTATION}

$\mathrm{K}_{\mathrm{d}} \quad$ Distribution coefficient, $\mathrm{ml} / \mathrm{g}$

$\tilde{\mathrm{K}}_{\mathrm{ji}} \quad$ Selectivity coefficient between species $\mathrm{j}$ and $\mathrm{i}$

RPP River Protection Program

SRTC Savannah River Technology Center

WSRC Westinghouse Savannah River Company

WTP Waste Treatment and Immobilization Plant

Greek

$\mu \quad$ Fluid viscosity, $\mathrm{cP}$

$\rho \quad$ Fluid density, g/ml

$\rho_{\text {bed }} \quad$ Bed density of lead column, $\mathrm{g} / \mathrm{ml}$ (dry resin mass per bed volume 


\section{EXECUTIVE SUMMARY}

\subsection{Objectives}

The objectives of this study, per the Integrated Sr/TRU Precipitation and Cs Ion Exchange Process Validation Task Technical and QA plan (Serkiz, 2002), are to use batch contact ion exchange testing of SuperLig 644 resin and simulants of LAW Envelopes A (AN-105) and C (AN-107) to:

$>$ Examine the effects of resin storage environment on the Cs removal behavior of SuperLig ${ }^{\circledR} 644$ resin from a standard alkaline salt solution.

$>$ Investigate Cs sorption over time to SuperLig ${ }^{\circledR} 644$ resin with simulants of LAW Envelopes A (AN-105) and C (AN-107).

$>$ Examine the sorption of Cs as a function of initial Cs concentration (develop a sorption isotherm).

Evaluate the effects of simulants of LAW Envelopes A (AN-105) and C (AN-107) on the chemical properties of SuperLig ${ }^{\circledR} 644$ resin.

$>$ Evaluate the effects of simulants of LAW Envelopes A (AN-105) and C (AN-107) on the physical properties of SuperLig ${ }^{\circledR} 644$ resin.

$>$ Provide data generated from this work for incorporation into the preliminary SRTC ion exchange models, a modeling effort described in a separate test specification.

\subsection{Conduct of Testing}

Batch contacts were performed with SuperLig ${ }^{\circledR} 644$ resin using Hanford waste simulants. Stable Cs ion was utilized so that the tests could be performed in a nonradiological fume hood at a reduced cost.

The overarching experimental approach taken in this work was to concurrently examine the timedependent changes in the chemical and physical properties of SuperLig ${ }^{\circledR} 644$ resin in contact with LAW Envelope A (AN-105) and LAW Envelope C (AN-107) waste tank simulants. Samples were prepared in a series of small-scale (up to $0.25 \mathrm{~L}$ simulant liquid) batch contacts between tank waste simulants and SuperLig ${ }^{\circledR} 644$ ion exchange resin. By the nature of this approach, only sorption, was investigated. The impact of potential precipitates on the resin regeneration (desorption processes) was not addressed. Within this batch contact approach, experiments were subdivided into: experimental controls; sorption isotherm; temporal effects (sorption kinetics); and, resin storage. 


\subsection{Results and Performance Against Objectives}

These tests satisfied the primary objectives of this test program and provided much needed information regarding the impact of simulant exposure and resin storage environment on the chemical and physical properties of SuperLig ${ }^{\circledR} 644$ resin. The character of precipitates forming on SuperLig ${ }^{\circledR} 644$ resin was also identified.

No systematic trends in $\mathrm{K}_{\mathrm{d}}$ as a function of storage time were observed with any of the storage conditions. At the end of the experiment (eight weeks of resin storage) the air-stored resin resulted in the lowest $K_{d}$ value and the DI-Water and nitrogen-gas stored $K_{d}$ values were virtually identical (see Figure 1-1). Differences between $K_{d}$ values were up to about 25 percent, but only statistically different after eight weeks storage. From a morphological standpoint, resin contacted with the simple alkaline simulant showed a similar response to resin exposed to AN105 simulant. That is a gradual rounding of the particles with time. Small amounts of $\mathrm{NaCl}$ precipitates were also observed.

Cs sorption behavior of SuperLig ${ }^{\circledR} 644$ resin exposed to AN105 and AN107 tank simulants was similar to that previously observed (see Figure 1-2 and Figure 1-3). That is, maximum sorption is achieved on the order of three to seven days after which sorption slowly declines as a function of time. The Cs sorption behavior was very similar for this resin in both the AN105 and AN107 simulants both in terms of the magnitude and time-dependent changes. For these studies, there was not a statistically significant difference (greater than about 20 percent) in $\mathrm{K}_{\mathrm{d}}$ values between the maximum sorption and the end of the study (eight weeks of contact).

Precipitates were identified on the resin solids after contact with the simulants. A relatively small surface coverage of an unknown aluminosilicate was identified for resins contacted with AN105 simulant and very large amounts of sodium oxalate solids were identified on resins contacted with AN107 simulant.

From a physical properties standpoint, simulant contact had a very profound influence on the resin character. Optical microscopy showed that resin exposed to AN105 simulant resulted in an increasingly rounded resin morphology. Resin contact with the AN107 simulant led to malleable agglomerated resin with smaller resin particles than the starting material (see Figure 1-4). Particle-size analysis using an optical technique showed the production of smaller particles during contact and the AN107 contacted solids exhibited a large shift (about one-half an order) of magnitude in the mean chord-length of the particles (see Figure 1-5).

The Langmuir model was fit to Cs sorption from AN105 simulant data and a total Cs binding site capacity of 0.333 mmole/g resin from Hamm(2000) to yield a best fit Langmuir constant (i.e., B) of 1.260E-4 M. These results, shown in Figure 1-6, are similar to previous resin batches with a slightly increased sorption over the $[\mathrm{Cs}]_{\text {aq }}$ operating window (less than 1 mmolar Cs).

Based on the experimental controls portion of this study, the following relative errors in batch contacts were estimated: 
- seven percent for ICP-MS analysis of Cs in the simulant blanks,

- 13 percent for ICP-MS Cs analysis with batch contact preparation,

- $\mathrm{f}$-factor analysis error of three percent (including weighing error), and

- 0.5 percent error in the volume of simulant.

These errors must be propagated during the development of isotherms, calculation of $\mathrm{Q}$, and $\mathrm{K}_{\mathrm{d}}$ values from these data. Errors associated with calculating $Q$ (i.e., sorbed concentration) and $K_{d}$ values from the difference in solution concentrations at the start and the end of batch contacts are relatively large (on order of 10 to 30 percent for typical sorption experiments).

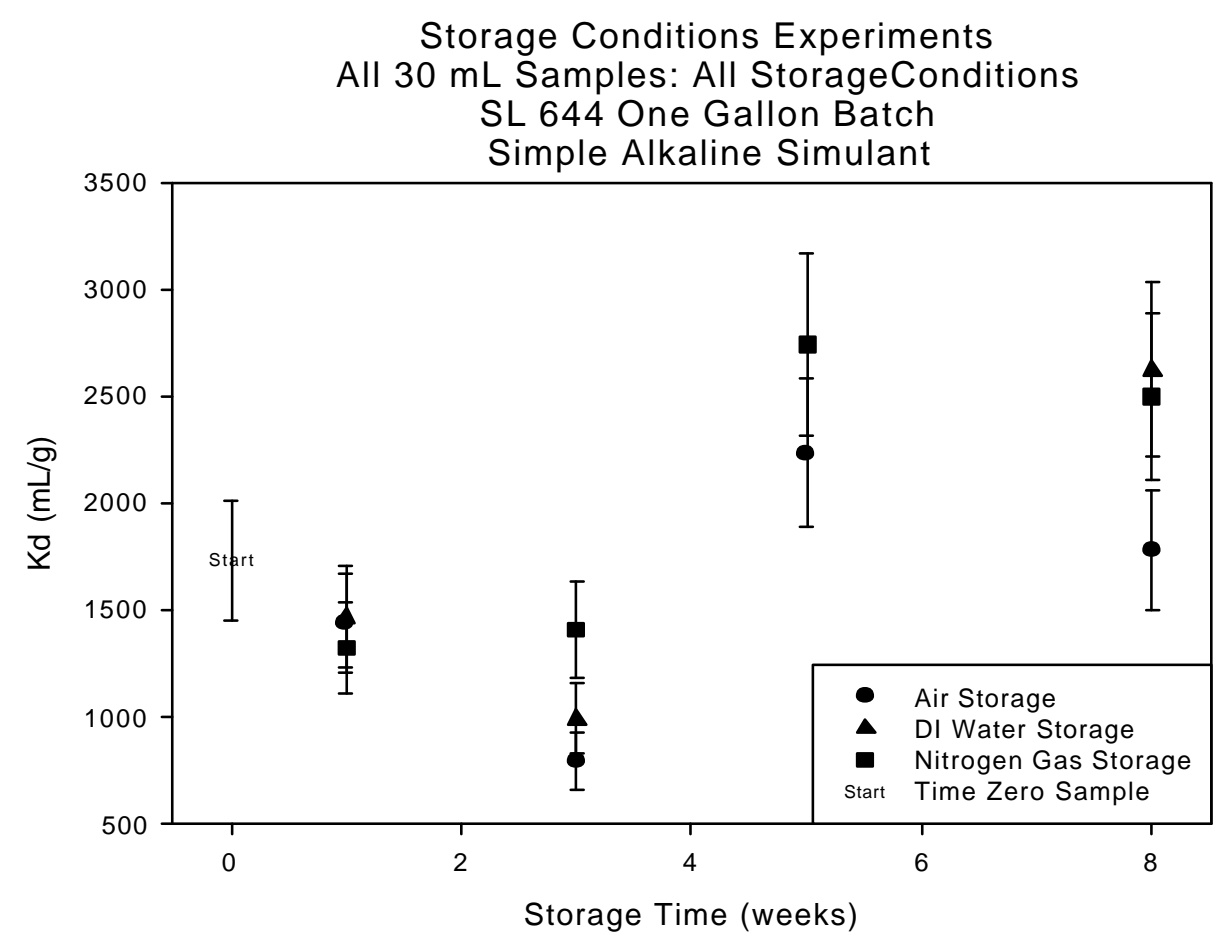

Figure 1-1 Cs $K_{d}$ versus storage duration in all storage conditions $30 \mathrm{~mL}$ samples. 


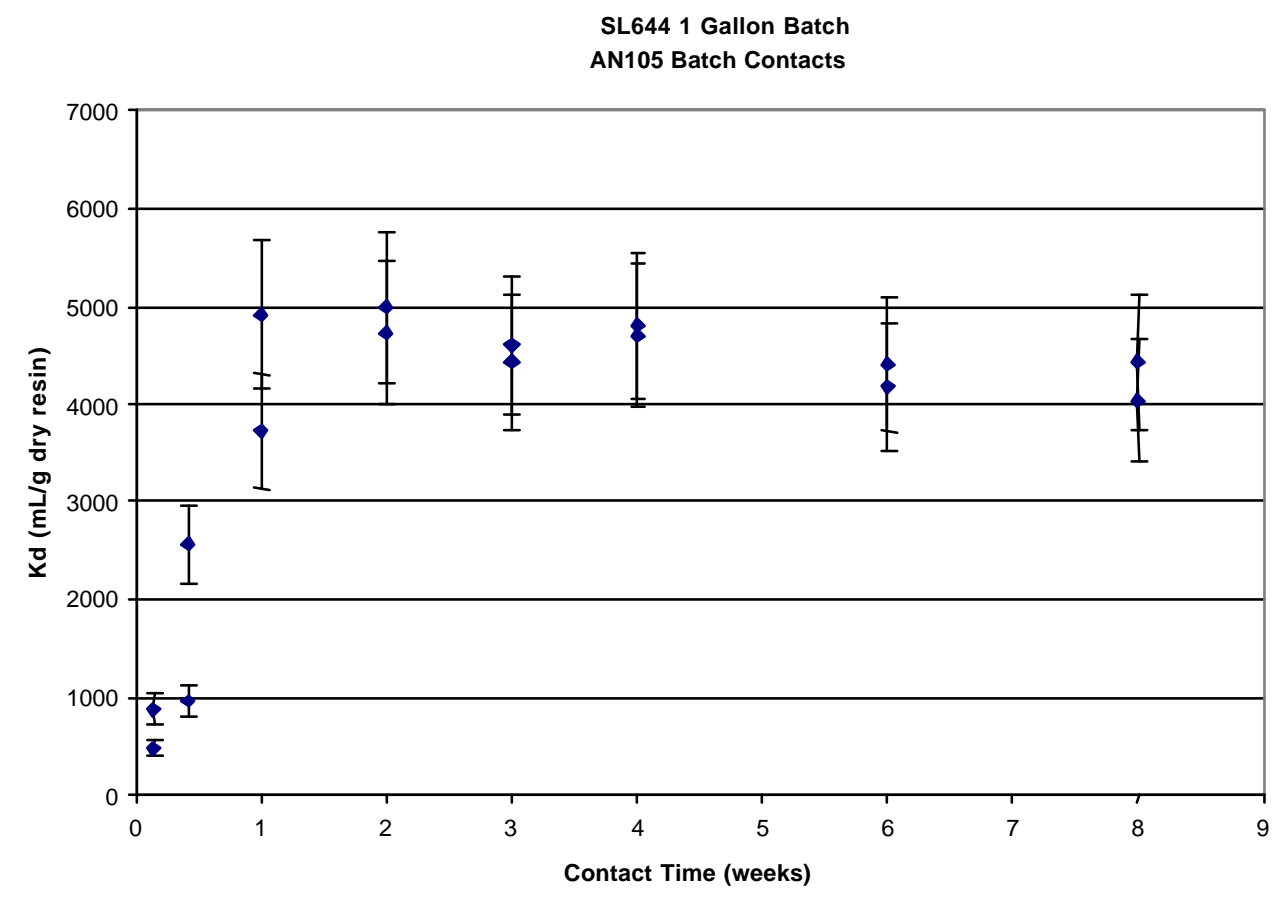

Figure 1-2 Cs-K $\mathrm{K}_{\mathrm{d}}$ versus contact time AN105 simulant 30-mL samples.

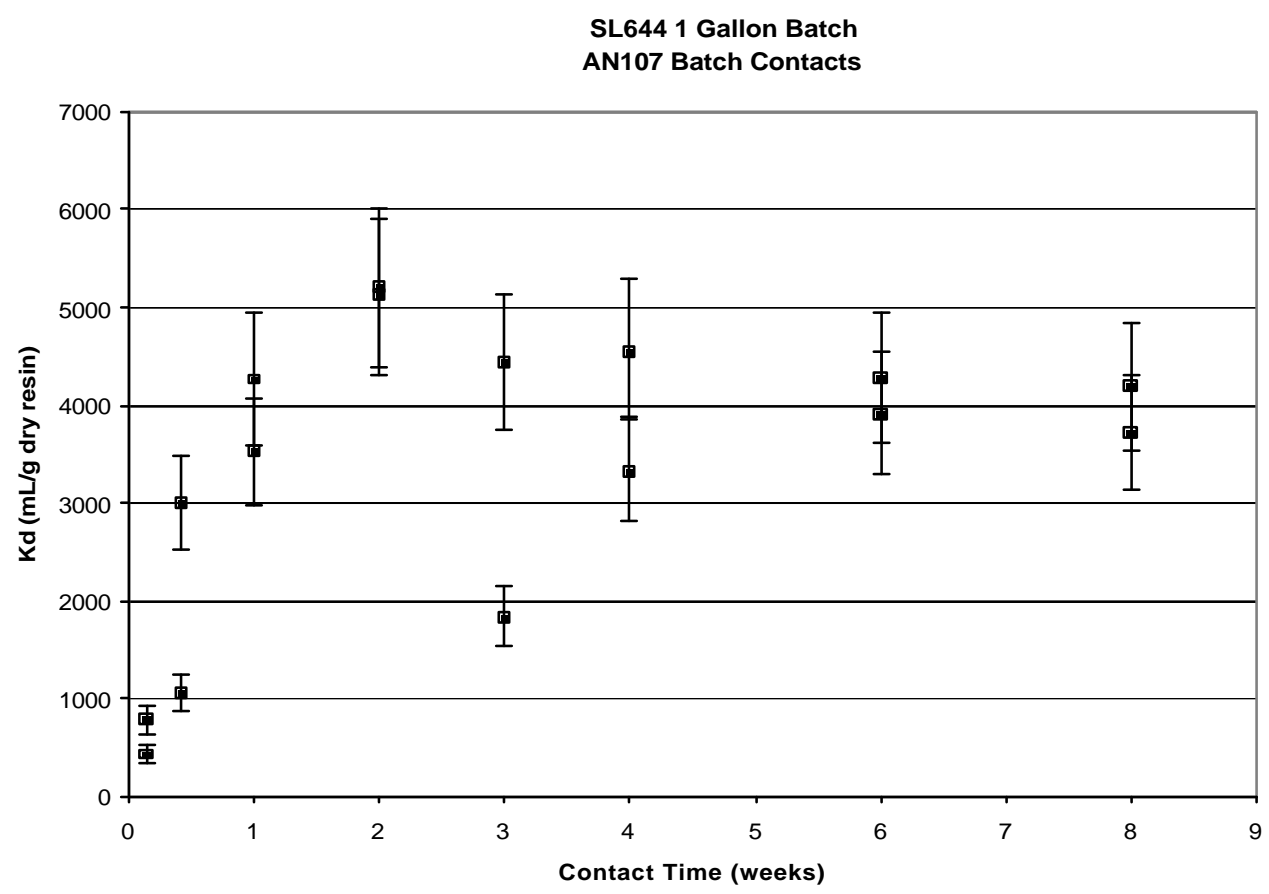

Figure 1-3 Cs- $\mathrm{K}_{\mathrm{d}}$ versus contact time AN107 simulant 30-mL samples. 

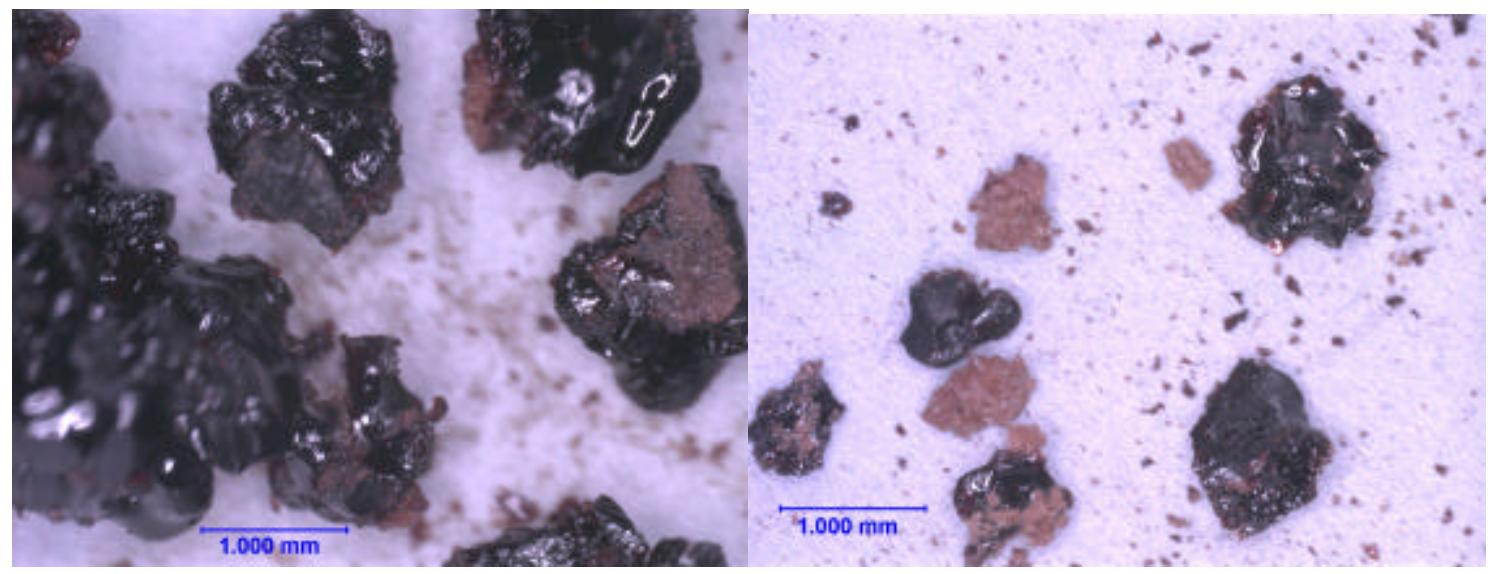

Figure 1-4 Optical Microscopy of 1 gallon SL644 contacted with AN107, 8 weeks dried slowly during storage (left) AN107 Stagnant C dried in vacuo (right)

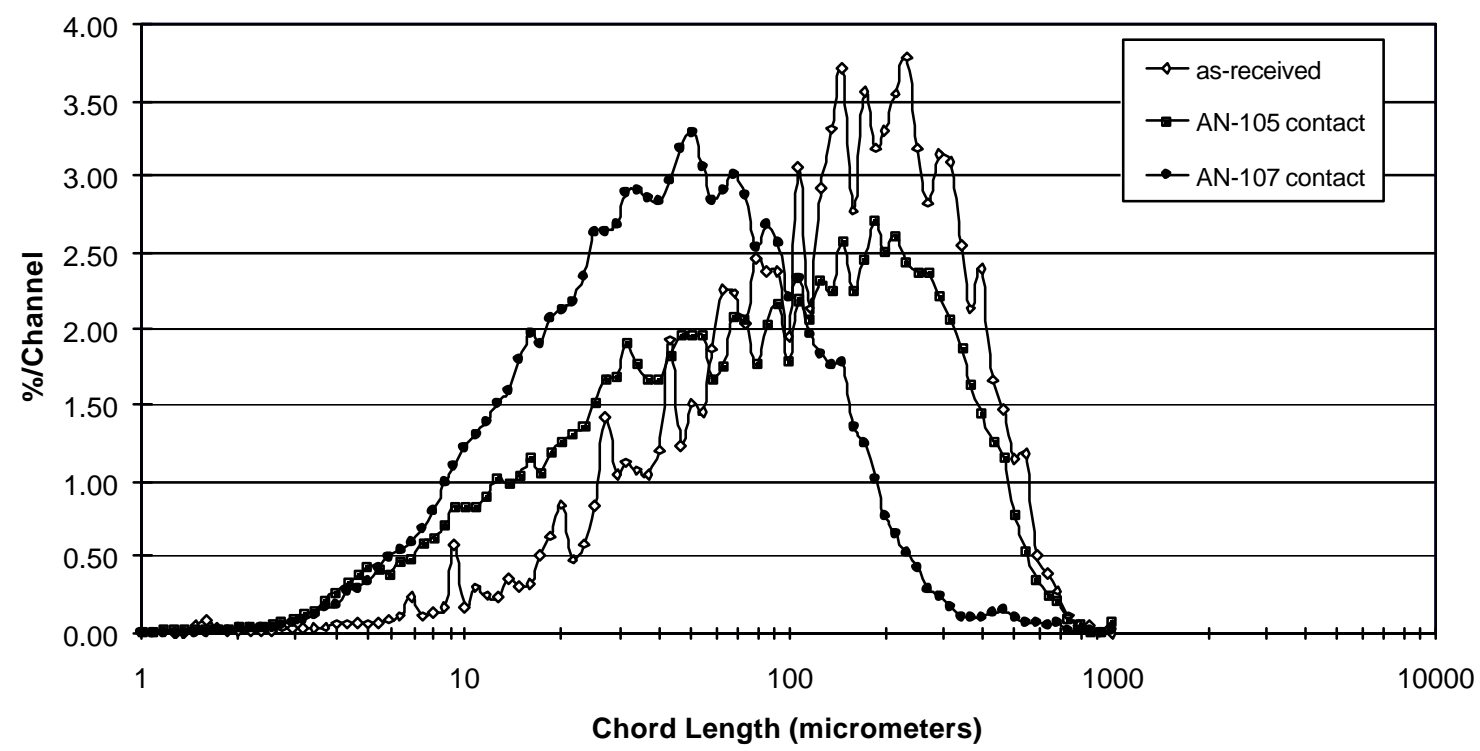

Figure 1-5 AN105 and AN107 contacted chord-length distribution SuperLig ${ }^{\circledR} 644$ One Gallon Batch 


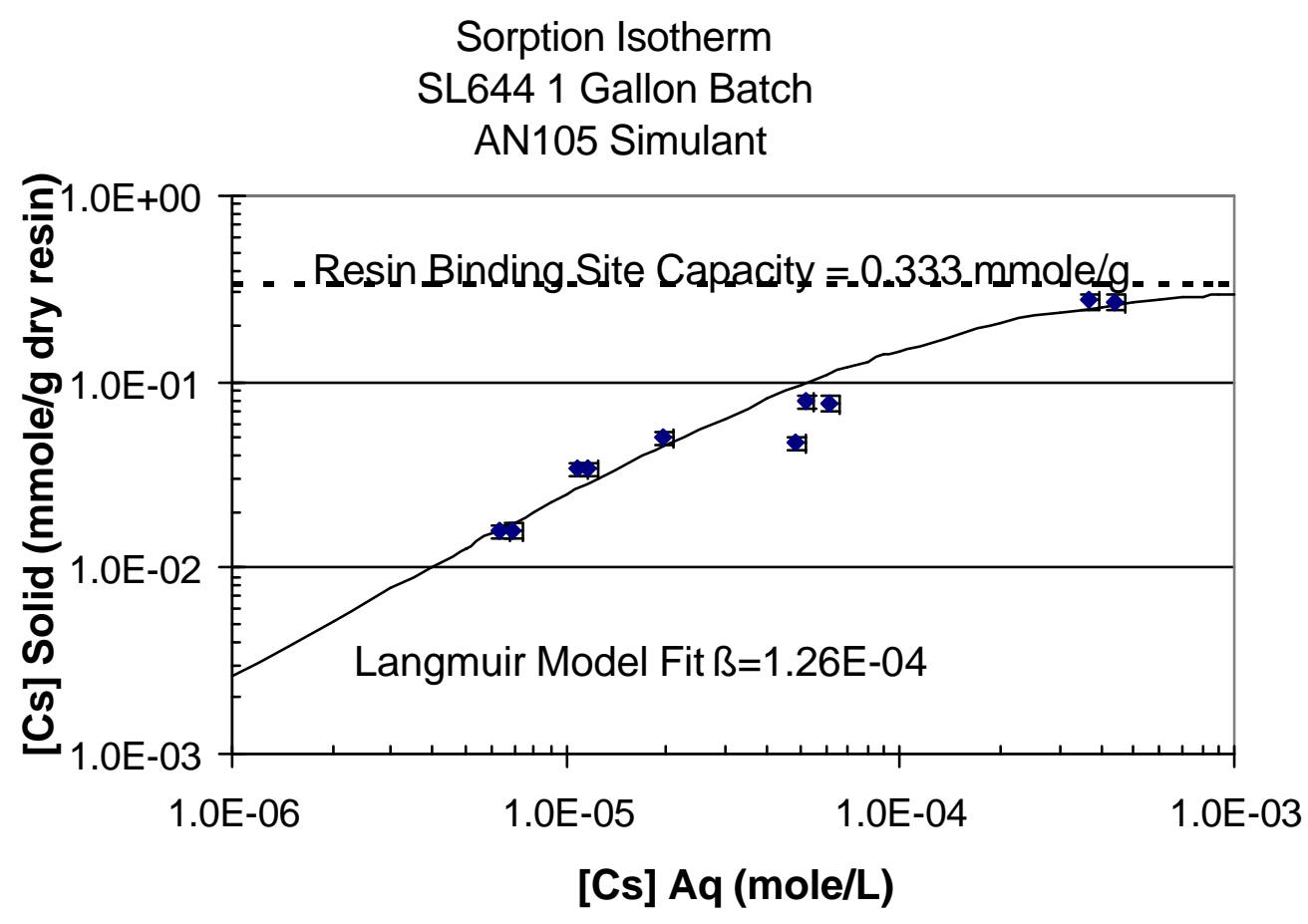

Figure 1-6 Cs sorption isotherm in AN105 simulant SL 644 (one gallon batch) 30-mL samples.

\subsection{Quality Requirements}

This work was conducted in accordance with the RPP-WTP QA requirements specified for work conducted by SRTC as identified in DOE IWO MOSRLE60. SRTC has provided matrices to WTP demonstrating compliance of the SRTC QA program with the requirements specified by WTP. Specific information regarding the compliance of the SRTC QA program with RW-0333P, Revision 10, NQA1 1989, Part 1, Basic and Supplementary Requirements and NQA-2a 1990, Subpart 2.7 is contained in these matrices.

Work was conducted with the approved Task Technical and QA Plan. The additional RW-0333P QA requirements do not apply to this task. Researchers at SRTC followed the WSRC Quality Assurance Program, which has been approved by WTP, and the WSRC Quality Assurance Management Plan (WSRC-RP-92-225). This program contains appropriate quality assurance requirements for this task from NQA-1-1989, and NQA-2a-1990, Part 2.7, as indicated by the QA Plan Checklist in the Task Technical Plan. 


\subsection{Issues}

Issues of potential plant significance identified in this work include the following.

- Errors associated with calculating Q (i.e., sorbed concentration) and $\mathrm{K}_{\mathrm{d}}$ values from the difference in solution concentrations at the start and the end of batch contacts are relatively large (on order of 10 to 30 percent for typical sorption experiments). Therefore, statistically significant differences in $\mathrm{Q}$ or $\mathrm{K}_{\mathrm{d}}$ generated from this approach are not observable unless they are quite large. An alternative approach that would reduce the overall error in these parameters is to measure solid-phase concentrations directly. While this approach is more costly, it might be appropriate in experiments where smaller differences in resin performance are being evaluated.

- A second source of error associated with the batch-contact approach utilized in this study is the uncertainty associated with knowing if the liquid film diffusion effects have been overcome. More simply stated, was the applied agitation sufficient to overcome film diffusion effects and, thereby, not affect the time for equilibration. This effect was evident in comparing the $30-\mathrm{mL}$ and $250-\mathrm{mL}$ contacts, where longer time-periods were required to reach equilibrium for the larger and presumably less well agitated samples. Even with this potential error, data within a particular sample size should allow for evaluation of the desired experimental parameter (storage condition, simulant composition, etc.).

- Even though precipitates were found to form on the resin during exposure to waste-tank simulants, their influence on Cs removal was only on the order of a 20 to 25 percent reduction in Cs binding over the eight week contact period investigated.

- $\quad$ Exposure of SuperLig ${ }^{\circledR} 644$ resin to waste-tank simulants had a significant impact on the particle-size distribution of the resin. In all cases evaluated, exposure to alkaline simulants led to an increased fraction of smaller resin particles. This was especially dramatic during exposure to the AN107 simulant. This resin response could have obvious negative impacts on the hydraulic performance.

No other issues were identified.

\section{INTRODUCTION AND BACKGROUND}

Millions of gallons of radioactive waste were produced as a by-product of nuclear weapons programs at various government sites across the United States. The current legacy waste inventory has essentially been reduced to two main sites (Richland, WA and Aiken, SC) and is currently managed by the Federal Government's Department of Energy. Separate waste treatment processes have been developed for each site as a result of differences in waste composition and regulatory requirements. For the Hanford site, waste treatment strategy was originally contracted to BNFL, Inc. 
Based on limited initial testing and extensive nuclear waste processing experience, BNFL, Inc. developed a treatment flow sheet that included the following basic steps: 1) separation of low volume, high activity solids from high volume, lower activity supernate, 2) treatment of the supernate for removal of specific radionuclides (strontium, transuranics, cesium, and technetium) using precipitation and ion exchange technologies, 3) evaporation of the bulk decontaminated low-activity supernate, 4) vitrification of the decontaminated and concentrated supernate to generate low activity waste glasses, and 5) vitrification of high activity solids and ion exchange eluate solutions to generate concentrated high activity glasses. This treatment process was designed to minimize the volume of high activity waste requiring disposal and is described in greater detail in Hamm et al., 2000.

Extensive testing from 1998-2001 has been conducted in support of the original BNFL design for the Hanford waste treatment plant at the Savannah River Technology Center (SRTC) in Aiken, SC and at Pacific Northwest National Laboratory (PNNL) in Richland, WA. These test results indicate that the conceptual design plan was adequate and the Department of Energy subsequently contracted Bechtel National Inc. to design, build, and perform initial operations of the waste treatment plant at the Hanford site. The River Protection Project - Waste Treatment and Immobilization Plant (RPP-WTP) for treatment of the Hanford radioactive waste is currently under construction. Final design validation and process optimization tests are continuing at SRTC and at PNNL during the design and construction phase.

The initial plant treatment schedule focuses on 10 waste storage tanks which have been categorized into four general waste types (or Envelopes). Envelopes A, B, and C refer to liquid supernate samples which vary in chemical composition, while Envelope D refers to solids (sludge) primarily isolated from tank heels. Extensive testing has been conducted on both simulants and actual samples in each waste category that were retrieved from the tanks.

\subsection{Purpose of Work}

Post-filtration precipitates have been observed in supernate actual and stimulant waste during testing of the flow-sheet chemistry. Under certain conditions, precipitates have been implicated in adverse ion exchange resin performance (Helfferich, 1995).

Work was conducted to address the research requirements contained in R \& T Plan TSS-S111 as described in "Integrated Sr/TRU Precipitation and Cs Ion Exchange Porcess Validation" (Abodishish, 2001 24590-WTP-TSP-RT-01-027, Rev. 0). The experimental approach used to address the research needs is documented in Technical Task and QA Plan for this work (Serkiz, 2002).

The strontium/transuranics (Sr/TRU) precipitation step prior to ion exchange has shown the generation of post-filtration precipitate in both AN-107 (LAW Envelope C) actual and simulated waste filtrate within 24 hours after filtration. These precipitates generally formed on organic surfaces (e.g., polymer storage bottle walls) (Nash and Saito, 2001). These findings suggest that solids from this post-filtration 
precipitation process could form preferentially on the organic SuperLig ${ }^{\circledR} 644$ resin and adversely affect the cesium ion exchange properties of the resin. This study was designed to investigate the impacts of post-filtration precipitate formation on the removal of Cs from Hanford high-level waste tank simulants using SuperLig ${ }^{\circledR} 644$ ion exchange resin.

\subsection{Experimental Approach}

Cesium removal from tank waste simulants by SuperLig ${ }^{\circledR} 644$ ion exchange resin was used as the primary measure for the impact of precipitates. Secondary chemical properties investigated included Cs sorption kinetics and the presence and character of surface precipitates. Particle shape, size distribution, density of dry solids, color, and morphology of precipitates were monitored as indications of changes in physical properties of the ion exchange resin.

The overarching experimental approach taken in this work was to concurrently examine the timedependent changes in the chemical and physical properties of SuperLig ${ }^{\circledR} 644$ resin in contact with LAW Envelope A (AN-105) and LAW Envelope C (AN-107) tank simulants. Batch contact samples were prepared in a series of small-scale (up to $0.25 \mathrm{~L}$ simulant liquid) contacts consisting of waste tank simulants and SuperLig ${ }^{\circledR} 644$ ion exchange resin. By the nature of this approach, only sorption was investigated. The impact of potential precipitates on the resin regeneration (desorption processes) was not addressed.

Within this batch contact approach, experiments were subdivided as follows:

- $\quad$ Experimental controls;

- $\quad$ Sorption isotherm;

- $\quad$ Temporal effects (sorption kinetics); and

- $\quad$ Resin storage.

Each of these sub experiments are described in the following sections.

Ultimately, data generated from this work will be used as input for the SRTC ion exchange modeling efforts. Results of these tests provide insights as to the impacts of solution composition on resin performance. The data will be utilized to evaluate model predictions of column performance. The models will be based on sorption isotherms and kinetic tests developed from small-scale batch contact with various solution compositions. 


\section{EXPERIMENTAL}

\subsection{Resin}

IBC Advanced Technologies, Inc. (American Fork, UT) has developed a proprietary ion exchange resin, namely the SuperLig ${ }^{\circledR}$ 644, which was designed to selectively separate Cs in the presence of high concentrations of sodium and potassium like those found in high ionic-strength alkaline high-level radioactive tank waste. Previous studies have shown that this organic resin is capable of achieving high decontamination factors for Cs in both simulated and actual Hanford alkaline waste (Brown et al., 1995a; Brown et al., 1996; and Bray et al., 1995, King et al., 2000). Furthermore, because hydrogen ions in solution (i.e., $\mathrm{H}^{+}$or $\mathrm{H}_{3} \mathrm{O}^{+}$) compete for resin ion exchange sites, Cs sorbed to SuperLig ${ }^{\circledR} 644$ resin can be eluted with strong acids and the resin can be used for multiple ion exchange cycles (Brown et al., 1995b).

The physical appearance of SuperLig ${ }^{\circledR} 644$ resin has been variable between production batches and also depends on the chemical form of the resin (hydrogen or sodium form). Of particular importance to the physical behavior of the resin is the fact that it swells and shrinks (by more than a factor of two) in response to changes in solution $\mathrm{pH}$ and ionic strength. Resin shape is generally angular and exhibits a wide particle-size distribution relative to commercial polystyrene bead-type resins.

A single sample of SuperLig ${ }^{\circledR} 644$ resin was used for all experiments in this study. Originally, the Task Technical Plan for this study indicated the use of a subsample of the 20-L batch of SuperLig ${ }^{\circledR} 644$ shipped to SRTC on 01/09/2002. Because this resin was significantly different from the subsequent production batch the 1-gallon production batch (I-D5-03-06-02-35-60) shipped from IBC Advanced Technologies on 04/09/02 was used in this study based on the written direction of the project manager Jim Toth. The resin sample was received in the hydrogen form under distilled water. Prior to characterizing the chemical properties of this resin sample, a subsample of about 0.5 liters was collected using the general vertical compositing technique in ASTM D2687-95(2001). To summarize the sampling, (1) the "as received" resin container was tumbled end-over-end about a dozen times, (2) the resin was allowed to settle for approximately one minute, (3) a resin core was extracted from the larger sample using a ten-inch glass tube that was open on both ends (note: in order to prevent the resin core from coming out of the glass tube the opening at the top of the coring tube was reduced to about $1 / 4$-inch in diameter and the operator's thumb was placed over this opening during the withdrawal of the resin core), (4) Steps 1-3 were repeated until about 0.5 L of resin subsample was collected.

\subsubsection{Characterization and Pretreatment}

The resin subsample was subjected to limited characterization. The "as received" sample was analyzed for elemental composition, particle size distribution, porosity, and density with a portion of the characterization being conducted in support of the Pilot-Scale Simulant testing. Pretreatment consisted 
of a 10:1 ratio of solution $(\mathrm{mL})$ to resin $(\mathrm{g})$ with the following batch treatments: $1 \mathrm{hr}$ in $0.5 \mathrm{M} \mathrm{HNO}_{3}$; three DI water washes for approximately 5 minutes each, two one-hour treatments in $0.25 \mathrm{M} \mathrm{NaOH}$ (DI water rinse between the two). After pretreatment, resin was rinsed with five ten-minute DI water rinses . This treatment placed the resin in the sodium form, and this "pretreated" resin was the form used in the further chemical studies.

\subsection{Simulant Preparation}

In order to minimize costs associated with sample isolation, transfer, and handling, recipes have been developed at SRTC to prepare nonradioactive simulants of various tank samples based on analysis data from actual waste tank samples. Supernate simulants have been developed for several specific waste tanks and are being used for testing throughout the RPP-WTP test program. All tank supernate compositions are dominated by sodium salts (nitrate, nitrite, hydroxide, and aluminate are the dominant counter anions), that are present in high concentrations (2-10 $\left.\mathrm{M} \mathrm{Na}^{+}\right)$. All waste samples are highly caustic. There are many minor waste constituents. Cesium and technetium are present at concentrations that are several orders of magnitude lower than the concentrations of the primary constituents. These conditions, therefore, require treatment technologies that are highly selective for removal of trace constituents. The baseline treatment methodology for the supernate involves evaporation or dilution to near $5 \mathrm{M} \mathrm{Na}$. For the Envelope $\mathrm{C}$ waste only, a precipitation process is employed to remove radioactive strontium and transuranic elements. The supernate is then treated by ion exchange to remove cesium and technetium.

AN105 and AN107 simulants were made to the composition prescribed in Eibling et al. (2000). The concentrations of selected species added during initial simulant preparation, based on the recipes reported by Eibling (2000), are provided in Table 3-1. Table 3-2 provides the average measured concentrations of the experimental simulant blanks included in the batch contact testing.

A simple alkaline salt solution representing the arithmetic mean of the Phase 1 LAW feed as developed by Larry Hamm of SRTC (Serkiz, 2002) was used in storage condition sub experiments. The use of a simplified simulant was designed to remove simulant complexity as a confounding factor to the understanding of more fundamental properties of the SuperLig ${ }^{\circledR} 644$ resin. The simple alkaline simulant was made to $5 \mathrm{M} \mathrm{Na}$ using $1.1 \mathrm{M} \mathrm{NaOH}, 1.25 \mathrm{M} \mathrm{NaNO}_{3}, 0.15 \mathrm{M} \mathrm{KNO}_{3}$, and $2.5 \mathrm{M}$ as the $\Sigma\left(\mathrm{NaNO}_{2}+\mathrm{NaCl}\right)$. The effect of counter anion composition $\left(\mathrm{NO}_{2}{ }^{-}\right.$or $\left.\mathrm{Cl}\right)$ was evaluated by making three simulants: $2.5 \mathrm{M} \mathrm{NaNO}_{2}, 2.5 \mathrm{M} \mathrm{NaCl}$, and $1.4 \mathrm{M} \mathrm{NaCl}+1.1 \mathrm{M} \mathrm{NaNO}_{2}$. Each of these simulants was spiked with $\mathrm{CsNO}_{3}$ to a final concentration of about $7 \mathrm{mg} / \mathrm{L} \mathrm{Cs}$. One-day contacts with the one gallon SuperLig ${ }^{\circledR} 644$ resin batch were conducted and no significant differences in the Cs-Kd values were observed between simulants. For ease of preparation, the $2.5 \mathrm{M} \mathrm{NaCl}$ composition simulant was chosen for all further work. 
Table 3-1 Expected Concentrations of Selected Species in Original Hanford Simulants Based on Reagents Added.

\begin{tabular}{|c|c|c|}
\hline Simulant & $\begin{array}{c}\text { AN-105 } \\
{[\mathbf{M}]}\end{array}$ & $\begin{array}{c}\text { AN-107 } \\
{[\mathbf{M}]}\end{array}$ \\
\hline \hline $\mathrm{Na}$ & 5.000 & 5.000 \\
\hline $\mathrm{K}$ & 0.090 & 0.027 \\
\hline $\mathrm{Al}$ & 0.687 & 0.008 \\
\hline $\mathrm{S}$ & 0.004 & 0.051 \\
\hline $\mathrm{P}$ & 0.003 & 0.007 \\
\hline $\mathrm{Cr}$ & 0.012 & $0.000^{2}$ \\
\hline $\mathrm{Mg}$ & $1.04 \mathrm{E}-04$ & $6.07 \mathrm{E}-04$ \\
\hline $\mathrm{Ca}$ & $4.66 \mathrm{E}-04$ & $1.59 \mathrm{E}-03$ \\
\hline $\mathrm{Sr}$ & $0.000^{2}$ & $4.46 \mathrm{E}-05$ \\
\hline Ba & $0.000^{2}$ & $3.20 \mathrm{E}-05$ \\
\hline $\mathrm{Cd}$ & $1.37 \mathrm{E}-05$ & $3.36 \mathrm{E}-04$ \\
\hline $\mathrm{B}$ & $2.21 \mathrm{E}-03$ & $1.91 \mathrm{E}-03$ \\
\hline Si & $3.51 \mathrm{E}-03$ & $0.000^{2}$ \\
\hline Mn & $0.000^{2}$ & $6.01 \mathrm{E}-03$ \\
\hline Fe & $0.000^{2}$ & $1.79 \mathrm{E}-02$ \\
\hline Ni & $0.000^{2}$ & $5.32 \mathrm{E}-03$ \\
\hline Mo & $4.00 \mathrm{E}-04$ & $2.20 \mathrm{E}-04$ \\
\hline Pb & $1.20 \mathrm{E}-04$ & $1.10 \mathrm{E}-03$ \\
\hline & & \\
\hline Nitrate & 1.243 & 2.188 \\
\hline Nitrite & 1.126 & 0.784 \\
\hline Sulfate & 0.004 & 0.051 \\
\hline Phosphate & 0.003 & 0.007 \\
\hline Chloride & 0.120 & 0.030 \\
\hline Flouride & 0.005 & 0.004 \\
\hline Oxalate & $3.24 \mathrm{E}-03$ & 0.006 \\
\hline Formate & $2.99 \mathrm{E}-02$ & 0.136 \\
\hline & & \\
\hline Added Hydroxide & 1.60 & 0.012 \\
\hline Carbonate & 0.098 & 0.825 \\
\hline TIC & 0.098 & 0.825 \\
\hline TOC & 0.140 & 1.981 \\
\hline
\end{tabular}

${ }^{1}$ The AN-107 simulant solution was significantly altered from the original composition during strontium/transuranics precipitation process.

${ }^{2}$ Indicates species absent from the Eibling recipe and not added to simulant. 
Table 3-2 ICP-ES Measured Molar Concentrations (mole/L) of Selected Species in Experimental Blanks of Hanford Simulants Used for Batch Contacts.

\begin{tabular}{|c|c|c|c|c|}
\hline \multirow{2}{*}{ Simulant } & \multicolumn{2}{|c|}{ AN-105 } & \multicolumn{2}{c|}{ AN-107 } \\
\hline Element & Average & Std Dev & Average & Std Dev \\
\hline \hline $\mathrm{Na}$ & 4.91 & 0.09 & $6.72^{1}$ & 0.14 \\
\hline $\mathrm{K}$ & $1.00 \mathrm{E}-01$ & $6.89 \mathrm{E}-03$ & $4.23 \mathrm{E}-02$ & $7.82 \mathrm{E}-03$ \\
\hline $\mathrm{Al}$ & 0.59 & 0.01 & $7.04 \mathrm{E}-03$ & $2.31 \mathrm{E}-04$ \\
\hline $\mathrm{S}$ & $4.02 \mathrm{E}-03$ & $8.91 \mathrm{E}-05$ & $4.90 \mathrm{E}-02$ & $1.31 \mathrm{E}-03$ \\
\hline $\mathrm{P}$ & $2.73 \mathrm{E}-03$ & $9.04 \mathrm{E}-05$ & $6.82 \mathrm{E}-03$ & $5.18 \mathrm{E}-04$ \\
\hline $\mathrm{Cr}$ & $1.13 \mathrm{E}-02$ & $1.74 \mathrm{E}-04$ & $1.59 \mathrm{E}-03$ & $8.47 \mathrm{E}-05$ \\
\hline $\mathrm{Mg}$ & $<6.91 \mathrm{E}-06$ & NA & $9.871 \mathrm{E}-06$ & $2.378 \mathrm{E}-06$ \\
\hline $\mathrm{Ca}$ & $3.63 \mathrm{E}-06$ & $2.09 \mathrm{E}-06$ & $1.28 \mathrm{E}-03$ & $1.01 \mathrm{E}-04$ \\
\hline $\mathrm{Sr}$ & $3.01 \mathrm{E}-07$ & $1.85 \mathrm{E}-07$ & $1.65 \mathrm{E}-03^{1}$ & $1.10 \mathrm{E}-04$ \\
\hline $\mathrm{Ba}$ & $7.67 \mathrm{E}-07$ & $1.69 \mathrm{E}-07$ & $1.25 \mathrm{E}-05$ & $3.00 \mathrm{E}-06$ \\
\hline $\mathrm{Cd}$ & $1.15 \mathrm{E}-05$ & $8.17 \mathrm{E}-07$ & $2.49 \mathrm{E}-07$ & NA \\
\hline $\mathrm{B}$ & $2.23 \mathrm{E}-03$ & $5.33 \mathrm{E}-05$ & $1.99 \mathrm{E}-03$ & $7.59 \mathrm{E}-05$ \\
\hline $\mathrm{Si}$ & $2.82 \mathrm{E}-03$ & $9.31 \mathrm{E}-05$ & $2.24 \mathrm{E}-04$ & $3.90 \mathrm{E}-05$ \\
\hline $\mathrm{Mn}$ & $3.28 \mathrm{E}-07$ & NA & $1.18 \mathrm{E}-04^{2}$ & $1.56 \mathrm{E}-04$ \\
\hline $\mathrm{Fe}$ & $7.67 \mathrm{E}-05$ & $1.23 \mathrm{E}-05$ & $1.11 \mathrm{E}-03^{2}$ & $1.25 \mathrm{E}-04$ \\
\hline $\mathrm{Ni}$ & $3.57 \mathrm{E}-06$ & $6.32 \mathrm{E}-07$ & $4.80 \mathrm{E}-03$ & $1.99 \mathrm{E}-04$ \\
\hline $\mathrm{Mo}$ & $4.00 \mathrm{E}-04$ & $6.89 \mathrm{E}-06$ & $2.26 \mathrm{E}-04$ & $1.50 \mathrm{E}-05$ \\
\hline $\mathrm{Pb}$ & $1.15 \mathrm{E}-04$ & $2.98 \mathrm{E}-06$ & $1.94 \mathrm{E}-04$ & $1.65 \mathrm{E}-05$ \\
\hline $\mathrm{Cs}{ }^{3}$ & $4.14 \mathrm{E}-04$ & $4.82 \mathrm{E}-05$ & $5.74 \mathrm{E}-04$ & $3.08 \mathrm{E}-05$ \\
\hline
\end{tabular}

${ }^{1}$ Indicates species whose concentrations were expected to increase due to precipitation processing.

${ }^{2}$ Indicates species whose concentrations were expected to decrease due to precipitation processing.

${ }^{3}$ Cs analysis by ICP-MS.

Notes: Number of separate analyses AN105 = 17 and AN107 = 15 .

$\mathrm{NA}=$ Standard deviation calculation ot applicable because a less than two measurements were above method detection limit.

\subsection{Batch Contacts}

This study primarily relied on a batch contact approach to establish the sorption behavior of Cs in simulated alkaline waste. The general approach to conducting these batch contacts was to add SuperLig ${ }^{\circledR} 644$ resin (described in Section 3.1.1) to alkaline waste tank simulant at a target resin- tosimulant ratio of $1 \mathrm{~g}$ dry resin to $100 \mathrm{~mL}$ of simulant, agitating the sample (resin and simulant) for a specified time interval, separating the resin solids from the reacted simulant, and analyzing the reacted simulant and resin solids. 
Resin samples for batch contacts were collected by the following approach. The pretreated subsample described in Section 3.1.1 was stored under distilled water. A portion of this subsample was transferred from the storage container to a Buchner funnel with Whatman ${ }^{\mathrm{TM}}$ filter paper using the general vertical compositing technique in ASTM D2687-95(2001). House vacuum was pulled on the resin in the Buchner funnel until free flowing liquid ceased and then for an additional three minutes. Vertical cores of the resin were collected using glass tubing from the resin cake in the Buchner funnel and transferred to aluminum weighing pans and weighed. Because sorption calculations (e.g., $\mathrm{K}_{\mathrm{d}}$ and resin loading) needed to be made on a dry weight of resin basis, a minimum of two separate resin cores were collected to determine an experiment-specific f-factor. If only two f-factor samples were collected, these f-factor samples were collected as the first sample and last sample. If a large number of contacts (more than eight) were being started at one time then a third f-factor sample was collected near the middle of the sampling. Target resin sample weights were $5 \mathrm{~g}$ of wet resin for the 250 - $\mathrm{mL}$ contacts, 0.6 $\mathrm{g}$ of resin for the 30 -mL contacts, and $1 \mathrm{~g}$ for $\mathrm{f}$-factor analysis. With an $\mathrm{f}$-factor of $\sim 0.5$, this resulted in a 1:100 ( $\mathrm{g}$ dry resin: $\mathrm{mL}$ simulant) solid to liquid ratio.

After weighing the wet resin and the weighing pan, the f-factor samples were placed in an oven at $45^{\circ} \mathrm{C}$ overnight. Samples were removed from the oven, placed in a desiccator to cool for about an hour, and then weighed. Samples were placed back in oven for at least two hours at $45^{\circ} \mathrm{C}$, then cooled in a desiccator, and weighed. This process of drying to constant weight was repeated until consecutive weights differ by less than $0.01 \mathrm{~g}$. The f-factor is then calculated as:

$\mathrm{f}-$ factor $=$ final wt. dry resin $(\mathrm{g}) /$ initial wt. wet resin $(\mathrm{g})$

Eq $(1-1)$

For the batch contacts, wet resin samples were added to an appropriate amount of simulant in polyethylene bottles. All experimental conditions were completed in duplicate and were conducted with two 30-mL samples of simulant in cases where no resin solid characterization was required and a duplicate of one $30-\mathrm{mL}$ sample and one $250-\mathrm{mL}$ samples when solids characterization was required. A minimum of one experimental blank, defined as simulant in a polyethylene bottle without resin, was included for each set of contacts. Samples were sealed in the polyethylene bottle by wrapping Parafilm ${ }^{\circledR}$ between the bottle cap and bottle. For the shaken samples, sealed bottles were then placed on a "Lab Line Microprocessor Shaker" rotating water bath maintained at $25 \pm 0.2^{\circ} \mathrm{C}$ and rotating at approximately 60 rotations per minute. Water temperature was monitored once evey five minutes using a Type $\mathrm{J}$ thermocouple interfaced and logged to a Dell ${ }^{\circledR}$ Laptop PC using Labview ${ }^{\mathrm{TM}}$ library software. For stagnant contacts, samples were placed in a Fischer Scientific "Isotemp 205" water bath maintained at $25 \pm 0.2^{\circ} \mathrm{C}$.

At the end of the prescribed contact time, samples were removed from the water baths and filtered. For the $30-\mathrm{mL}$ contacts, samples were filtered with a syringe through a $0.45 \mu \mathrm{M}$ Acrodisc ${ }^{\circledR}$ syringe filter. With the 250-mL contacts, resin solids were separated from the simulant using a $500 \mathrm{~mL}$ Nalgene ${ }^{\circledR}$ disposable $0.45 \mu \mathrm{M}$ nylon ${ }^{\circledR}$ filter under house vacuum. The resin was then rinsed with $50 \mathrm{~mL}$ of DI water in the filter and under house vacuum. The filter was subsequently removed from the filter 
unit and the filter and solids stored in a sealed plastic Petri dish until analysis. Filtrates from the 30-mL and 250-mL contacts were stored in new polyethylene bottles prior to analysis.

\subsubsection{Analytical Techniques}

This section contains a description of the analytical techniques used to characterize the chemical and physical behavior of SuperLig ${ }^{\circledR} 644$ resin as well as precipitates formed on the resin during the batch contact experiments described above.

\subsubsection{Aqueous -Phase Analyses}

The aqueous-phase analytical methods used in this study are described below.

\subsection{ICP-MS Cs Analysis}

A Fison Instruments inductively coupled plasma (argon) mass spectrometer (ICP-MS), modified VG PlasmaQuad PQ1, was used to determine stable cesium concentrations in supernate from the batch contacts. All analyses were conducted by the Analytical Development Section (ADS) of the SRTC and are covered by that section's quality assurance procedures and practices.

The ICP-MS was calibrated to National Institute of Standards and Technology traceable Cs standards diluted to the one to $25 \mu \mathrm{g} / \mathrm{L}$ range. Standards and samples were spiked with an internal standard of In115 to assist in monitoring changes in analytical performance. Batch contact supernate samples were diluted 1:(2,000 to 5,000) and analyzed by collecting mass-133 data (for Cs-133). Samples were generally analyzed in sets of five to 10 and then the instrument performance checked by analyzing the 5 $\mu \mathrm{g} / \mathrm{L}$ Cs-133 standard.

\subsection{Turbidity}

Turbidity was measured using a light scatting technique calibrated against NIST traceable standards. In all experiments, samples for turbidity analyses were collected in sealed $30-\mathrm{mL}$ bottles.

\subsubsection{Solid-Phase Analyses}

Both optical microscopy (OM) and scanning electron microscopy (SEM) were used to characterize the SL644 resins before and after treatment with simulant. Optical microscopy of the resins allowed for imaging of the visible features of the surface of the material including variations in color and ability to transmit light. SEM offers not only the advantage of higher magnification but also the large depth of field over a range of magnifications which allows for the generation of three dimensional images of solid material surfaces. A disadvantage of SEM is that it requires materials be stable under vacuum conditions (i.e., Samples must be completely dried) and under electron irradiation. Another 
disadvantage of SEM is that in the case of insulating materials such as organic resins the material surface must first be coated with a conducting material.

Additionally, energy dispersive x-ray (EDX) analysis was used in combination with SEM to further probe the chemical composition of surface precipitates. This technique was not used to examine the resin itself. Similarly, where appropriate, x-ray diffraction (XRD) analysis was used to further characterize observed precipitates.

\subsection{Optical Microscopy}

Optical microscope images were generated using a Nikon SMZ1500 microscope lens with a Diagnostics Instruments camera interfaced to a personal computer (PC) using SPOT software. The sample was illuminated using a Southern Micro Instruments 150 Watt tungsten halogen light source. The complete set of optical micrographs generated in this study have been recorded on compact disc (Appendix A). Table A-1 is a log of micrographs located in Appendix A.

\subsection{SEM/EDX}

Scanning electron microscopy (SEM) images were obtained on a dual stage ISI DS-130 (1984) instrument. Imaging on the lower stage was carried out in either secondary electron (SE) or backscatter electron (BSE) mode with a range of approximately $15 \mathrm{X}$ to 3,000X magnification. The lower stage was also equipped with an energy dispersive X-ray (EDX) detector capable of quantitative elemental surface analysis. Upper stage imaging was carried out in SE mode with a sample-dependent upper magnification limit of 50,000X.

Samples were dried in vacuo prior to mounting. In a typical experiment, the same sample was used for both upper and lower stage imaging. The sample was first mounted onto a $10 \mathrm{~mm}$ aluminum or copper stub using double-sided conductive tape cut to an appropriate size. The sample was then coated with carbon by evaporation of carbon strands. Upper stage imaging was carried out first and then the same sample as originally mounted was attached to a second mount of appropriate geometry for the lower stage experiments. A number of experiments were carried out using only the upper stage in which case the samples were sputter coated with palladium. During the analysis in the lower stage of the instrument, specific areas or spots on the surface were mapped using EDX detection. Only surface precipitates were mapped with the EDX analysis. The complete set of SEM micrographs and EDX spectra generated in this study have been recorded on compact disc (Appendix A). Table A-1 is a log of micrographs and spectra located in Appendix A.

\subsection{XRD}

X-ray diffraction data were collected on a Bruker D8 X-ray Diffractometer by step scanning over the $2 \Theta$ ranges of $5-70^{\circ}$ with a step size of $0.02^{\circ}$ and a dwell time of $1 \mathrm{~s}$. All instrument parameters are 
listed in Table A-1. All XRD spectra generated in this study have been recorded on compact disc (Appendix A). Table A-1 presents a log of XRD spectra located in Appendix A.

\section{Table 3-3 Instrument parameters.}

\begin{tabular}{|c|c|}
\hline Radiation Source & $\mathrm{CuK} \alpha \mathrm{X}$-ray \\
\hline Source Power & $45 \mathrm{kV}, 40 \mathrm{~mA}$ \\
\hline Wavelength & $1.5405982 \AA$ \\
\hline Goniometer & Bruker D8 \\
\hline Divergence Slit & $1^{\circ}$ \\
\hline Divergence Soller Slit & None \\
\hline Divergence Antiscatter & $1^{\circ}$ \\
\hline Specimen Rotation & No \\
\hline Diffracted Beam Antiscatter & $1^{\circ}$ \\
\hline Diffracted Beam Soller Slit & $2^{\circ}$ \\
\hline Secondary Monochromator & Curved pyrolytic graphite \\
\hline Receiving Slit & $0.15^{\circ}$ \\
\hline Detector & NaI Scintillation \\
\hline $2 \theta$ Range & $5^{\circ}-70^{\circ}$ \\
\hline Step Interval & $0.02^{\circ}(2 \theta)$ \\
\hline Fixed counting Time & $1 \mathrm{~s} / \mathrm{step}$ \\
\hline
\end{tabular}

\subsection{Experimental Control Experiments}

Generally, three sets of experimental controls were employed in this study. The first was to use "equipment blanks" (simulant without added resin) to ensure that Cs is not being lost to the equipment by sorption during the experiments. The second is the use of replicates to evaluate the degree of error introduced in conducting the batch contact studies and the associated analytical measurements. The third control was to randomly repeat $10 \%$ of the experimental conditions.

Equipment blanks were included in contact experiments with Simulants A and C spiked with Cs. These samples were shaken for periods of 0,1 , and 3 days and 1, 2, 3, 4, 6, and 8 weeks (see Table 3-4). After the prescribed period, the samples were filtered and filtrate analyzed for Cs concentration.

All batch contacts for a given set of experimental conditions were conducted in duplicate. Random replicates of 10 percent ( 5 replicates) of the batch contact tests in the experimental matrix (47 batch contacts) were conducted (see Table 3-4). Replicate contacts were conducted simultaneously with the primary contacts to prevent variability associated with potential time-dependent changes in resin properties. 


\subsection{Sorption Isotherm}

Generally speaking, a sorption (i.e., surface excess) isotherm is the function relating, at constant temperature and pressure, the sorbed concentration to the aqueous phase concentration of the species of interest at equilibrium. In the case of the equilibrium isotherm model being developed by Hamm et al. (2000), the final aqueous phase concentration of the specie of interest $\left(\mathrm{c}_{\mathrm{f}}(\mathrm{mmole} / \mathrm{L})\right)$ is related to the surface site loading (Q) (i.e., absorbed concentration (mmole/g dry resin)) for the specie of interest. In the case of the modeling for SuperLig ${ }^{\circledR} 644$ resin, Cs is the element of interest and the mathematical form used to relate the aqueous and sorbed concentrations in this modeling effort is the Langmuir isotherm. Based on our previous experience, and in a simplified form, for cesium on the SuperLig ${ }^{\circledR} 644$ resin the isotherm can be expressed as:

$$
Q=\frac{\bar{C}_{T} c_{f}}{c_{f}+\beta}
$$

where:

$$
\begin{array}{lll}
\mathrm{Q} & - & \text { cesium loading of resin (mmole of Cs/gram of dry resin) } \\
\overline{\mathrm{C}}_{\mathrm{T}} & - & \text { total cesium exchange capacity (mmole of Cs/gram of dry resin) } \\
\mathrm{c}_{\mathrm{f}} & - & \text { liquid-phase Cs concentration at equilibrium (final conc.) }[\mathrm{M}] \\
\beta & - & \text { beta parameter reflecting competitor impact }[\mathrm{M}]
\end{array}
$$

Langmuir Equation is generally fit to experimental data to obtain the Langmuir constant $\beta$.

Implicit in this approach is that a finite number of specie-specific binding sites exist and as more of the specie of interest is added to the system the fractional sorption of the specie will decrease. Therefore, the total specie concentration in the system is an important parameter in explaining sorption behavior of the resin. In addition to total specie concentration, Helfferich (1995) points out that resin selectivity (competitive ion effects), solution speciation, and ionic strength can all influence the sorption behavior of the specie of interest and, therefore, can be important parameters to consider in a predictive sorption model.

The interpretation of the results from this study will largely rely on the sorption isotherm construct. Under special situations, where the initial aqueous Cs concentration $\left(\mathrm{Cs}_{\mathrm{i}}\right)$, solid:liquid ratio, and solution composition are controlled, a direct comparison of the data using a $\mathrm{K}_{\mathrm{d}}$ approach is probably appropriate. Where:

$\mathrm{K}_{\mathrm{d}}(\mathrm{mL} / \mathrm{g}$ dry resin $)=\frac{\overline{\mathrm{c}}_{\mathrm{f}}}{\mathrm{c}_{\mathrm{f}}}=\frac{\mathrm{q}}{\mathrm{c}_{\mathrm{f}}}$

$\overline{\mathrm{c}}_{\mathrm{f}}$ is the absorbed concentration of Cs. In this work this value was calculated from analytical results for initial $\left(\mathrm{Cs}_{\mathrm{i}}\right)$ and final $\left(\mathrm{Cs}_{\mathrm{f}}\right)$ cesium concentrations as: 


$$
\overline{\mathrm{c}}_{\mathrm{f}}=\frac{\left(\mathrm{Cs} \mathrm{i}(\text { mole } / \mathrm{L})-\mathrm{Cs}_{\mathrm{f}}(\text { mole } / \mathrm{L})\right) \mathrm{x} \text { volume simulant }(\mathrm{L})}{\text { wt. of dry resin }(\mathrm{g})}
$$

Experimentally, a total of five separate batch contacts were conducted over a $\mathrm{Cs}_{\mathrm{i}}$ range from about 10 to $250 \mathrm{mg} / \mathrm{L}$ in Envelope A (AN105) simulant.

\subsection{Storage Condition Experiments}

SuperLig ${ }^{\circledR} 644$ resin was stored under three different conditions: dry with air in the headspace; under distilled water; and dry with nitrogen in the headspace. The experimental matrix for this sub experiment is presented as Table 3-5. At prescribed storage times (start [0 weeks], 1, 3, 5, and 8 weeks) resin samples from each of the three storage conditions were retrieved and subjected to batch contacts with simple alkaline salt simulant for three days. As with the temporal effects study, these contacts were conducted in duplicate with one $30-\mathrm{ml}$ and one $250-\mathrm{mL}$ sample at a solid to liquid ratio of approximately $1 \mathrm{~g}$ dry resin: $100 \mathrm{~mL}$ simulant. At the end of the contact, resin solids were separated and the reacted simulant analyzed for Cs via ICP-MS.

Additionally, resin solids from the $250-\mathrm{mL}$ contacts were analyzed by microscopy techniques.

\subsection{Temporal Effects Experiments}

The primary purpose of this work was to examine the potential for formation of post-filtration precipitates on SuperLig ${ }^{\circledR} 644$ resin and evaluate if these precipitates have an influence on the Cs removal performance of the resin. This was evaluated in a series of batch sorption experiments (see Section 3.3) with simulants of Envelopes A and $\mathrm{C}$ that were contacted for time periods of up to 8 weeks at $25^{\circ} \mathrm{C}$. The experimental matrix is summarized in Table 3-6.

Contacts were conducted in duplicate with one $30-\mathrm{mL}$ simulant sample that was analyzed solely for aqueous-phase changes and one $250-\mathrm{mL}$ sample in which both the aqueous and solid phases were analyzed. Resin solids were analyzed by optical microscopy, electron microscopy, energy dispersive xray for elemental composition, and particle-size distribution. 


\section{WESTINGHOUSE SAVANNAH RIVER COMPANY}

Integrated Sr/TRU Precipitation and

Cs Ion Exchange Process Validation (U)
Report: $\quad$ WSRC-TR-2003-00254

SRP-RPP-2003-00120

Revision (Date): $\quad$ Rev. 0 (8/04/03)

Table 3-4 Experimental Matrix - Experimental Controls

\begin{tabular}{|c|c|c|c|c|c|c|c|}
\hline Sample ID & Simulant & $\begin{array}{c}\text { Storage Time } \\
\text { (wk) }\end{array}$ & $\begin{array}{c}\text { Contact Time } \\
\text { (wk) }\end{array}$ & $\begin{array}{l}\text { Cs Added } \\
(\mathrm{mg} / \mathrm{L})\end{array}$ & Mixing & $\begin{array}{c}\text { Supernate } \\
\text { Analysis }\end{array}$ & Solids Analysis \\
\hline \multicolumn{8}{|c|}{ Equipment Blanks - Simulant A } \\
\hline EqBlk-A0 & A & 0 & NA & 78 & Shaken & Cs, pH, Turb. & None \\
\hline EqBlk-A1 & $\mathrm{A}$ & 1 & NA & 78 & Shaken & Cs, pH, Turb. & None \\
\hline EqBlk-A2 & $A$ & 2 & NA & 78 & Shaken & Cs, pH, Turb. & None \\
\hline EqBlk-A3 & $\mathrm{A}$ & 3 & NA & 78 & Shaken & $\mathrm{Cs}, \mathrm{pH}$, Turb. & None \\
\hline EqBlk-A4 & $\mathrm{A}$ & 4 & NA & 78 & Shaken & Cs, pH, Turb. & None \\
\hline EqBlk-A5 & $\mathrm{A}$ & 5 & NA & 78 & Shaken & Cs, pH, Turb. & None \\
\hline EqBlk-A6 & $A$ & 6 & NA & 78 & Shaken & Cs, pH, Turb. & None \\
\hline EqBlk-A7 & $\mathrm{A}$ & 7 & NA & 78 & Shaken & Cs, pH, Turb. & None \\
\hline EqBlk-A8 & A & 8 & NA & 78 & Shaken & Cs, pH, Turb. & None \\
\hline \multicolumn{8}{|c|}{ Equipment Blanks - Simulant C } \\
\hline EqBlk-C0 & $\mathrm{C}$ & 0 & NA & 78 & Shaken & Cs, pH, Turb. & None \\
\hline EqBlk-C1 & $\mathrm{C}$ & 1 & NA & 78 & Shaken & Cs, pH, Turb. & None \\
\hline EqBlk-C2 & $\mathrm{C}$ & 2 & NA & 78 & Shaken & Cs, pH, Turb. & None \\
\hline EqBlk-C3 & $\mathrm{C}$ & 3 & NA & 78 & Shaken & Cs, pH, Turb. & None \\
\hline EqBlk-C4 & $\mathrm{C}$ & 4 & NA & 78 & Shaken & $\mathrm{Cs}, \mathrm{pH}$, Turb. & None \\
\hline EqBlk-C5 & $\mathrm{C}$ & 5 & NA & 78 & Shaken & Cs, pH, Turb. & None \\
\hline EqBlk-C6 & C & 6 & NA & 78 & Shaken & Cs, pH, Turb. & None \\
\hline EqBlk-C7 & $\mathrm{C}$ & 7 & NA & 78 & Shaken & Cs, pH, Turb. & None \\
\hline EqBlk-C8 & $\mathrm{C}$ & 8 & NA & 78 & Shaken & Cs, pH, Turb. & None \\
\hline \multicolumn{8}{|c|}{ Random Replicates } \\
\hline 3-1 Rep & Alkaline Salt & 1 & 3 days & 78 & Shaken & Cs, pH, Turb. & OM, SEM, Density \\
\hline 8 Rep & $A$ & NA & 2 & 78 & Shaken & Cs, pH, Turb. & OM, Density \\
\hline 18 Rep & $\mathrm{C}$ & NA & 8 & 78 & Stagnant & $\mathrm{Cs}, \mathrm{pH}$, Turb. & OM, Density \\
\hline 24 Rep & $\mathrm{C}$ & NA & 6 & 78 & Shaken & Cs, pH, Turb. & OM, Density \\
\hline 26 Rep & $\mathrm{C}$ & NA & 8 & 78 & Shaken & Cs, pH, Turb. & OM, Density \\
\hline
\end{tabular}

Notes: $\mathrm{NA}=$ not applicable; $\mathrm{OM}=$ optical microscopy. 
Table 3-5 Experimental Matrix - Storage Conditions

\begin{tabular}{|c|c|c|c|c|c|c|c|}
\hline Sample ID & Simulant & $\begin{array}{c}\text { Storage Time } \\
(w k)\end{array}$ & $\begin{array}{c}\text { Contact } \\
\text { Time (days) }\end{array}$ & $\begin{array}{c}\mathrm{Cs} \\
\text { Added } \\
(\mathrm{mg} / \mathrm{L})\end{array}$ & Mixing & $\begin{array}{c}\text { Supernate } \\
\text { Analysis }\end{array}$ & $\begin{array}{l}\text { Solids } \\
\text { Analysis }\end{array}$ \\
\hline \multicolumn{8}{|c|}{ Stored Under Air Resin Dry } \\
\hline $1-0$ & Alkaline Salt & 0 & 3 & 78 & Shaken & Cs & OM, SEM \\
\hline $1-1$ & Alkaline Salt & 1 & 3 & 78 & Shaken & Cs & OM, SEM \\
\hline $1-3$ & Alkaline Salt & 3 & 3 & 78 & Shaken & Cs & OM, SEM \\
\hline $1-5$ & Alkaline Salt & 5 & 3 & 78 & Shaken & Cs & OM, SEM \\
\hline $1-8$ & Alkaline Salt & 8 & 3 & 78 & Shaken & Cs & OM, SEM \\
\hline \multicolumn{8}{|c|}{ Stored Under DI Water } \\
\hline $2-0$ & Alkaline Salt & 0 & 3 & 78 & Shaken & Cs & OM, SEM \\
\hline $2-1$ & Alkaline Salt & 1 & 3 & 78 & Shaken & Cs & OM, SEM \\
\hline $2-3$ & Alkaline Salt & 3 & 3 & 78 & Shaken & Cs & OM, SEM \\
\hline $2-5$ & Alkaline Salt & 5 & 3 & 78 & Shaken & Cs & OM, SEM \\
\hline $2-8$ & Alkaline Salt & 8 & 3 & 78 & Shaken & Cs & OM, SEM \\
\hline \multicolumn{8}{|c|}{ Stored Under Inert Gas Resin Dry } \\
\hline $3-0$ & Alkaline Salt & 0 & 3 & 78 & Shaken & Cs & OM, SEM \\
\hline 3-1 & Alkaline Salt & 1 & 3 & 78 & Shaken & Cs & OM, SEM \\
\hline $3-3$ & Alkaline Salt & 3 & 3 & 78 & Shaken & Cs & OM, SEM \\
\hline $3-5$ & Alkaline Salt & 5 & 3 & 78 & Shaken & Cs & OM, SEM \\
\hline $3-8$ & Alkaline Salt & 8 & 3 & 78 & Shaken & $\mathrm{Cs}$ & OM, SEM \\
\hline
\end{tabular}

Notes: $\mathrm{OM}=$ optical microscopy; $\mathrm{SEM}=$ scanning electron microscopy 
Table 3-6 Experimental Matrix Temporal Effects

\begin{tabular}{|c|c|c|c|c|c|c|}
\hline $\begin{array}{l}\text { Task Request } \\
\text { Sample ID }\end{array}$ & Simulant & $\begin{array}{c}\text { Contact } \\
\text { Time } \\
\text { (Weeks) }\end{array}$ & $\begin{array}{l}\text { Cs Added } \\
\text { (mg/L) }\end{array}$ & Mixing & $\begin{array}{c}\text { Supernate } \\
\text { Analysis }\end{array}$ & Solids Analysis $^{2}$ \\
\hline 4 & $\mathrm{~A}$ & 8 & 78 & Stagnant & Full Suite & OM, SEM, Density \\
\hline 5 & $\mathrm{~A}$ & 8 & 78 & Stagnant & Full Suite & OM, Density \\
\hline 6 & $A$ & 8 & 78 & Stagnant & Full Suite & OM, Density \\
\hline 7 & $\mathrm{~A}$ & 1 day & 78 & Shaken & Full Suite & OM, SEM, Density \\
\hline 8 & $A$ & 3 day & 78 & Shaken & Full Suite & OM, Density \\
\hline 9 & A & 1 & 78 & Shaken & Full Suite & OM, SEM, Density \\
\hline 10 & $A$ & 2 & 78 & Shaken & Full Suite & OM, Density \\
\hline 11 & $\mathrm{~A}$ & 3 & 78 & Shaken & Full Suite & OM, SEM, Density \\
\hline 12 & $\mathrm{~A}$ & 4 & 78 & Shaken & Full Suite & OM, Density \\
\hline 13 & $A$ & 6 & 78 & Shaken & Full Suite & OM, Density \\
\hline 14 & $A$ & 8 & 78 & Shaken & Full Suite & OM, SEM, Density \\
\hline 15 & \multicolumn{6}{|c|}{ Covered with equipment blanks (see Table 3-4). } \\
\hline 16 & $\mathrm{C}$ & 8 & 78 & Stagnant & Full Suite & OM, SEM, Density \\
\hline 17 & $\mathrm{C}$ & 8 & 78 & Stagnant & Full Suite & OM, Density \\
\hline 18 & C & 8 & 78 & Stagnant & Full Suite & OM, Density \\
\hline 19 & C & 1 day & 78 & Shaken & Full Suite & OM, SEM, Density \\
\hline 20 & $\mathrm{C}$ & 3 day & 78 & Shaken & Full Suite & OM, Density \\
\hline $21-24 h r^{3}$ & C & 1 & 78 & Shaken & Full Suite & OM, SEM, Density \\
\hline $21-48 \mathrm{hr}^{3}$ & C & 1 & 78 & Shaken & Full Suite & OM, Density \\
\hline $21-72 \mathrm{hr}^{3}$ & $\mathrm{C}$ & 1 & 78 & Shaken & Full Suite & OM, Density \\
\hline 22 & $\mathrm{C}$ & 2 & 78 & Shaken & Full Suite & OM, Density \\
\hline 23 & $\mathrm{C}$ & 3 & 78 & Shaken & Full Suite & OM, SEM, Density \\
\hline 24 & C & 4 & 78 & Shaken & Full Suite & OM, Density \\
\hline 25 & $\mathrm{C}$ & 6 & 78 & Shaken & Full Suite & OM, Density \\
\hline 26 & $\mathrm{C}$ & 8 & 78 & Shaken & Full Suite & OM, SEM, Density \\
\hline 27 & \multicolumn{6}{|c|}{ Covered with equipment blanks (see Table 3-4). } \\
\hline 28 & $\bar{A}$ & 3 & 20 & Shaken & Full Suite & OM, Density \\
\hline 29 & $A$ & 3 & 50 & Shaken & Full Suite & OM, Density \\
\hline 30 & $\bar{A}$ & 3 & 100 & Shaken & Full Suite & OM, Density \\
\hline 31 & $\bar{A}$ & 3 & 400 & Shaken & Full Suite & OM, Density \\
\hline
\end{tabular}

Notes: (1) NA = not applicable; (2) Full Suite $=\mathrm{Na}, \mathrm{K}, \mathrm{Cs}$, transition metals, and total inorganic carbon/total organic carbon (TIC/TOC); (3) OM = optical microscopy; (4) SEM = scanning electron microscopy; (3) 24, 48, and 72 hrs are the time after precipitation of the simulant that the batch contact was started. 


\section{RESULTS AND DISCUSSION}

\subsection{Unreacted Resin Characterization}

\subsubsection{Elemental Composition}

The elemental composition of $\mathrm{Na}$ and $\mathrm{K}$ of the 1- gallon resin sample was determined by microwave digestion of the solid in concentrated nitric acid and analysis of the resulting liquid by ion coupled plasma atomic emission spectrophotometry. The results of the analysis were $0.64 \mathrm{mg} \mathrm{K}$ and $0.03 \mathrm{mg} \mathrm{Na}$ per gram dry resin.

\subsubsection{Porosity and Density}

Two porosities, bed (i.e., void space in the resin bed) and particle (i.e., void space in the resin particle), and two densities, skeletal (i.e., density of resin particle) and bed (i.e., density of resin bed), were measured for the SuperLig ${ }^{\circledR} 644$ one-gallon batch resin (Table 4-1 and Table 4-2). These physical characteristics of the resin were determined using solution displacement methods with the general approach described in ASTM C128-01. Briefly, the porosities and bed density were measured by allowing a sample of dry, sodium form resin to swell in $\mathrm{NaCl}$ simulant before slurrying it into a burette. Volumes of simple alkaline simulant were added and eluted to provide data from which to calculate the physical parameters. The skeletal density was measured using a small pycnometer, which is a vessel of precisely calibrated volume. It was weighed containing resin and reagent as well as just reagent to determine the density of the resin particles. The skeletal densities show little variation due to experimental conditions.

Table 4-1 Porosity and density of SuperLig® 644 one-gallon batch resin measured in $\mathrm{NaCl}$ alkaline simulant.

\begin{tabular}{|c|c|c|}
\hline Bed Porosity & Particle Porosity & Bed Density $(\mathrm{g}$ resin $/ \mathrm{mL})$ \\
\hline 0.41 & 0.52 & 0.30 \\
\hline
\end{tabular}

Table 4-2 Skeletal density of SuperLig® 644 one-gallon batch resin measured in de-ionized water and $\mathrm{AN}-105$ simulant.

\begin{tabular}{|c|c|c|}
\hline Initial Resin Form & Reagent & Skeletal Density $(\mathrm{g} \mathrm{resim} / \mathrm{mL})$ \\
\hline Sodium & De-ionized Water & 1.30 \\
\hline Sodium & AN-105 & 1.37 \\
\hline Hydrogen & De-ionized Water & 1.36 \\
\hline Hydrogen & AN-105 & 1.31 \\
\hline
\end{tabular}




\subsubsection{Particle Size Distribution}

The particle size distribution of the SuperLig ${ }^{\circledR} 644$ one-gallon batch resin was determined using a wet sieve method. Wet resin was placed in the top of a tower of sieves on a shaker, and was then simultaneously rinsed with de-ionized water and shaken for twenty minutes to separate the resin particles into the various mesh sizes. Two wet sieve analyses were performed and the percent of resin retained by each sieve is reported in Table 4-3. Over $96 \%$ of the resin particles were between forty and sixty mesh in size. The rather low deviations between the two sieve analyses indicate that the asreceived sample was well mixed prior to conducting these measurements.

Table 4-3 Particle size distribution of SuperLig® 644 one-gallon batch resin by wet sieve analysis. (2 replicates)

\begin{tabular}{|c|c|c|c|c|}
\hline Mesh & Opening $(\mu \mathrm{m})$ & $\begin{array}{c}\text { Primary } \\
\% \text { Retained }\end{array}$ & $\begin{array}{c}\text { Replicate } \\
\% \text { Retained }\end{array}$ & $\begin{array}{c}\text { Average } \\
\% \text { Retained }\end{array}$ \\
\hline 30 & 600 & 3.19 & 0.59 & $1.9 \pm 1.8$ \\
\hline 40 & 425 & 58.65 & 62.45 & $60.6 \pm 2.8$ \\
\hline 50 & 300 & 24.05 & 24.16 & $24.1 \pm 0.1$ \\
\hline 60 & 250 & 11.93 & 11.58 & $11.8 \pm 02$ \\
\hline 80 & 180 & 2.01 & 1.13 & $1.6 \pm 0.6$ \\
\hline 100 & 150 & 0.17 & 0.08 & $0.1 \pm 01$ \\
\hline
\end{tabular}

Chord length analysis was conducted using a Lasentec FBRM (Focused Beam Reflectance Measurement) M400L. Raw chord length distributions are complicated by the fact that any given particle contains a number of measurable chords depending upon the particle shape. Even with these limitations, this approach is expected to provide a rapid means to analyze relative changes in particle size distributions on small sample sizes. The chord-length distribution for the as- received one gallon batch of SuperLig ${ }^{\circledR} 644$ is plotted in Figure 4-1. It shows that the most abundant measured chord length was between 150 to $400 \mu \mathrm{M}$. This is approximately equal to the resins retained on sieves 40 , 50, 60, 80, and 100 mesh. The Lasentec instrument clearly measures 2 parameters quite different from sieves and that chord length is a smaller parameter than nominal-particle diameter.

\subsubsection{Optical Microscopy}

As received samples of SL644 exhibited a variety of particle morphologies as observed under the optical microscope including resin particles with sharp angular edges, with scalloped markings, with rounded edges, scalloped markings, rounded edges, and elongated cylindrical strands

(

Figure 4-2). The sodium form of the 25 gallon Batch 1 resin is shown for comparison because the as received sample of the 1 gallon SL644 batch used in this study was shipped in the hydrogen form. The color of the resin particles of the hydrogen form of the SL644 resin appears orange under the optical 
microscope while the color of the sodium form appears as a darker reddish brown. The surface morphology does not appear significantly different comparing the hydrogen and sodium forms.

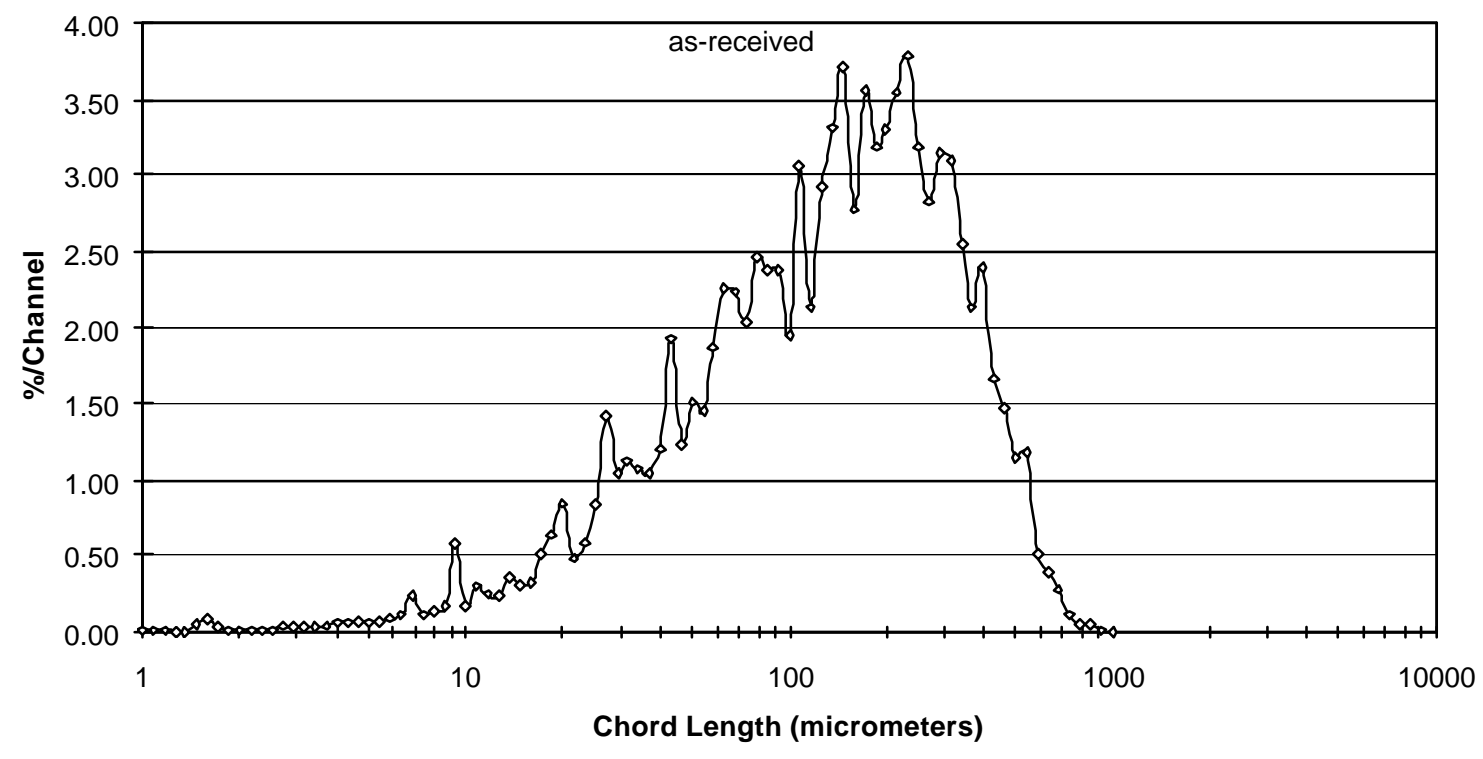

Figure 4-1 As-received chord-length distribution SuperLig ${ }^{\circledR} 644$ One Gallon Batch

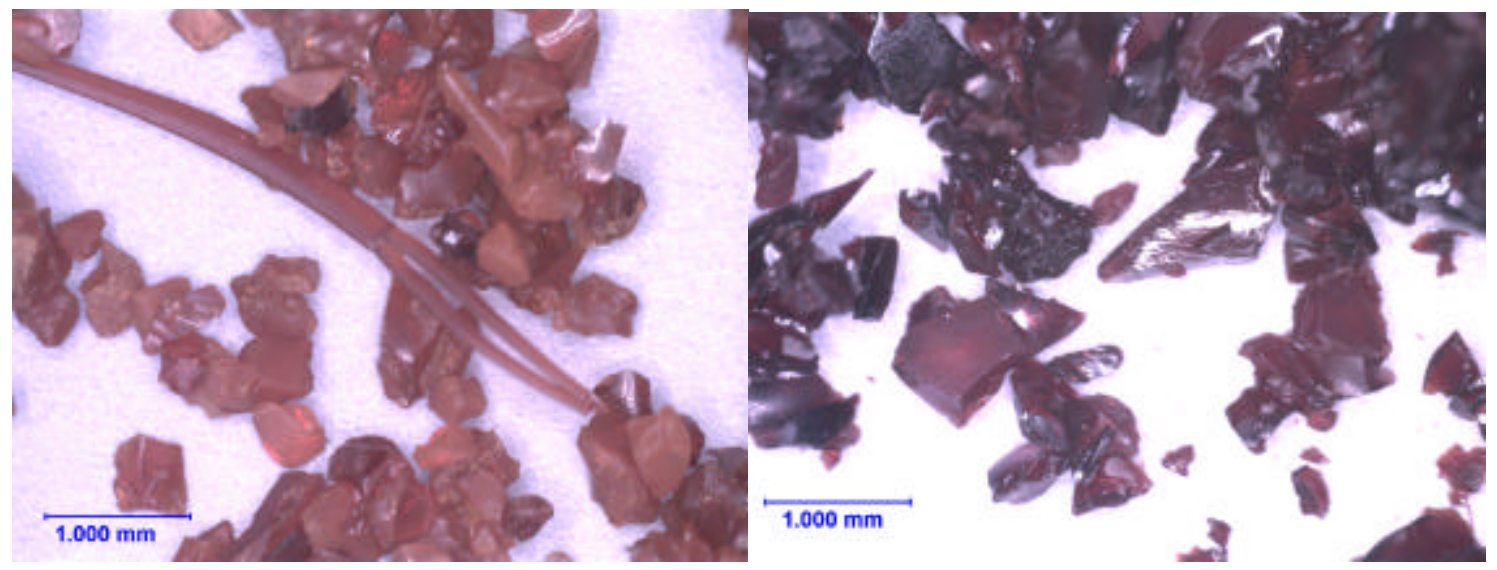

Figure 4-2 As received SL644 1 gallon batch (left). As received SL644 25 gallon Batch 1 sodium form (right).

\subsubsection{Scanning Electron Microscopy}

SL644 resins in both hydrogen and sodium forms were analyzed by scanning electron microscopy. As mentioned in the methods section of this report, scanning electron microscopy requires that the sample be much drier than the optical microscope samples. Thus, it was anticipated that the impact of greater dehydration would be apparent. Images of the hydrogen form and lower stage x-ray backscatter images of the sodium form are shown in Figure 4-3. Irregular surface morphology is evident even at 
relatively low magnification. The backscatter images most clearly show large fissures in the resin which in some cases nearly dissect resin particles.

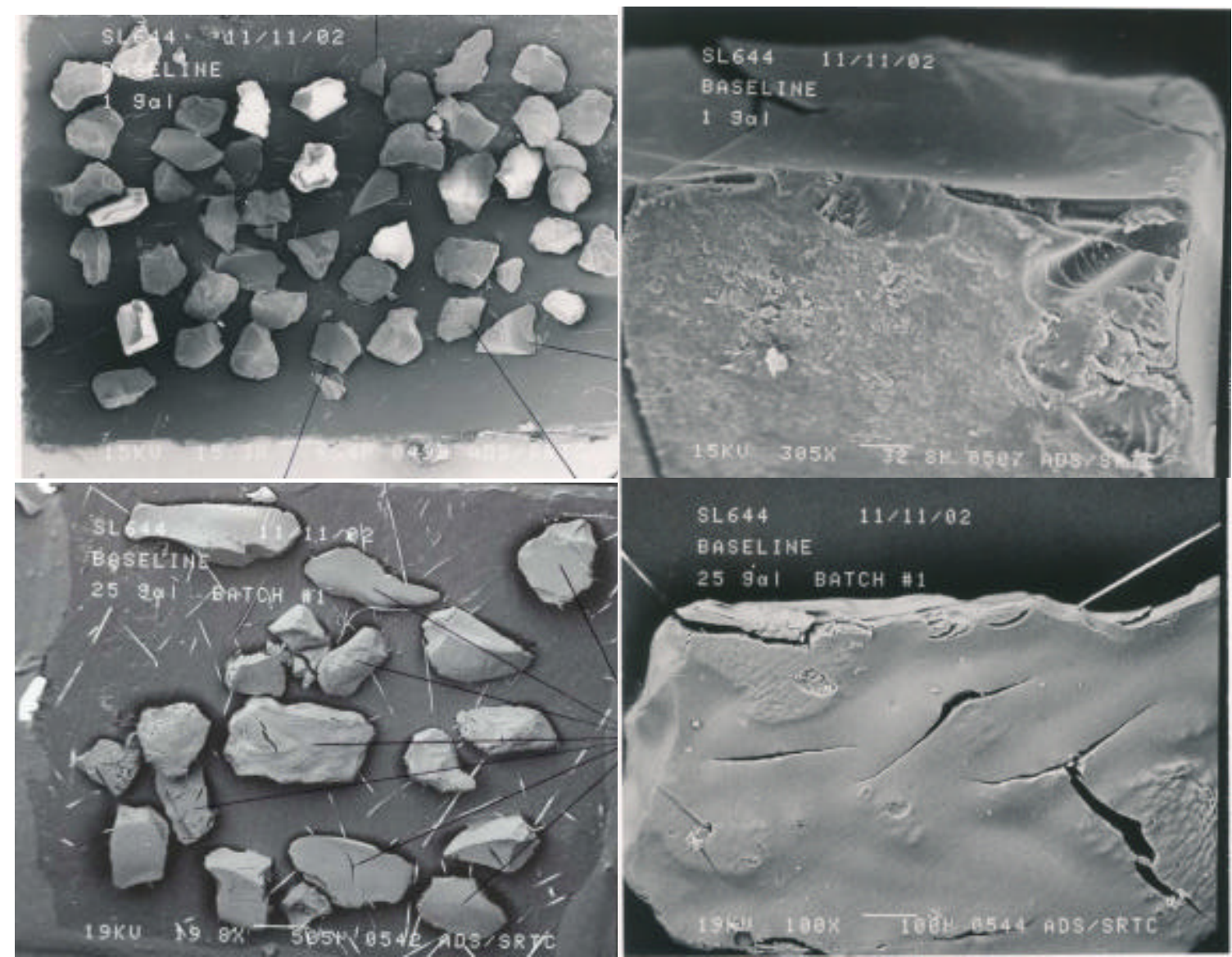

Figure 4-3 SL644 1 gallon batch hydrogen form SEM Upper stage image (15.3 X top left. $305 \mathrm{X}$ top right) SL644 25 gallon batch 1 sodium form SEM Backscatter image (19.0 X bottom left. 100X bottom right).

\subsubsection{X-Ray Diffraction}

Both hydrogen and sodium forms of SL644 Resins exhibit a simple amorphous XRD pattern (Figure 4-4), indicating that these were no detectable crystalline phases associated with the resin. 
Integrated Sr/TRU Precipitation and

Revision (Date): $\quad$ Rev. $0(8 / 04 / 03)$

Cs Ion Exchange Process Validation (U)

Page:

33 of 63
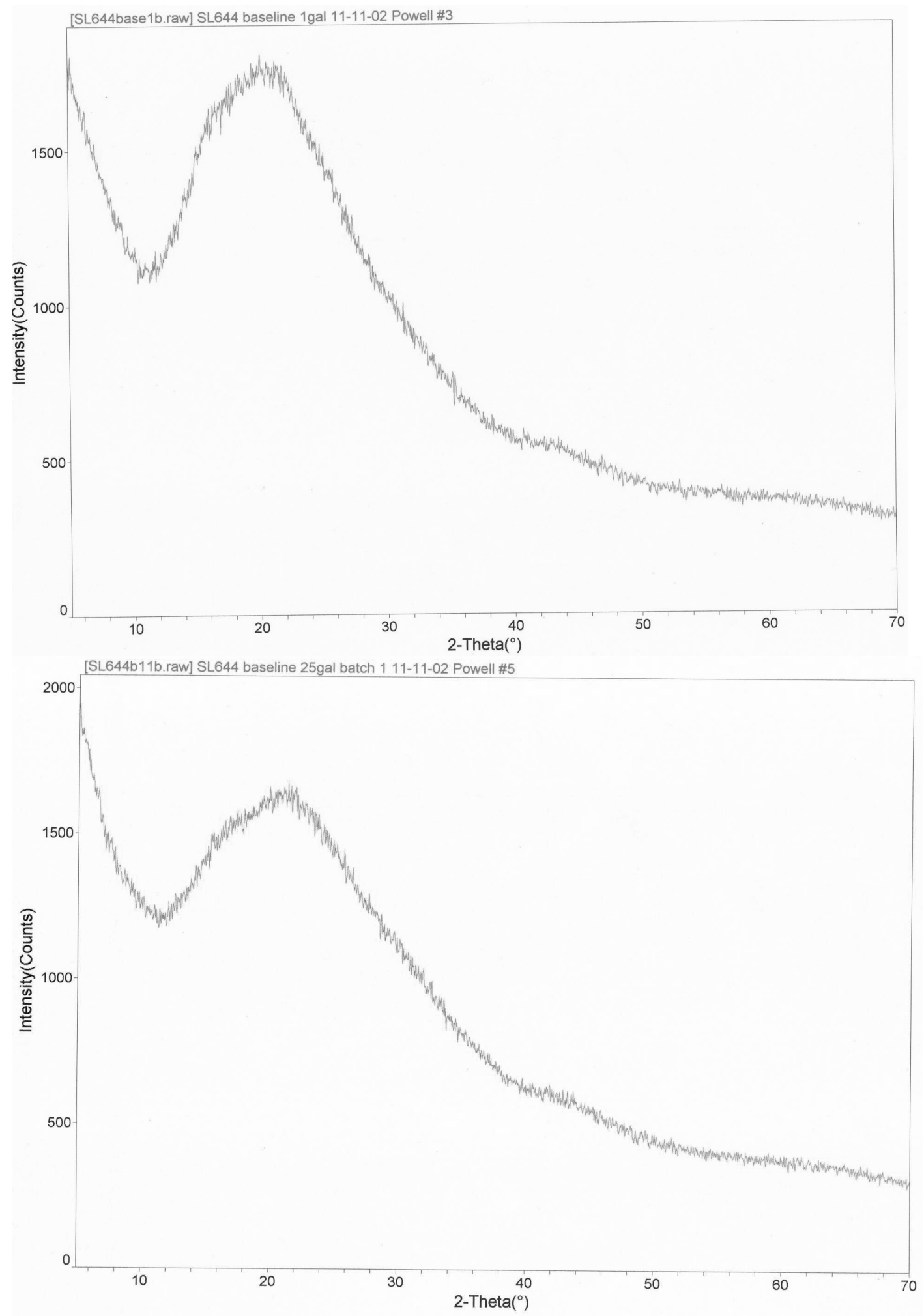

Figure 4-4 SL644 1 gallon batch hydrogen form (top). SL644 25 gallon batch 1 sodium form (bottom). 


\subsection{Experimental Control Experiments}

\subsubsection{Equipment Blanks}

ICP-MS results for simulant Cs concentrations are summarized in. These equipment blanks are samples treated identically to the temporal-effects samples but contained no resin. These blanks contain simulant from the same batch preparation (one each for AN105 and AN107). Therefore, the results should incorporate errors associated with simulant heterogeneity, loss of Cs to the experiment equipment, and analysis via ICP-MS. Simulants are filtered and well mixed prior to use, so simulant heterogeneity is not considered a credible source of error.

There are not large changes in blank concentrations over time. The slope from regression analysis is $0.24 \mathrm{mg}$ Cs (loss) per liter per week (0.43 percent of $\mathrm{C}_{0}$ per week) for AN105 blanks and $0.11 \mathrm{mg}$ Cs (gain) per liter per week ( 0.15 percent of $\mathrm{C}_{0}$ per week) for $\mathrm{AN} 107$ blanks. With analysis errors of between 1 and 5 percent for these samples (see below), no Cs loss to the equipment was observed.

The equipment blanks contain two unique duplicate samples for each storage time and simulant and each duplicate pair were analyzed by ICP-MS on different dates. The average standard deviation (at $2 \mathrm{~s}$ ) within these nine sample duplicate sets was 5.5 with a range of 0.18 to 24 percent for AN105 blanks and 1.1 with a range of 0.00 to 2.7 percent for AN107 blanks. For this sample set, the analytical error at the $95^{\text {th }}$ percentile confidence level for duplicate samples run on the same day appears to be on the order of 1 to 5 percent.

If it is assumed that there is no loss or addition of Cs from the simulant over time, then the equipment blanks can be used to estimate the analytical error for Cs measurement by ICP-MS where the samples are analyzed on different days. For the two simulant blank sample populations $(n=18)$ at the $95^{\text {th }}$ percentile confidence level the analytical error is 12 and 5.4 percent for AN105 and AN107, respectively. 
Table 4-4 Equipment Blank Simulant Concentration Results

\begin{tabular}{|c|c|c|}
\hline & AN105 & AN107 \\
\hline $\begin{array}{c}\text { Storage Time } \\
\text { (weeks) }\end{array}$ & $\begin{array}{c}\text { ICP-MS Result } \\
(\mathrm{mg} \mathrm{Cs} / \mathrm{L})\end{array}$ & $\begin{array}{l}\text { ICP-MS Result } \\
(\mathrm{mg} \mathrm{Cs} / \mathrm{L})\end{array}$ \\
\hline 0 & 55.6 & 73.0 \\
\hline 0 & 56.4 & 72.7 \\
\hline 1 & 56.2 & 79.5 \\
\hline 1 & 56.1 & 79.5 \\
\hline 2 & 56.0 & 73.1 \\
\hline 2 & 56.1 & 75.1 \\
\hline 3 & 55.3 & 77.5 \\
\hline 3 & 54.8 & 76.9 \\
\hline 4 & 55.0 & 75.9 \\
\hline 4 & 56.7 & 77.4 \\
\hline 5 & 55.4 & 77.5 \\
\hline 5 & 46.3 & 78.3 \\
\hline 6 & 48.0 & 76.0 \\
\hline 6 & 61.2 & 77.0 \\
\hline 7 & 54.8 & 77.6 \\
\hline 7 & 54.7 & 77.2 \\
\hline 8 & 54.9 & 75.1 \\
\hline 8 & 55.7 & 74.4 \\
\hline Average & 55.0 & 76.3 \\
\hline Std Dev (2s) & 6.4 & 4.1 \\
\hline$\%$ Std Dev (2s) & 11.6 & 5.4 \\
\hline
\end{tabular}

\subsubsection{Analytical Reruns}

Two sets of samples from this project were reanalyzed on different days for Cs by ICP-MS and the results are contained in. The first set was reanalyzed the day after the initial analysis and the average standard deviation at the $95^{\text {th }}$ percentile confidence level was 1.2 percent, while the average standard deviation for the sample set reanalyzed roughly two months later was 5.5 percent. 
Table 4-5 ICP-MS Reruns

\begin{tabular}{|c|c|c|c|c|c|}
\hline & \multicolumn{5}{|c|}{ Cs Result by ICP-MS (mg/L) } \\
\hline LIMS ID & $\mathbf{1 / 1 3 / 0 3}$ & $\mathbf{1 / 1 4 / 0 3}$ & $\mathbf{1 1 / 0 7 / 0 2}$ & $\mathbf{1 / 1 4 / 0 3}$ & \% Std Dev at 2s \\
\hline 187515 & 12.8 & 13.1 & NA & NA & 2.32 \\
\hline 187516 & 7.61 & 7.75 & NA & NA & 1.82 \\
\hline 187517 & 12.55 & 12.6 & NA & NA & 0.40 \\
\hline 187518 & 4.31 & 4.31 & NA & NA & 0.00 \\
\hline 187519 & 9.92 & 9.88 & NA & NA & 0.40 \\
\hline 187520 & 6.14 & 6.17 & NA & NA & 0.49 \\
\hline 187521 & 77.2 & 79.3 & NA & NA & 2.68 \\
\hline 187522 & 77.6 & 78.8 & NA & NA & 1.53 \\
\hline 188239 & NA & NA & 9.31 & 9.52 & 2.23 \\
\hline 188240 & NA & NA & 2.74 & 2.89 & 5.33 \\
\hline 188241 & NA & NA & 8.78 & 9.25 & 5.21 \\
\hline 188242 & NA & NA & 2.25 & 2.39 & 6.03 \\
\hline 188243 & NA & NA & 9.00 & 9.44 & 4.77 \\
\hline 188245 & NA & NA & 72.8 & 78.4 & 7.41 \\
\hline 188246 & NA & NA & 72.3 & 77.9 & 7.46 \\
\hline \multicolumn{7}{|r|}{} & \multicolumn{2}{|c|}{ 2nd Set Average } & 1.16 \\
\cline { 3 - 6 } & & &
\end{tabular}

\subsubsection{Random Replicates}

The results of the Cs analyses of random replicates along with those of corresponding primary samples are summarized in Table 4-6. In this experiment batch contacts for the primary and replicate samples, as well as duplicate samples for both, were started at the same time with the same simulant batch. Somewhat surprisingly, there was a significant systematic variation between the final aqueous Cs concentration between the $250-\mathrm{mL}$ and $30-\mathrm{mL}$ samples for shorter contact times (less than one week). In almost all cases for this study, the shorter contact times resulted in higher final aqueous Cs concentrations for the $250-\mathrm{mL}$ samples than for the corresponding 30- $\mathrm{mL}$ duplicate sample. Even though these samples were on the same shaker table, it is thought that insufficient agitation of the larger samples resulted in slower equilibration than for the corresponding $30-\mathrm{mL}$ samples.

Within a given contact sample size (either 250 or $30 \mathrm{~mL}$ ), however, there is good agreement between the final aqueous Cs concentration at the end of the contact period. The average standard deviation at the $95^{\text {th }}$ percentile confidence level was 12 percent (with a range of 2 to 48 ) between sample replicates of the same size and variations did not exhibit a systematic variation with contact sample size. With analytical errors contributing on the order of 5 to 10 percent to the overall uncertainty, batch contact preparation errors (e.g., simulant volume, f-factor determination, and resin weight) appear to contribute on the order of 2 to 5 percent of the total experimental uncertainty. 
Table 4-6 Random Replicate Results

\begin{tabular}{|c|c|c|c|c|c|c|c|c|}
\hline \multirow[b]{2}{*}{ Sample ID } & \multirow[b]{2}{*}{$\begin{array}{l}\text { Sample } \\
\text { Size } \\
(\mathrm{mL}) \\
\end{array}$} & \multirow[b]{2}{*}{$\begin{array}{l}\text { Initial } \\
\text { Cs } \\
\text { Conc } \\
\text { (mg/L) } \\
\end{array}$} & \multicolumn{3}{|c|}{ Primary Sample } & \multicolumn{3}{|c|}{ Replicate Sample } \\
\hline & & & $\begin{array}{l}\text { Final Aq } \\
\text { Cs } \\
(\mathrm{mg} / \mathrm{L})\end{array}$ & $\begin{array}{c}\mathrm{L}: \mathrm{S} \\
\text { Ratio(mL } \\
\text { Simulant/ } \\
\text { g dry } \\
\text { resin) }\end{array}$ & $\begin{array}{l}250 \mathrm{~mL}: \\
30 \mathrm{~mL} \\
\text { Final aq } \\
\text { Cs }\end{array}$ & $\begin{array}{l}\text { Final Aq } \\
\text { Cs } \\
(\mathrm{mg} / \mathrm{L})\end{array}$ & $\begin{array}{l}\text { L:S } \\
\text { Ratio(mL } \\
\text { Simulant/ } \\
\text { g dry } \\
\text { resin) }\end{array}$ & $\begin{array}{l}250 \mathrm{~mL}: 3 \\
0 \mathrm{~mL} \\
\text { Final aq } \\
\text { Cs }\end{array}$ \\
\hline $\begin{array}{l}\text { Alkaline Salt } \\
1 \text { Week Storage } \\
\text { Under Nitrogen } \\
3 \text { Day Contact } \\
\end{array}$ & 250 & 72.5 & 11.3 & 89 & 2.47 & NA & NA & NA \\
\hline " Dup & 30 & 72.5 & 4.58 & 89 & NA & NA & NA & NA \\
\hline $\begin{array}{c}\text { AN105, 3 Day } \\
\text { Contact, Shaken }\end{array}$ & 250 & 56.0 & 6.45 & 126 & 2.47 & 6.21 & 126 & 2.51 \\
\hline “ Dup & 30 & 56.0 & 2.61 & 126 & NA & 2.47 & 126 & NA \\
\hline $\begin{array}{l}\text { AN107, } 8 \text { Weeks } \\
\text { Contact, Stagnant }\end{array}$ & 250 & 74.8 & 5.17 & 180 & 1.53 & 3.16 & 179 & 0.97 \\
\hline “ " " Dup & 30 & 74.8 & 3.37 & 172 & NA & 3.25 & 174 & NA \\
\hline $\begin{array}{l}\text { AN107, } 4 \text { Weeks } \\
\text { Contact, Shaken }\end{array}$ & 250 & 76.7 & 2.89 & 179 & 0.75 & 2.96 & 179 & 0.99 \\
\hline “ Dup & 30 & 76.7 & 3.83 & 175 & NA & 2.99 & 177 & NA \\
\hline $\begin{array}{l}\text { AN107, } 8 \text { Weeks } \\
\text { Contact, Shaken }\end{array}$ & 250 & 74.8 & 3.06 & 179 & 0.93 & 3.20 & 179 & 0.96 \\
\hline “ Dup & 30 & 74.8 & 3.28 & 171 & NA & 3.35 & 175 & NA \\
\hline
\end{tabular}

\subsubsection{Interpretation of Errors}

The experimental controls portion of this study has allowed us to quantify the relative errors in measuring Cs sorption behavior on SuperLig ${ }^{\circledR} 644$ and will, thus, be used to interpret the temporal effects and storage effects experiments. While it was necessary to use a large sample size $(250 \mathrm{~mL})$ to prepare enough reacted resin samples for further characterization, these samples appear to take a longer timeperiod to reach equilibrium than the $30-\mathrm{mL}$ contacts. So, while the relative trends within each of the contact sample sizes should be consistent, the $30-\mathrm{mL}$ contacts are expected to reach equilibrium more quickly and should, therefore, be relied on for a more quantitative measure of Cs sorption behavior.

For the remainder of the data interpretation, the following relative errors will be used:

- seven percent for ICP-MS analysis of Cs in the simulant blanks,

- 13 percent for ICP-MS Cs analysis with batch contact preparation,

- $\mathrm{f}$-factor analysis error of three percent (including weighing error), and

- 0.5 percent error in the volume of simulant. 
These errors must be propagated during the development of isotherms and calculation of $\mathrm{Q}$ and $\mathrm{K}_{\mathrm{d}}$ values from these data. Below is a quick derivation for estimating the measurement uncertainty (i.e., variance) in $\mathrm{K}_{\mathrm{d}}$ values. Note that resin sample variability is not accounted for below. Here we are addressing only the measurement uncertainty associated with a particular equilibrium test. Starting with the typical expression for calculating a $\mathrm{K}_{\mathrm{d}}$ value:

$$
\mathrm{K}_{\mathrm{d}}=\frac{\Delta \mathrm{c}}{\mathrm{c}_{\mathrm{f}}} \phi
$$

where

$$
\Delta \mathrm{c}=\mathrm{c}_{\mathrm{i}}-\mathrm{c}_{\mathrm{f}} \quad ; \quad \phi=\frac{\mathrm{V}_{\text {soln }}}{\mathrm{m}_{\text {res }}}
$$

and

$$
\begin{array}{ll}
\mathrm{K}_{\mathrm{d}} & \text { - distribution coefficient }(\mathrm{ml} / \mathrm{g}) \\
\mathrm{c}_{\mathrm{i}} & \text { - initial Cs liquid-phase concentration }(\mathrm{M} \text { or } \mathrm{ppm}) \\
\mathrm{c}_{\mathrm{f}} & \text { - final equilibrium Cs liquid-phase concentration }(\mathrm{M} \text { or } \mathrm{ppm}) \\
\mathrm{m}_{\mathrm{res}} & \text { - mass of dry resin in its Na-form }(\mathrm{g}) \\
\mathrm{V}_{\text {soln }} & \text { - volume of liquid-phase sample }(\mathrm{ml}) \\
\phi & \text { - phase ratio }(\mathrm{ml} / \mathrm{g}) \\
\Delta \mathrm{c} & \text { - reduction in liquid-phase Cs concentration }(\mathrm{M} \text { or } \mathrm{ppm})
\end{array}
$$

One can obtain an estimate of the uncertainty in a $\mathrm{K}_{\mathrm{d}}$ value, due the uncertainties associated with the parameters that define it, by assuming:

- A linear response surface applies in the vicinity of the measurement point (for measurement deviations that are not significantly removed from its true value this should be a reasonable approximation); and

- The various parameters that define the $\mathrm{K}_{\mathrm{d}}$ value, as shown in Eq. (4-1), are independent random variables.

By making the above assumptions, the variance in $\mathrm{K}_{\mathrm{d}}$ can be estimated using the propagation of errors method (Freund, 1971). First, Eq. (4-1) must be linearized about some point of interest (denoted by the subscript "o"):

$$
\begin{aligned}
\left(\mathrm{K}_{\mathrm{d}}-\mathrm{K}_{\mathrm{do}}\right)= & {\left[\frac{\phi_{\mathrm{o}}}{\mathrm{c}_{\mathrm{fo}}}\right]\left(\mathrm{c}_{\mathrm{i}}-\mathrm{c}_{\mathrm{io}}\right)-\left[\frac{\mathrm{c}_{\mathrm{io}}}{\mathrm{c}_{\mathrm{fo}}^{2}} \phi_{\mathrm{o}}\right]\left(\mathrm{c}_{\mathrm{f}}-\mathrm{c}_{\mathrm{fo}}\right) } \\
& +\left[\frac{\Delta \mathrm{c}_{\mathrm{o}}}{\mathrm{c}_{\mathrm{fo}}} \frac{\phi_{\mathrm{o}}}{\mathrm{V}_{\text {soln }, \mathrm{o}}}\right]\left(\mathrm{V}_{\text {soln }}-\mathrm{V}_{\text {soln } \mathrm{o}}\right)-\left[\frac{\Delta \mathrm{c}_{\mathrm{o}}}{\mathrm{c}_{\mathrm{fo}}} \frac{\phi_{\mathrm{o}}}{\mathrm{m}_{\text {res }, \mathrm{o}}}\right]\left(\mathrm{m}_{\text {res }}-\mathrm{m}_{\text {res }, \mathrm{o}}\right)
\end{aligned}
$$


Given Eq. (4-2) and making use of the method of propagation of errors, the variance in a $\mathrm{K}_{\mathrm{d}}$ value can be expressed as:

$$
\sigma_{\mathrm{K}_{\mathrm{d}}}^{2}=\left[\frac{\phi_{\mathrm{o}}}{\mathrm{c}_{\mathrm{fo}}}\right]^{2} \sigma_{\mathrm{c}_{\mathrm{i}}}^{2}+\left[\frac{\mathrm{c}_{\mathrm{io}}}{\mathrm{c}_{\mathrm{fo}}^{2}} \phi_{\mathrm{o}}\right]^{2} \sigma_{\mathrm{c}_{\mathrm{f}}}^{2}+\left[\frac{\Delta \mathrm{c}_{\mathrm{o}}}{\mathrm{c}_{\mathrm{fo}}} \frac{\phi_{\mathrm{o}}}{\mathrm{V}_{\mathrm{so} \text { In }, \mathrm{o}}}\right]^{2} \sigma_{\mathrm{V}_{\mathrm{soln}}}^{2}+\left[\frac{\Delta \mathrm{c}_{\mathrm{o}}}{\mathrm{c}_{\mathrm{fo}}} \frac{\phi_{\mathrm{o}}}{\mathrm{m}_{\mathrm{res}, \mathrm{o}}}\right]^{2} \sigma_{\mathrm{m}_{\mathrm{res}}}^{2}
$$

where

$$
\begin{array}{ll}
\mathrm{s}_{\mathrm{Kd}} & - \text { standard deviation in } \mathrm{Kd}(\mathrm{ml} / \mathrm{g}) \\
\sigma_{\mathrm{c}_{\mathrm{i}}} & - \text { standard deviation in } \mathrm{c}_{\mathrm{i}}(\mathrm{M} \text { or ppm) } \\
\sigma_{\mathrm{c}_{\mathrm{f}}} & - \text { standard deviation in } \mathrm{c}_{\mathrm{f}}(\mathrm{M} \text { or ppm) } \\
\sigma_{\mathrm{V}_{\mathrm{soln}}} & - \text { standard deviation in } \mathrm{V}_{\mathrm{soln}}(\mathrm{ml}) \\
\sigma_{\mathrm{m}_{\mathrm{res}}} & - \text { standard deviation in } \mathrm{m}_{\mathrm{res}}(\mathrm{g})
\end{array}
$$

For convenience, lets define relative uncertainties (i.e., a percent change in some quantity) in terms of percentage of deviation from the current sampling point:

$$
\left.\delta_{\mathrm{i}} \equiv \frac{\sigma_{\mathrm{i}}}{\mathrm{X}_{\mathrm{io}}} \quad \mathrm{i}=\mathrm{K}_{\mathrm{d}}, \mathrm{c}_{\mathrm{i}}, \mathrm{c}_{\mathrm{f}}, \mathrm{V}_{\text {soln }}, \mathrm{m}_{\text {res }}, \text { (sometimes } \phi\right)
$$

By dividing Eq. (4-3) by Eq. (4-1), then simplifying, we obtain the expression:

or

$$
\begin{gathered}
\delta_{\mathrm{K}_{\mathrm{d}}}^{2}=\left[\frac{\mathrm{c}_{\mathrm{io}}}{\Delta \mathrm{c}_{\mathrm{o}}}\right]^{2} \delta_{\mathrm{c}_{\mathrm{i}}}^{2}+\left[\frac{\mathrm{c}_{\mathrm{io}}}{\Delta \mathrm{c}_{\mathrm{o}}}\right]^{2} \delta_{\mathrm{c}_{\mathrm{f}}}^{2}+[1]^{2} \delta_{\mathrm{v}_{\text {soln }}}^{2}+[1]^{2} \delta_{\mathrm{m}_{\mathrm{res}}}^{2} \\
\delta_{\mathrm{K}_{\mathrm{d}}}^{2}=\left[\frac{\mathrm{c}_{\mathrm{io}}}{\Delta \mathrm{c}_{\mathrm{o}}}\right]^{2}\left(\delta_{\mathrm{c}_{\mathrm{i}}}^{2}+\delta_{\mathrm{c}_{\mathrm{f}}}^{2}\right)+\left(\delta_{\mathrm{V}_{\mathrm{soln}}}^{2}+\delta_{\mathrm{m}_{\mathrm{res}}}^{2}\right)
\end{gathered}
$$

If we chose to combine the liquid volume and resin mass terms into the single phase-ratio term, Eq. (46) takes the form:

$$
\delta_{\mathrm{K}_{\mathrm{d}}}^{2}=\left[\frac{\mathrm{c}_{\mathrm{io}}}{\Delta \mathrm{c}_{\mathrm{o}}}\right]^{2}\left(\delta_{\mathrm{c}_{\mathrm{i}}}^{2}+\delta_{\mathrm{c}_{\mathrm{f}}}^{2}\right)+\delta_{\phi}^{2}
$$

Equations (4-6) and (4-7) provide us with estimates of the variance in a $\mathrm{K}_{\mathrm{d}}$ value given the uncertainties associated with the measured variables that define it. A similar set of derivations can be performed to estimate the variance in Cs loading. Starting with the estimated Cs loading value:

$$
\mathrm{Q}=\mathrm{K}_{\mathrm{d}} \mathrm{c}_{\mathrm{f}}
$$


we arrive at the expression:

$$
\delta_{\mathrm{Q}}^{2}=\left[\frac{\mathrm{c}_{\mathrm{io}}}{\Delta \mathrm{c}_{\mathrm{o}}}\right]^{2} \delta_{\mathrm{c}_{\mathrm{i}}}^{2}+\left[\frac{\mathrm{c}_{\mathrm{fo}}}{\Delta \mathrm{c}_{\mathrm{o}}}\right]^{2} \delta_{\mathrm{c}_{\mathrm{f}}}^{2}+\left(\delta_{\mathrm{v}_{\mathrm{soln}}}^{2}+\delta_{\mathrm{m}_{\mathrm{res}}}^{2}\right)
$$

The overall error in absorbed concentration necessarily is a function of $\mathrm{Cs}_{\mathrm{i}}$ and $\mathrm{Cs}_{\mathrm{f}}$ where, as illustrated in Table 4-7, the relative error increases with decreasing absorption.

Table 4-7 Relative error of $Q$ as a function of final Cs concentration

\begin{tabular}{|c|c|}
\hline Final Cs $(\mathrm{mg} / \mathrm{L})$ & Relative Standard Deviation of Q \\
\hline 1 & 7.7 \\
\hline 5 & 8.1 \\
\hline 10 & 8.8 \\
\hline 30 & 14 \\
\hline 50 & 29 \\
\hline 60 & 48 \\
\hline 70 & 107 \\
\hline \multicolumn{2}{|c|}{ Cs Initial $=80 \mathrm{mg} / \mathrm{L}$} \\
\hline
\end{tabular}

\subsection{Sorption Isotherm}

Sorption isotherm data for Cs absorption to the 1 gallon batch of SuperLig ${ }^{\circledR} 644$ from AN-105 simulant are presented in Table 4-8 and graphically in Figure 4-5. Initial Cs concentrations in the simulant ranged from approximately 10 to $250 \mathrm{mg} / \mathrm{L}$. As is typical of Langmuir type sorption, the curve is nearly linear at low aqueous concentrations of Cs where there exists a large excess of sorption sites relative to the aqueous phase concentration of Cs. In the high Cs concentration regime, the curve asymptotically flattens to the limit of the total binding site concentration of the resin.

The Langmuir model (Equation 3-1) was fit to the experimental data in Table 4-8 and a total Cs binding site capacity of $0.333 \mathrm{mmole} / \mathrm{g}$ resin from Hamm(2000) to yield a best fit Langmuir constant (i.e., B) of 1.260E-4 M. As a point of reference, the Langmuir model fit for this dataset will be included on other isotherm plots. 
Table 4-8 AN105 Isotherm Data

SL644-1 Gallon Batch

\begin{tabular}{|c|c|c|}
\hline $\begin{array}{c}{[\mathrm{Cs}] \text { Initial }} \\
(\mathrm{mmole} / \mathrm{L})\end{array}$ & $\begin{array}{c}\text { [Cs] Aqueous Result ICP-MS } \\
(\mathrm{mmole} / \mathrm{L})\end{array}$ & $\begin{array}{c}\text { [Cs] Solid } \\
(\mathrm{mmole} / \mathrm{g} \text { dry resin })\end{array}$ \\
\hline $9.48 \mathrm{E}-02$ & $6.95 \mathrm{E}-03 \pm 9.03 \mathrm{E}-04$ & $1.59 \mathrm{E}-02 \pm 1.31 \mathrm{E}-03$ \\
\hline $9.48 \mathrm{E}-02$ & $6.30 \mathrm{E}-03 \pm 8.19 \mathrm{E}-04$ & $1.58 \mathrm{E}-02 \pm 1.29 \mathrm{E}-03$ \\
\hline $2.02 \mathrm{E}-01$ & $1.16 \mathrm{E}-02 \pm 1.51 \mathrm{E}-03$ & $3.42 \mathrm{E}-02 \pm 2.76 \mathrm{E}-03$ \\
\hline $2.02 \mathrm{E}-01$ & $1.08 \mathrm{E}-02 \pm 1.41 \mathrm{E}-03$ & $3.43 \mathrm{E}-02 \pm 2.75 \mathrm{E}-03$ \\
\hline $4.21 \mathrm{E}-01$ & $4.85 \mathrm{E}-02 \pm 6.31 \mathrm{E}-03$ & $4.70 \mathrm{E}-02 \pm 4.06 \mathrm{E}-03$ \\
\hline $4.21 \mathrm{E}-01$ & $1.96 \mathrm{E}-02 \pm 2.55 \mathrm{E}-03$ & $5.04 \mathrm{E}-02 \pm 4.02 \mathrm{E}-03$ \\
\hline $4.85 \mathrm{E}-01$ & $5.18 \mathrm{E}-02 \pm 6.73 \mathrm{E}-03$ & $7.82 \mathrm{E}-02 \pm 6.68 \mathrm{E}-03$ \\
\hline $4.85 \mathrm{E}-01$ & $6.13 \mathrm{E}-02 \pm 7.97 \mathrm{E}-03$ & $7.67 \mathrm{E}-02 \pm 6.73 \mathrm{E}-03$ \\
\hline $1.91 \mathrm{E}+00$ & $3.66 \mathrm{E}-01 \pm 4.75 \mathrm{E}-02$ & $2.73 \mathrm{E}-01 \pm 2.64 \mathrm{E}-02$ \\
\hline $1.91 \mathrm{E}+00$ & $4.41 \mathrm{E}-01 \pm 5.73 \mathrm{E}-02$ & $2.68 \mathrm{E}-01 \pm 2.78 \mathrm{E}-02$ \\
\hline
\end{tabular}

250-mL contact

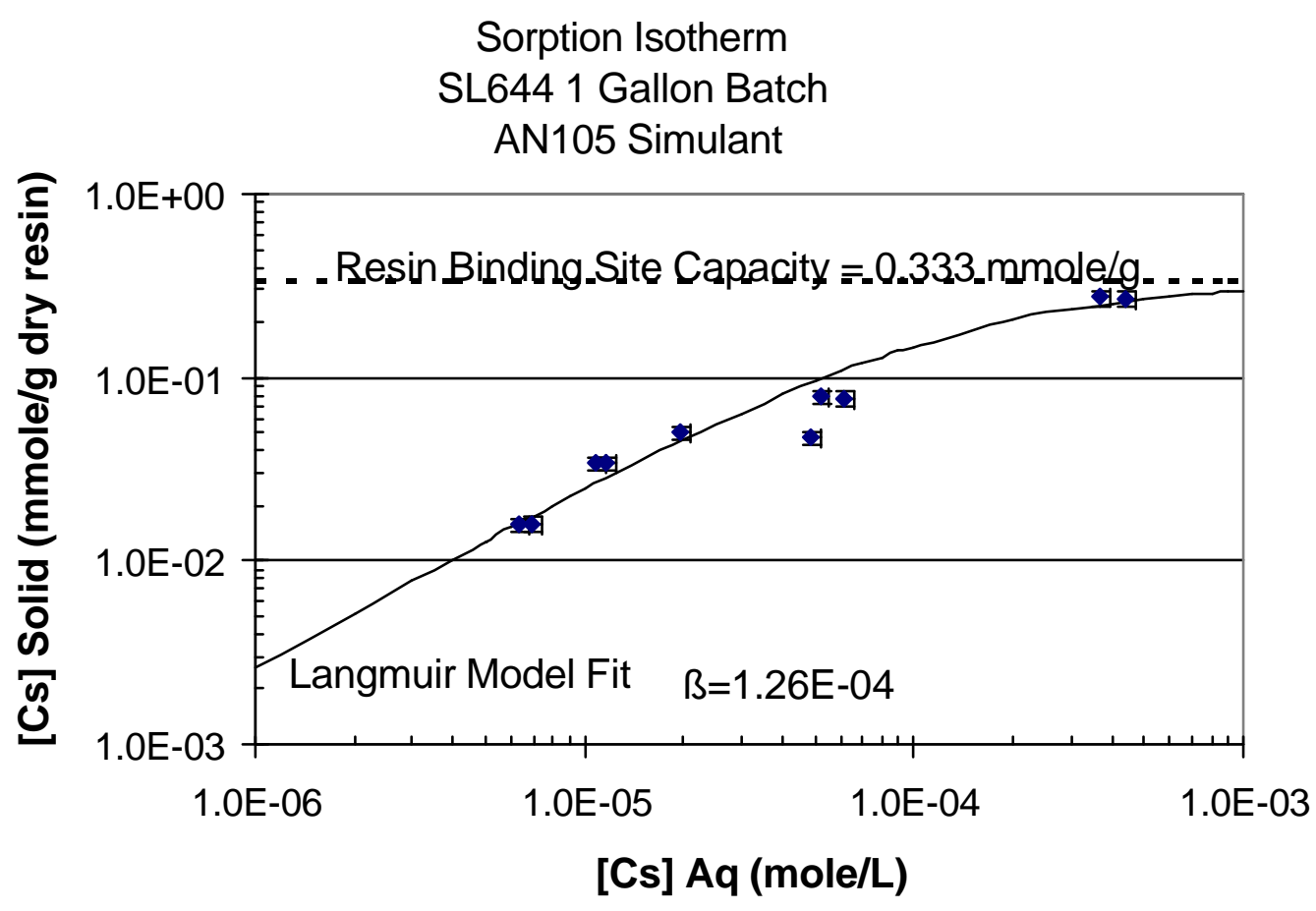

Figure 4-5 Cs sorption isotherm in AN105 simulant SL 644 (one gallon batch) 30-mL samples.

\subsection{Temporal Effects}

The results of the temporal effects experiments are organized and discussed in terms of chemical performance of the resin and post-reaction characterization of the resin solids. 


\subsubsection{Chemical Performance}

Batch contact results from the temporal effects experiments are summarized in Table 4-9 and Table 4-10 for AN105 and AN107 simulants, respectively. Because the solid:liquid ratio and initial Cs concentrations don't vary significantly within each of the datasets, temporal effects data within each simulants can be compared directly using a $\mathrm{K}_{\mathrm{d}}$ construct. Data with $\mathrm{K}_{\mathrm{d}}$ versus contact time are presented graphically in Figure 4-6 and Figure 4-7, for AN105 and AN107 simulants, respectively.

For both simulants the data show that sorption reaches a maximum level in roughly the one to two week timeframe. As noted previously, there is an affect of sample volume for the one and three day contacts with the $30-\mathrm{mL}$ samples exhibiting a faster absorption rate. With contacts greater than three days in length, there was no statistical difference within all the sample pairs except the three-week contact in AN107 simulant. After the three-week sorption maximum, there appears to be a gradual, but statistically non-significant $(?=0.05)$, decline in Cs sorption. Plotted in isotherm space, with a linear $\mathrm{x}$ axis, the conclusions are the same (see Figure 4-8 and Figure 4-9) Q versus Final [Cs]aq for AN105 and AN107 data, respectively.

Table 4-9 AN105 Temporal Effects Cs Sorption Results

\begin{tabular}{|c|c|c|c|c|c|c|c|}
\hline $\begin{array}{c}\text { Contact } \\
\text { Time } \\
\text { (weeks) }\end{array}$ & $\begin{array}{c}\text { Sample } \\
\text { Vol (mL) }\end{array}$ & $\begin{array}{c}\text { Liquid:Solid } \\
\text { (mL/g dry } \\
\text { resin) }\end{array}$ & $\begin{array}{c}\text { Initial [Cs] } \\
\text { (mole/L) }\end{array}$ & $\begin{array}{c}\text { Final [Cs] } \\
\text { (mole/L) }\end{array}$ & $\begin{array}{c}\text { Solid Cs } \\
\text { (mmole/g } \\
\text { dry resin) }\end{array}$ & $\begin{array}{c}\text { Kd } \\
\text { (mL/g } \\
\text { dry } \\
\text { resin) }\end{array}$ & s Kd \\
\hline 0.1 & 250 & 126 & $4.21 \mathrm{E}-04$ & $8.73 \mathrm{E}-05$ & $4.21 \mathrm{E}-02$ & 482 & 91 \\
\hline 0.1 & 30 & 126 & $4.21 \mathrm{E}-04$ & $5.25 \mathrm{E}-05$ & $4.65 \mathrm{E}-02$ & 886 & 152 \\
\hline 0.4 & 250 & 126 & $4.21 \mathrm{E}-04$ & $4.85 \mathrm{E}-05$ & $4.70 \mathrm{E}-02$ & 968 & 164 \\
\hline 0.4 & 30 & 126 & $4.21 \mathrm{E}-04$ & $1.96 \mathrm{E}-05$ & $5.04 \mathrm{E}-02$ & 2570 & 405 \\
\hline 1 & 250 & 126 & $4.22 \mathrm{E}-04$ & $1.38 \mathrm{E}-05$ & $5.15 \mathrm{E}-02$ & 3720 & 579 \\
\hline 1 & 30 & 126 & $4.22 \mathrm{E}-04$ & $1.05 \mathrm{E}-05$ & $5.18 \mathrm{E}-02$ & 4920 & 760 \\
\hline 2 & 250 & 126 & $4.22 \mathrm{E}-04$ & $1.10 \mathrm{E}-05$ & $5.18 \mathrm{E}-02$ & 4720 & 729 \\
\hline 2 & 30 & 126 & $4.22 \mathrm{E}-04$ & $1.04 \mathrm{E}-05$ & $5.18 \mathrm{E}-02$ & 4980 & 770 \\
\hline 3 & 250 & 126 & $4.14 \mathrm{E}-04$ & $1.11 \mathrm{E}-05$ & $5.08 \mathrm{E}-02$ & 4600 & 711 \\
\hline 3 & 30 & 126 & $4.14 \mathrm{E}-04$ & $1.14 \mathrm{E}-05$ & $5.07 \mathrm{E}-02$ & 4430 & 686 \\
\hline 4 & 250 & 126 & $4.20 \mathrm{E}-04$ & $1.08 \mathrm{E}-05$ & $5.16 \mathrm{E}-02$ & 4800 & 742 \\
\hline 4 & 30 & 126 & $4.20 \mathrm{E}-04$ & $1.10 \mathrm{E}-05$ & $5.16 \mathrm{E}-02$ & 4700 & 727 \\
\hline 6 & 250 & 126 & $4.11 \mathrm{E}-04$ & $1.14 \mathrm{E}-05$ & $5.03 \mathrm{E}-02$ & 4400 & 682 \\
\hline 6 & 30 & 126 & $4.11 \mathrm{E}-04$ & $1.20 \mathrm{E}-05$ & $5.03 \mathrm{E}-02$ & 4180 & 648 \\
\hline 8 & 250 & 126 & $4.16 \mathrm{E}-04$ & $1.15 \mathrm{E}-05$ & $5.10 \mathrm{E}-02$ & 4430 & 686 \\
\hline 8 & 30 & 126 & $4.16 \mathrm{E}-04$ & $1.26 \mathrm{E}-05$ & $5.09 \mathrm{E}-02$ & 4030 & 625 \\
\hline
\end{tabular}


Table 4-10 AN107 Temporal Effects Cs Sorption Results

\begin{tabular}{|c|c|c|c|c|c|c|c|}
\hline $\begin{array}{c}\text { Contact } \\
\text { Time } \\
\text { (weeks) }\end{array}$ & $\begin{array}{c}\text { Sample } \\
\text { Vol (mL) }\end{array}$ & $\begin{array}{c}\text { Liquid:Solid } \\
\text { (mL/g dry } \\
\text { resin) }\end{array}$ & $\begin{array}{c}\text { Initial [Cs] } \\
\text { (mmole/L) }\end{array}$ & $\begin{array}{c}\text { Final [Cs] } \\
(\text { mmole/L) }\end{array}$ & $\begin{array}{c}\text { Solid Cs } \\
\text { (mmole/g } \\
\text { resin) }\end{array}$ & $\begin{array}{c}\text { Kd } \\
\text { (mL/g } \\
\text { dry } \\
\text { resin) }\end{array}$ & s Kd \\
\hline 0.1 & 250 & 176 & $5.48 \mathrm{E}-04$ & $1.59 \mathrm{E}-04$ & $6.86 \mathrm{E}-02$ & 432 & 91 \\
\hline 0.1 & 30 & 167 & $5.48 \mathrm{E}-04$ & $9.48 \mathrm{E}-05$ & $7.58 \mathrm{E}-02$ & 800 & 145 \\
\hline 0.4 & 250 & 178 & $5.48 \mathrm{E}-04$ & $7.90 \mathrm{E}-05$ & $8.37 \mathrm{E}-02$ & 1059 & 186 \\
\hline 0.4 & 30 & 167 & $5.48 \mathrm{E}-04$ & $2.88 \mathrm{E}-05$ & $8.66 \mathrm{E}-02$ & 3005 & 477 \\
\hline 1 & 250 & 179 & $5.48 \mathrm{E}-04$ & $2.65 \mathrm{E}-05$ & $9.36 \mathrm{E}-02$ & 3532 & 558 \\
\hline 1 & 30 & 177 & $5.48 \mathrm{E}-04$ & $2.18 \mathrm{E}-05$ & $9.33 \mathrm{E}-02$ & 4274 & 670 \\
\hline 2 & 250 & 180 & $5.48 \mathrm{E}-04$ & $1.86 \mathrm{E}-05$ & $9.67 \mathrm{E}-02$ & 5205 & 811 \\
\hline 2 & 30 & 179 & $5.48 \mathrm{E}-04$ & $1.87 \mathrm{E}-05$ & $9.55 \mathrm{E}-02$ & 5117 & 797 \\
\hline 3 & 250 & 180 & $5.48 \mathrm{E}-04$ & $2.24 \mathrm{E}-05$ & $9.96 \mathrm{E}-02$ & 4440 & 697 \\
\hline 3 & 30 & 180 & $5.48 \mathrm{E}-04$ & $4.83 \mathrm{E}-05$ & $8.88 \mathrm{E}-02$ & 1839 & 303 \\
\hline 4 & 250 & 179 & $5.58 \mathrm{E}-04$ & $2.17 \mathrm{E}-05$ & $9.93 \mathrm{E}-02$ & 4568 & 715 \\
\hline 4 & 30 & 177 & $5.58 \mathrm{E}-04$ & $2.88 \mathrm{E}-05$ & $9.61 \mathrm{E}-02$ & 3336 & 529 \\
\hline 6 & 250 & 178 & $5.81 \mathrm{E}-04$ & $2.31 \mathrm{E}-05$ & $9.92 \mathrm{E}-02$ & 4293 & 673 \\
\hline 6 & 30 & 167 & $5.81 \mathrm{E}-04$ & $2.49 \mathrm{E}-05$ & $9.76 \mathrm{E}-02$ & 3918 & 616 \\
\hline 8 & 250 & 179 & $5.77 \mathrm{E}-04$ & $2.30 \mathrm{E}-05$ & $9.68 \mathrm{E}-02$ & 4205 & 659 \\
\hline 8 & 30 & 175 & $5.77 \mathrm{E}-04$ & $2.47 \mathrm{E}-05$ & $9.20 \mathrm{E}-02$ & 3726 & 586 \\
\hline
\end{tabular}




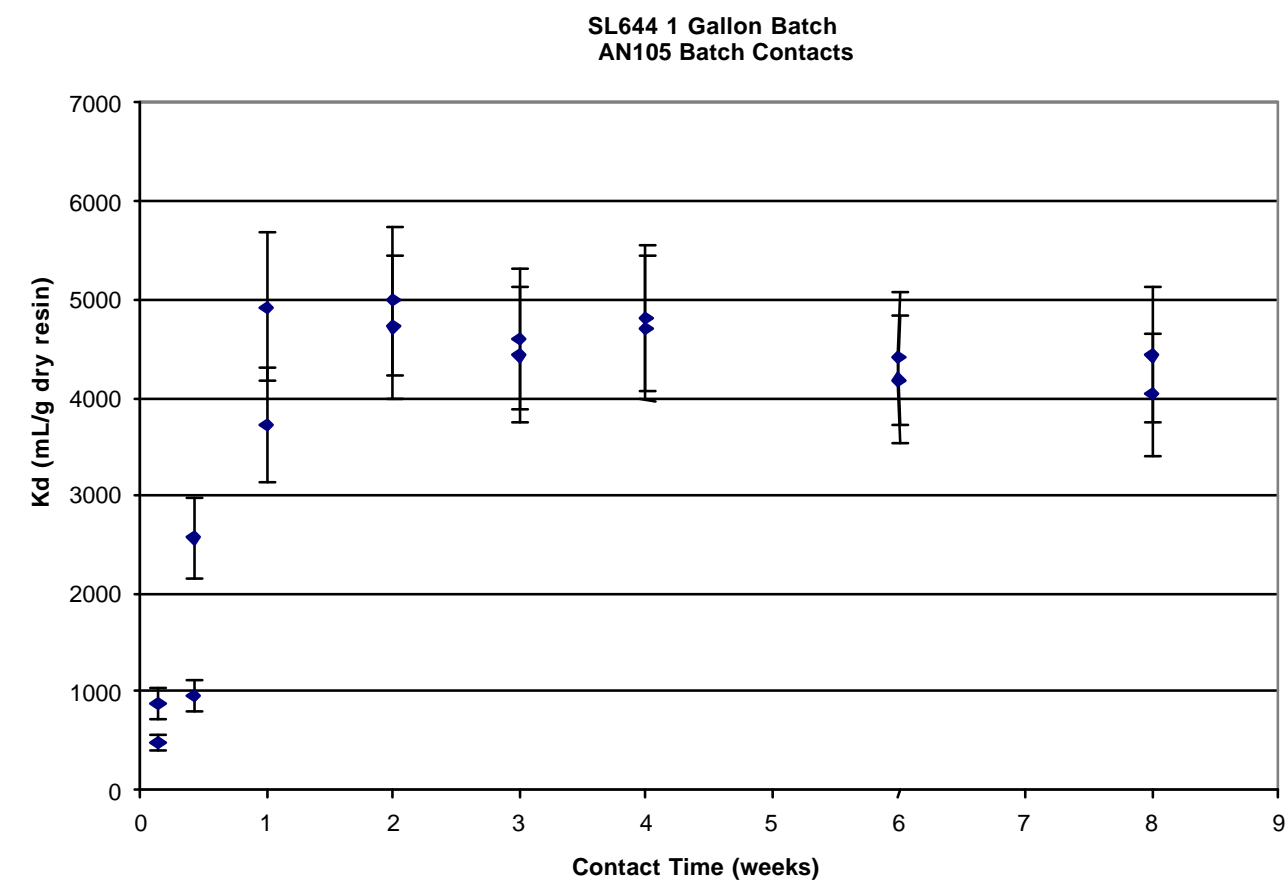

Figure 4-6 Cs- $\mathrm{K}_{\mathrm{d}}$ versus contact time AN105 simulant 30-mL samples.

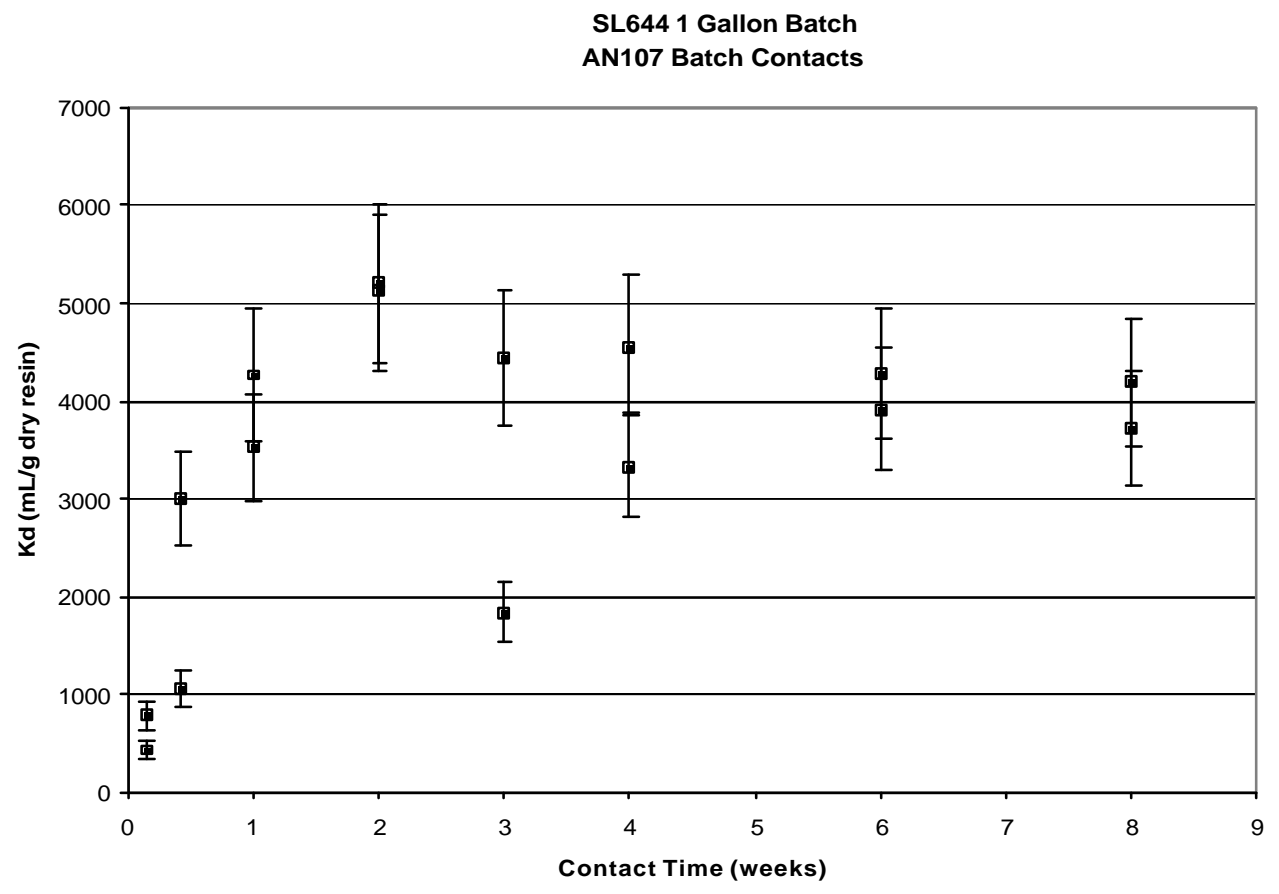

Figure 4-7 Cs- $K_{d}$ versus contact time AN107 simulant 30-mL samples. 


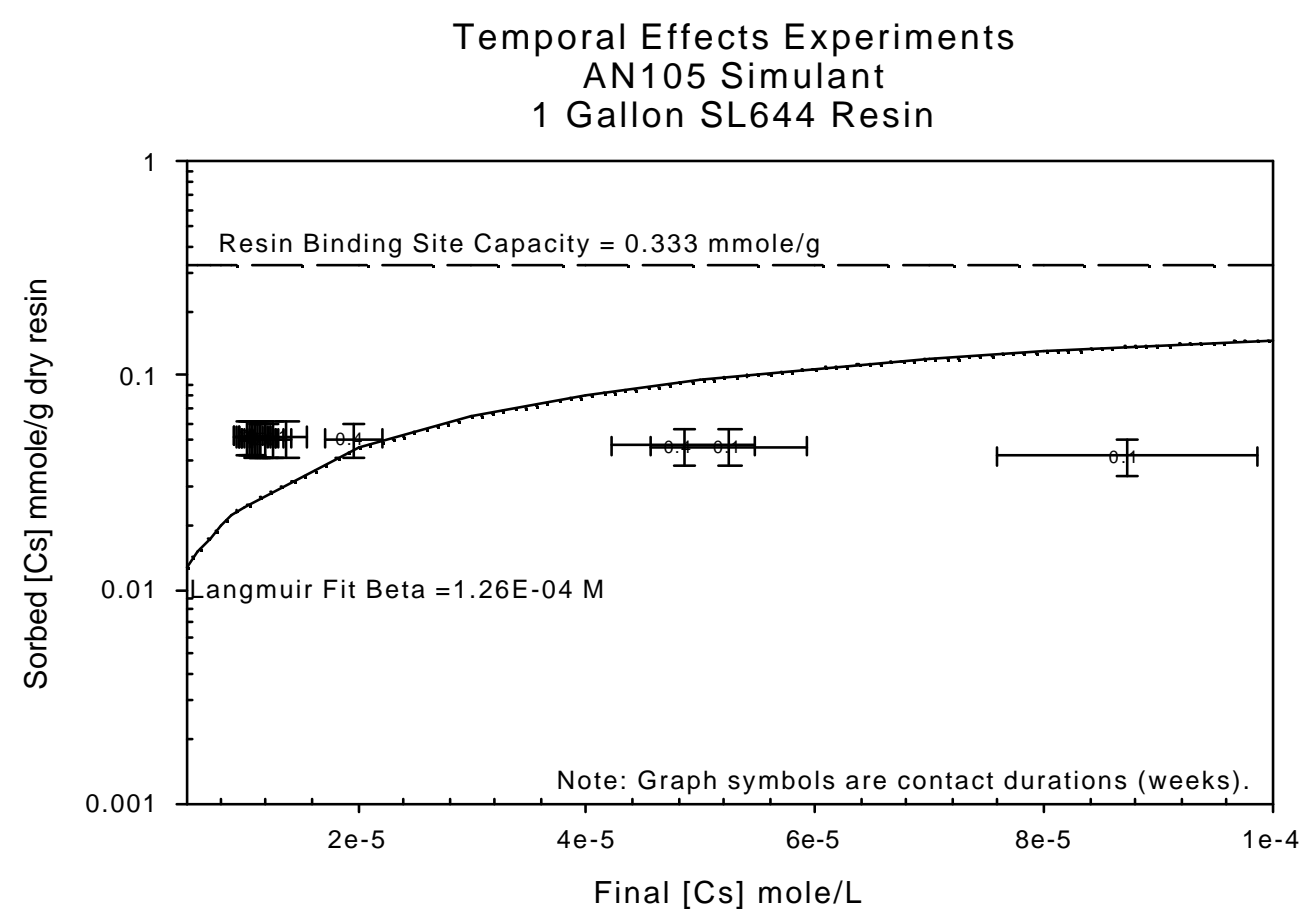

Figure 4-8 $Q$ versus Final $[\mathrm{Cs}]_{\mathrm{aq}}$ AN105 simulant.

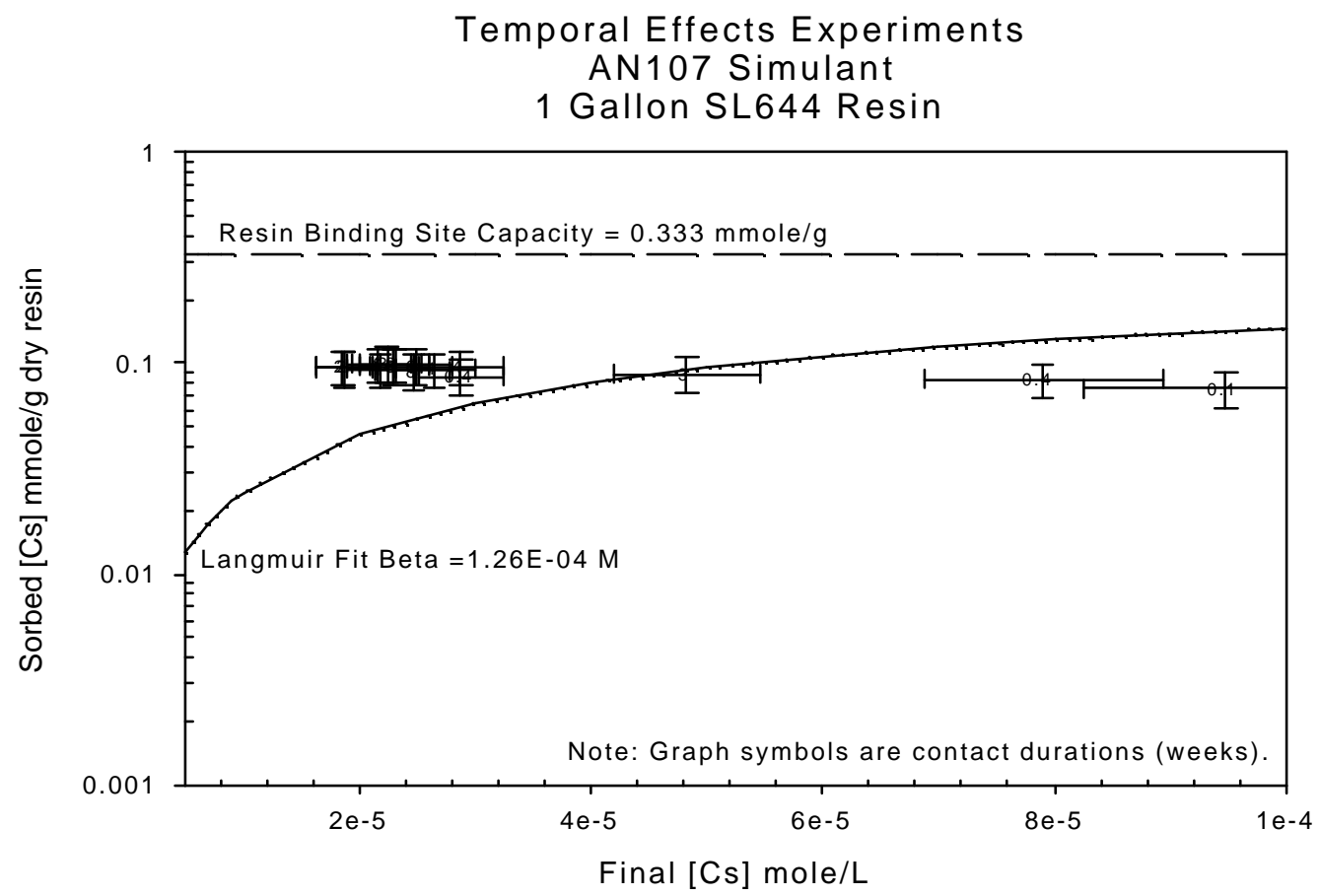

Figure 4-9 $Q$ versus Final $[\mathrm{Cs}]_{\text {aq }}$ AN105 simulant 30-mL samples. 


\subsubsection{Resin Characterization}

\subsubsection{Optical Microscopy}

\subsection{AN105 Simulant}

SL644 resin exposed to the AN105 simulant (Figure 4-10) qualitatively shows no gross changes in apparent particle size distribution or surface morphology as compared to the "as-received" resin (Figure 4-2). Resins exposed to the AN105 simulant do appear, however, slightly darker than the as-received resin presumably due to conversion of the resin to the sodium form. After exposure to the AN105 simulant, particle edges qualitatively appear more blunt on average than in the "as received" resin. This effect is more pronounced with longer exposure to the simulant.

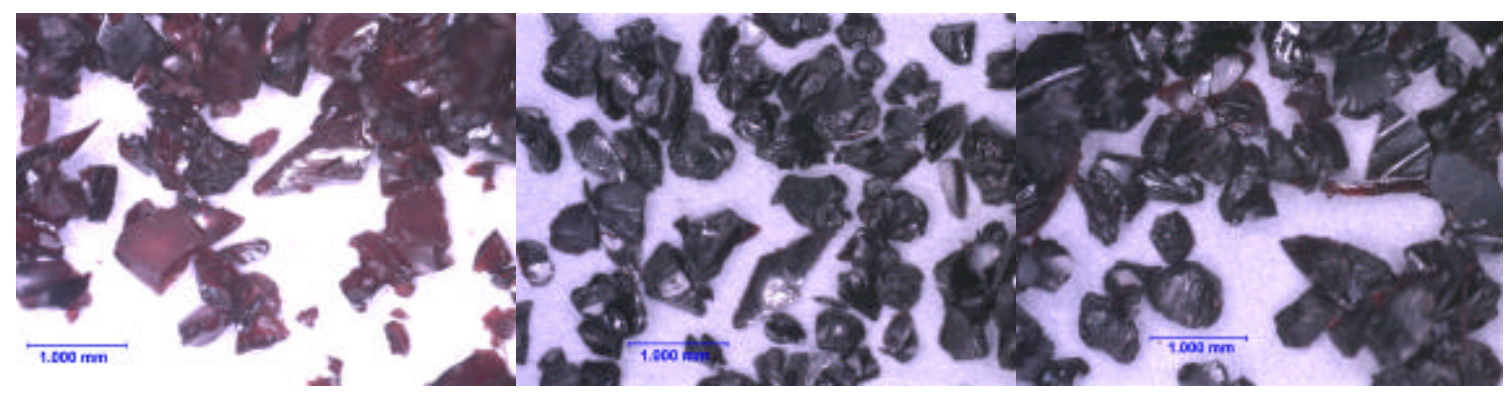

Figure 4-10 SL644 25 gallon Batch 1(left). AN105 1 week (center). AN105 Stagnant A 8 weeks (right).

\subsection{AN107 Simulant}

In contrast to the resins exposed to AN105 simulant, SL644 resin treated similarly with AN107 simulant appear quite differently under the optical microscope. As mentioned previously, samples were not stored in completely air-tight containers, consequently some of the samples which were all originally stored moist retained some residual moisture (Figure 4-11) while others evaporated residual moisture slowly (Figure 4-12). For the AN107 resins that maintained some residual moisture, the in resin particles appear as individual resin particles coated with a liquid that rapidly evaporates at ambient conditions (Figure 4-11). As the liquid evaporates, an orange brown residue is left behind. The moist AN107 resin was quite malleable in contrast to the resins exposed to the simple alkaline and AN105 simulants which were much more rigid. A single AN107 resin particle was readily severed in two pieces using a small wooden dowel approximately 1-mm in diameter.

The morphology of the AN107 resins which dried slowly during storage appeared quite different from the moist resins due to the formation of large clumps of resin particles that agglomerated together 
(Figure 4-12). After drying an agglomeration of resin in vacuo, clumps of orange solid material form and appear to be crystalline in nature. This solid was identified by XRD as sodium oxalate (see Section 4.4.2.3)

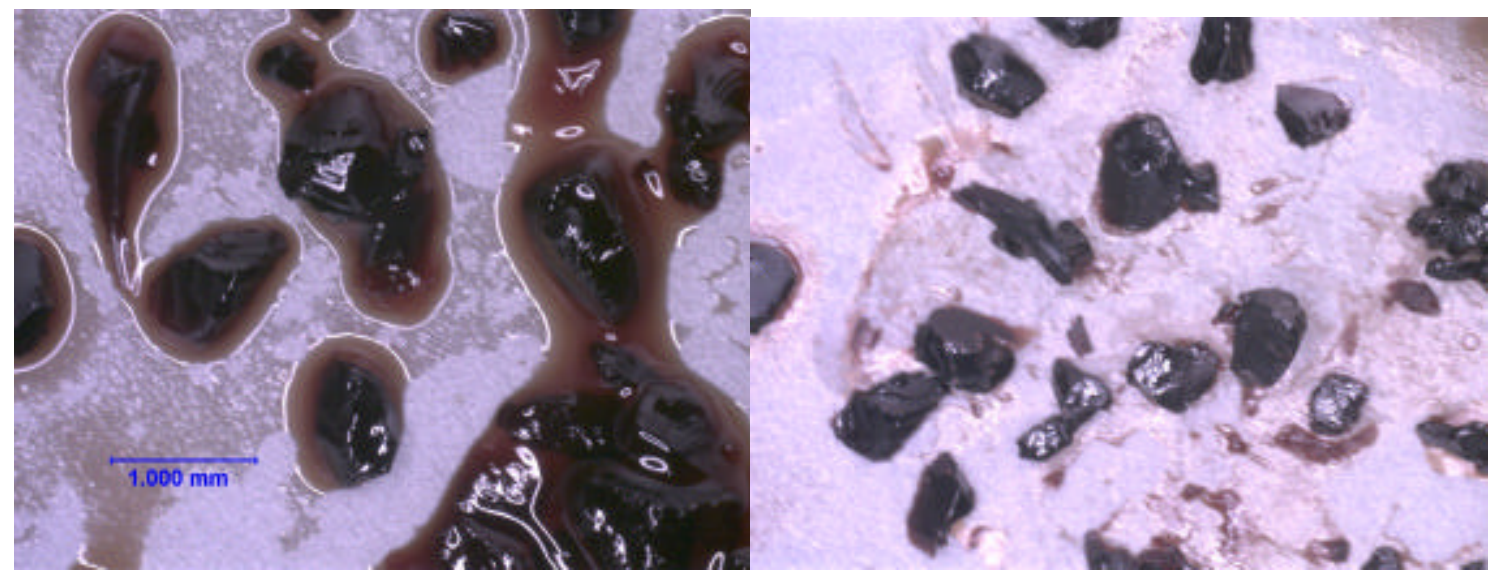

Figure 4-11 Optical Microscopy of SL644 one-gallon batch contact with AN107. 2 weeks stored moist (left) after 10 minutes (right)

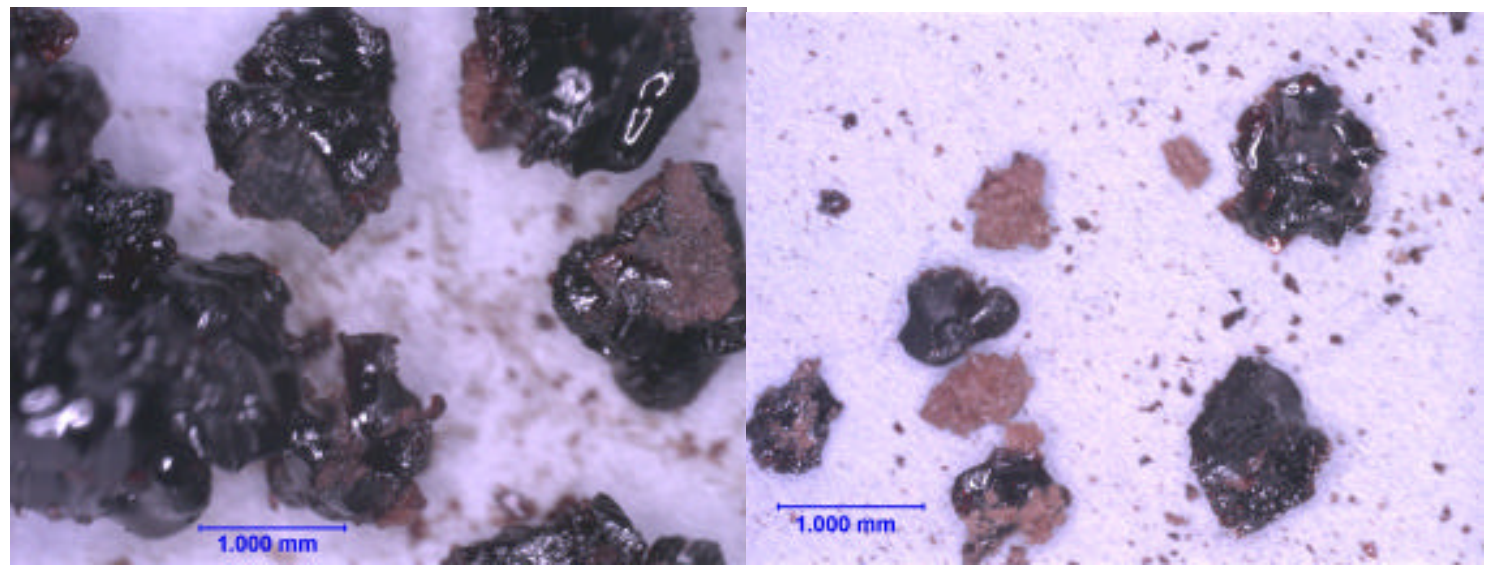

Figure 4-12 Optical Microscopy of SL644 one-gallon batch contact with AN107. 


\subsubsection{Scanning Electron Microscopy}

\subsection{AN105 Simulant}

SEM images of the AN105 resin exposed for 8 weeks are shown in Figure 4-13. As with the resins contacted with the simple alkaline simulant, large fissures were observed on the resin surface even at lower magnification. At higher magnification, a variety of highly irregular surface morphologies were observed and presumably could act as sites of resin degradation (Figure 4-13). On multiple resin particles investigated by SEM, formations of clusters of spherical particles were observed (Figure 4-14). EDX revealed the chemical composition to be aluminum and silicon. Given the higher aluminum and silicon concentrations in the AN105 simulant and the fact that these clusters were not observed on the "as received" resin or the simple alkaline resins they are attributed to the precipitation of chemical species found in the simulant contacted. It is not clear, however, given the nature of the analytical technique whether these aluminosilicates were formed as a precipitate during exposure to the simulant in bulk or, rather, during separation and storage. A number of unique surface precipitates were observed and probed by EDX (Appendix A), however, because they were not identified on multiple resin particles we do not report their composition in this text. 

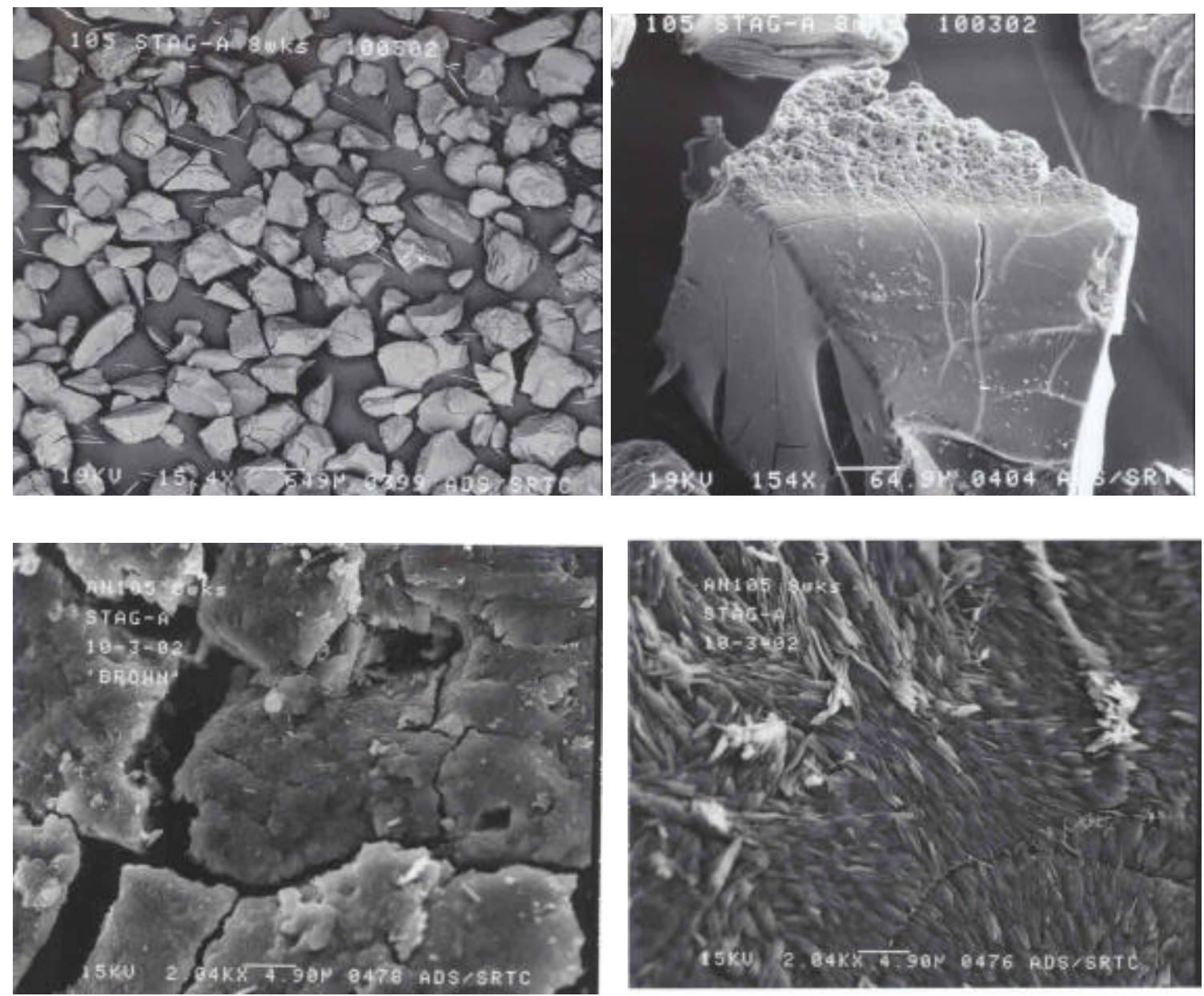

Figure 4-13 SEM images of SL644 AN105. 8 weeks Stagnant A: 15.4 X (upper left), $154 \mathrm{X}$ (upper right), $2040 \mathrm{X}$ (lower left and lower right) 


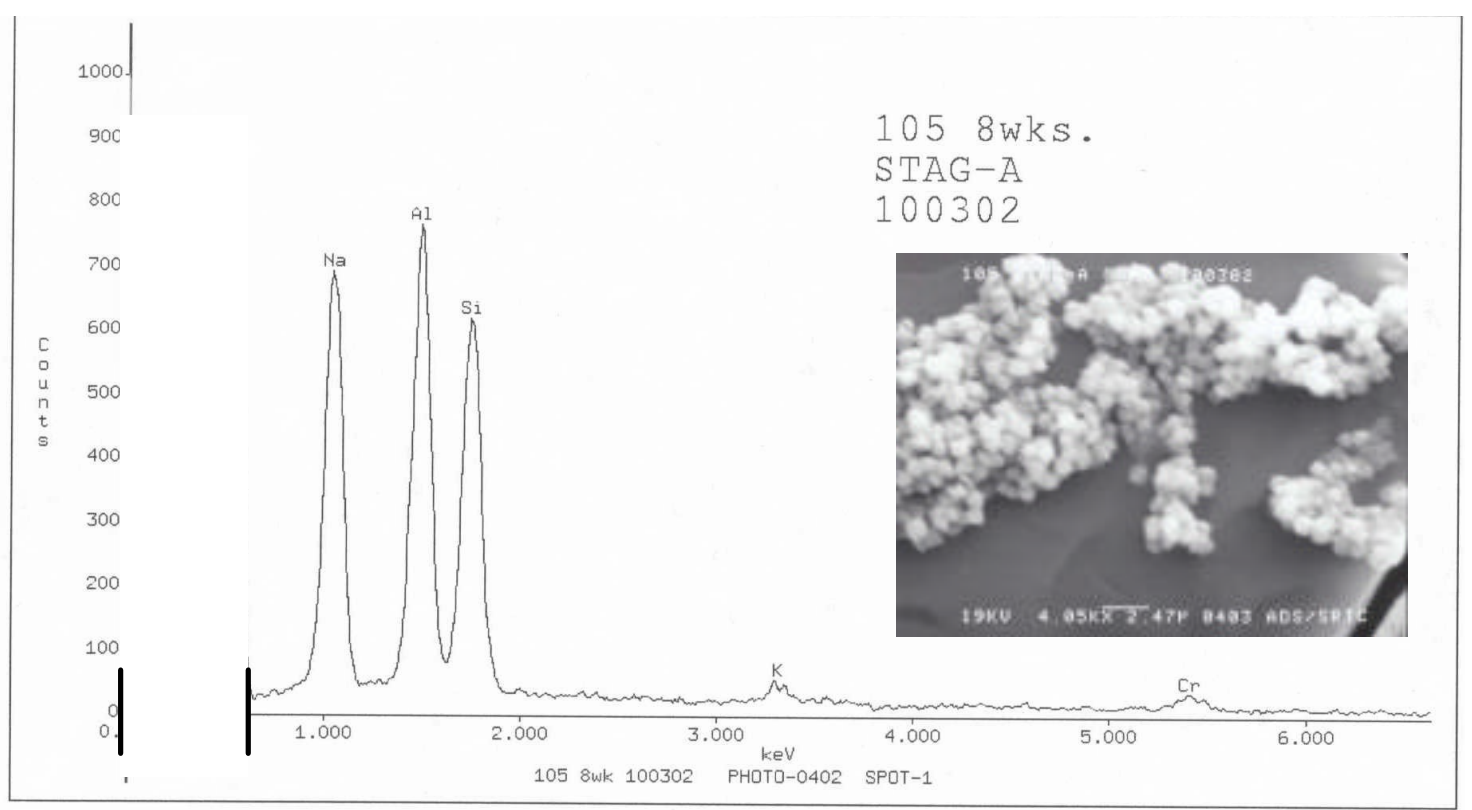

Figure 4-14 SEM image of SL644 one-gallon batch contact with AN105.

8 weeks Stagnant A (inset) and EDX spectrum of spherical precipitate.

\subsection{AN107 Simulant}

The surface of resin exposed to AN107 simulant were coated with numerous rod-like crystals. EDX revealed that the elemental composition of the crystals consists of carbon, oxygen, and sodium (Figure 4-15). XRD definitively identified the organic compound as sodium oxalate (see section 4.4.2.3). The high organic content of the AN107 simulant appears to favor partitioning of the sodium oxalate to the resin particles. The sodium oxalate partitioned to the resin is not readily removed with a brief deionized water rinse employed in this study. 


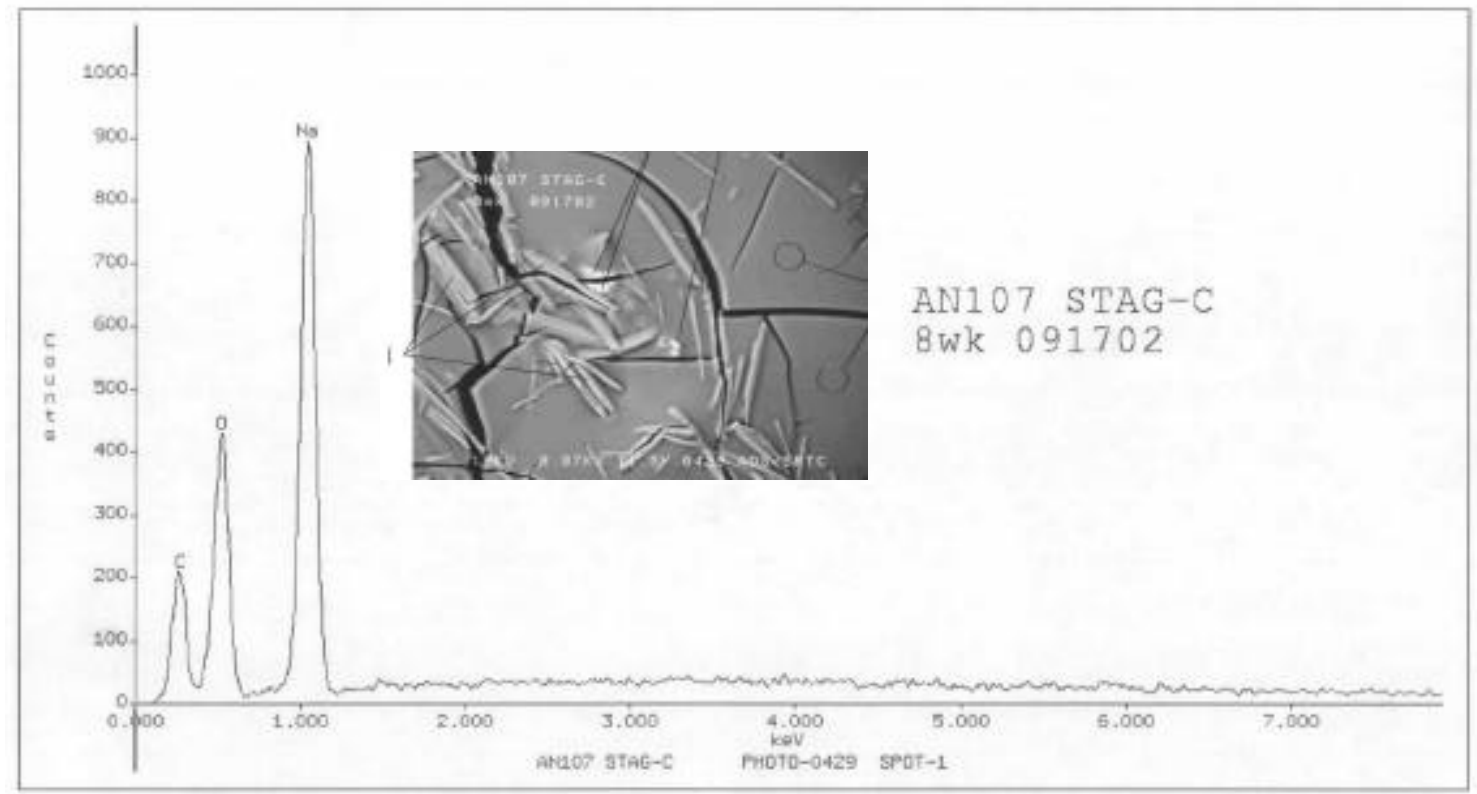

AN107 STAG-C PHOTO-0429 SPOT-1

Accelerating Voltage: $19 \mathrm{KeV}$ Take Off Angle: 11.3099 $9^{\circ}$ Live Time: 21.02 seconds Dead Time: 6.194 seconds

Figure 4-15 SEM image of SL644 one-gallon batch contact with AN107. 8 weeks Stagnant C (inset) and EDX spectrum of rod-like crystals of sodium oxalate.

\subsubsection{X-Ray Diffraction}

Further characterization of the resin exposed to the AN107 simulant by XRD reveals that the rod-like crystals observed by optical microscopy and SEM exhibit an x-ray diffraction pattern characteristic of sodium oxalate (Figure 4-16). Detection limits are on the order of 0.5 percent by weight for the instrument employed in this study. Although not quantified, the XRD analysis shows that greater than 0.5 percent by weight of sodium oxalate is present in resin exposed to AN107. Quantification is possible if this is an important parameter. 


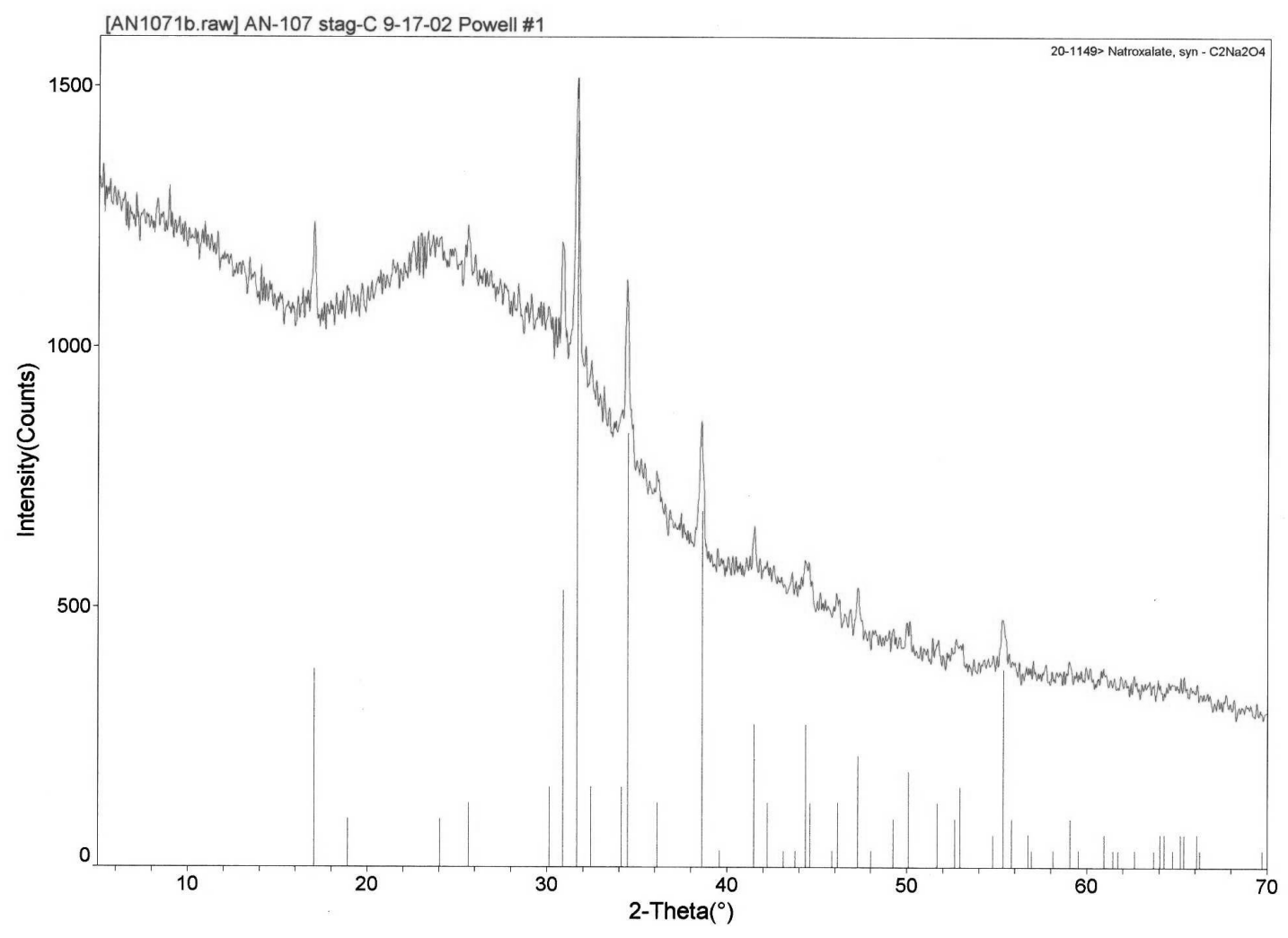

Figure 4-16 XRD patterns of SL644 one-gallon batch contact with AN107. 8 weeks Stagnant C (resin and precipitate) (top) with overlay of the XRD pattern for sodium oxalate for comparison (bottom).

\subsubsection{Particle Size Distribution}

Lasentec FBRM chord length analysis was conducted on SuperLig ${ }^{\circledR} 644$ resin solids in DI water after eight weeks of contact with AN105 and AN107 simulants. These data are plotted in along with the as received resin data as a reference (Figure 4-17). These data indicate a shift to smaller chord lengths for resin solids exposed to alkaline simulants. For the AN105 reacted resin solids, the maximum chord length does not change significantly but there is an increase in the relative proportion of smaller particle. The effects for resin exposed to AN107 are much more pronounced. Resin solids from this contact exhibit a shift of about one-half an order of magnitude in the mean chord-length. Data from both contacts are suggestive of the formation of fines during the contact process with the AN107 contacted sample clearly showing a much greater effect than the AN105 contact. 


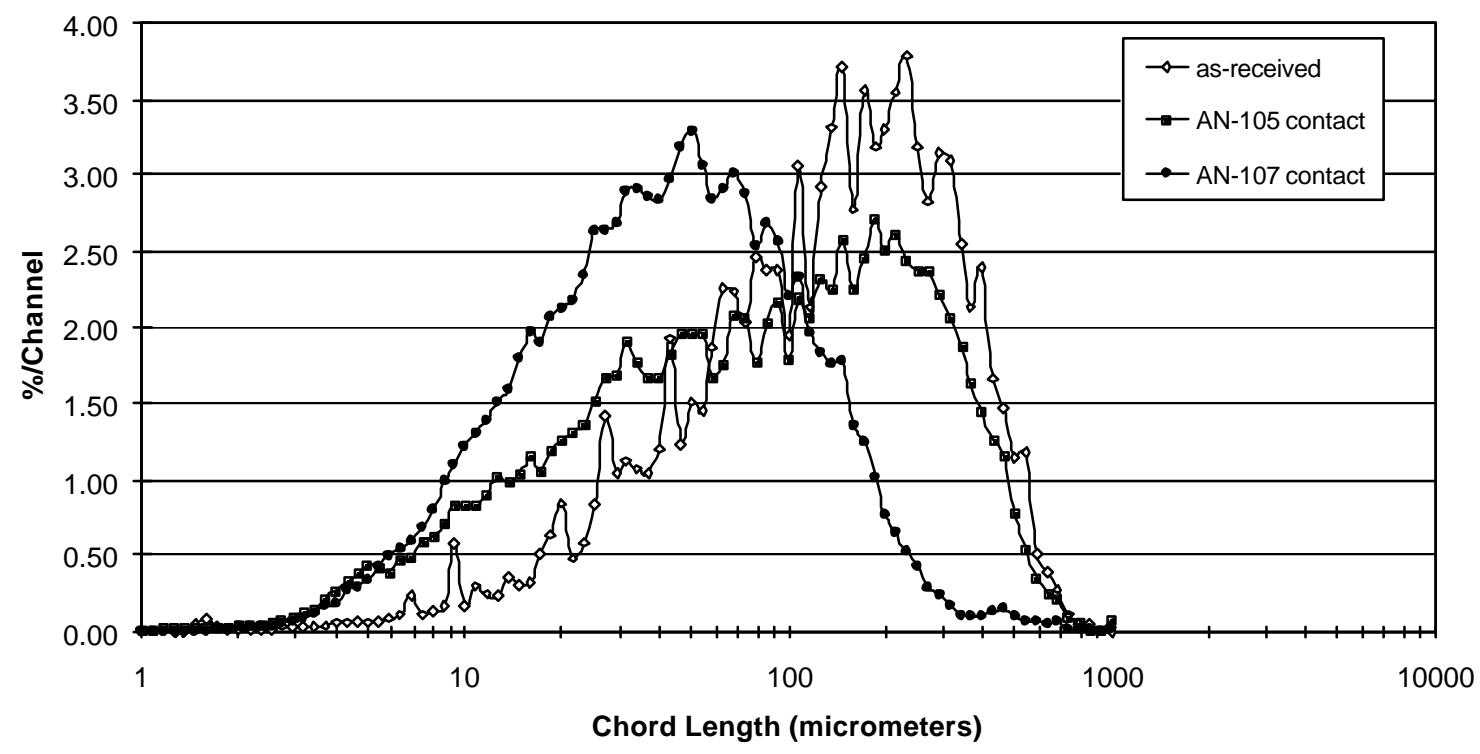

Figure 4-17 AN105 and AN107 contacted chord-length distribution SuperLig ${ }^{\circledR} 644$ One Gallon Batch

\subsubsection{Temporal Effects Summary}

The chemical performance (Cs sorption) of the exposure of Superlig 644 resin to AN105 and AN107 tank simulants was similar to previously observed behavior for this material. That is, maximum sorption is achieved on the order of three to seven days after which sorption slowly declines as a function of time. The Cs sorption behavior was very similar for this resin in both the AN105 and AN107 simulants both in terms of the magnitude and time-dependent changes. For these studies, there was not a statistically significant difference (greater than about 20 percent) in $K_{d}$ values between the maximum sorption and the end of the study (eight weeks of contact).

Precipitates were identified on the resin solids after contact with the simulants. A relatively small surface coverage of an unknown aluminosilicate was identified for resins contacted with AN105 simulant and very large amounts of sodium oxalate solids were identified on resins contacted with AN107 simulant.

From a physical properties standpoint, simulant contact had a very profound influence on the resin character. Optical microscopy showed that resin exposed to AN105 simulant resulted in increasingly rounded resin morphology. Resin contact with the AN107 simulant led to malleable agglomerated resin with smaller resin particles than the starting material. Particle size analysis using an optical technique showed the production of smaller particles during contact and the AN107 contacted solids exhibited a large shift (about one-half an order) of magnitude in the mean chord-length of the particles. 
Because the physical and chemical properties of this resin are presumably changing simultaneously, it is not possible with this dataset to discern the relative contribution from each source or synergistic effects.

\subsection{Storage Conditions}

The results of the storage conditions experiments are organized and discussed in terms of chemical performance of the resin and post-reaction characterization of the resin solids. In these experiments, Superlig® 644 resin was stored under air, DI water, and nitrogen. At specified times resin was removed from storage and contacted with Cs-containing simple alkaline salt simulant for three days. After the contact, the resin was separated from the simulant and the simulant analyzed for stable Cs to evaluate changes in chemical performance due to storage conditions. The resin solids were also analyzed to characterize precipitates that formed during the contacting process.

\subsubsection{Chemical Performance}

Batch contact results from the storage conditions experiments are summarized in Table 4-11. With the exception of the zero-week storage sample (a three-day contact on the initial storage resin samples), the liquid-to-solid ratios are within several percent and the initial Cs concentrations are all the same. This allows a direct comparison of the effects of storage conditions within this dataset using an evaluation of $\mathrm{K}_{\mathrm{d}}$ values from batch contact experiments.

The air storage $K_{d}$ data are plotted as a function of storage time in Figure 4-18. As was observed for the temporal effects study for the shorter contact times, these data exhibit a systematic bias in $\mathrm{K}_{\mathrm{d}}$ values between the two contact sample sizes. This, as discussed previously, is likely due to differences in degree of agitation (i.e., liquid film mass transfer coefficient) between the two sample sizes. Within the air-storage $\mathrm{K}_{\mathrm{d}}$ dataset, there is no systematic trend in $\mathrm{K}_{\mathrm{d}}$ for either the 30 - or $250-\mathrm{mL}$ contact results even though some of the differences are outside the standard error assigned for these results (e.g., the three week 30-mL sample compared to the other $30-\mathrm{mL}$ samples). Less variability was observed between the $250-\mathrm{mL}$ results as compared to the $30-\mathrm{mL}$ samples. $\mathrm{K}_{\mathrm{d}}$ data for all storage conditions as a function of storage time are plotted in Figure 4-19. In all but the one week storage sample, the airstored resin resulted to the lowest $K_{d}$ value. Differences between $K_{d}$ values were up to about 25 percent, but was only statistically different after eight weeks storage.

Storage condition data are plotted in isotherm space for 30-mL samples in Figure 4-20, Figure 4-21 and Figure 4-22 for air, DI water, and nitrogen gas storage, respectively. A similar systematic trend exists between each storage condition, that is degree of sorption generally follows 8 week $>5$ week $>3$ week $\approx 1$ week. Samples for a particular resin storage duration (i.e., 1, 3, 5, and 8 weeks) for all three storage conditions were analyzed for Cs by ICP-MS on the same day and this suggests that an analytical bias is the source of the trends in $\mathrm{K}_{\mathrm{d}}$ as a function of storage time. 
Table 4-11 Summary of chemical performance for storage condition experiments with Simple Alkaline Salt simulant.

\begin{tabular}{|c|c|c|c|c|c|c|c|}
\hline Sample ID & $\begin{array}{c}\text { Storage } \\
\text { Time } \\
\text { (weeks) }\end{array}$ & $\begin{array}{c}\text { Sample } \\
\text { Volume }(\mathrm{mL}) \\
\end{array}$ & $\begin{array}{l}\text { Liquid:Solid } \\
\text { (mL/g dry } \\
\text { resin) }\end{array}$ & $\begin{array}{c}\text { Initial [Cs] } \\
\text { (mole/L) }\end{array}$ & $\begin{array}{c}\text { Final [Cs] } \\
(\mathrm{mole} / \mathrm{L})\end{array}$ & $\begin{array}{l}\text { Solid [Cs] } \\
\text { (mmole/g } \\
\text { dry resin) } \\
\end{array}$ & $\begin{array}{c}\mathrm{Kd} \\
(\mathrm{mL} / \mathrm{g}) \\
\end{array}$ \\
\hline 0-Week Contact & 0 & 250 & 114 & $5.46 \mathrm{E}-04$ & 9.33E-05 & $5.14 \mathrm{E}-02$ & 551 \\
\hline 0-Week Contact Dup & 0 & 30 & 114 & $5.46 \mathrm{E}-04$ & 3.37E-05 & 5.84E-02 & 1731 \\
\hline \multicolumn{8}{|c|}{ Stored Under Air } \\
\hline 1-Week Storage & 1 & 250 & 89 & $5.46 \mathrm{E}-04$ & $8.73 \mathrm{E}-05$ & $4.10 \mathrm{E}-02$ & 470 \\
\hline 1-Week Storage Dup & 1 & 30 & 89 & $5.46 \mathrm{E}-04$ & $3.16 \mathrm{E}-05$ & 4.57E-02 & 1445 \\
\hline 3-Week Storage & 3 & 250 & 93 & $5.46 \mathrm{E}-04$ & 9.63E-05 & 4.16E-02 & 431 \\
\hline 3-Week Storage Dup & 3 & 30 & 93 & $5.46 \mathrm{E}-04$ & $5.73 \mathrm{E}-05$ & $4.54 \mathrm{E}-02$ & 793 \\
\hline 5-Week Storage & 5 & 250 & 88 & $5.46 \mathrm{E}-04$ & $7.00 \mathrm{E}-05$ & 4.17E-02 & 595 \\
\hline 5-Week Storage Dup & 5 & 30 & 87 & $5.46 \mathrm{E}-04$ & $2.05 \mathrm{E}-05$ & $4.58 \mathrm{E}-02$ & 2235 \\
\hline 8-Week Storage & 8 & 250 & 89 & $5.46 \mathrm{E}-04$ & $9.78 \mathrm{E}-05$ & 4.00E-02 & 409 \\
\hline 8-Week Storage Dup & 8 & 30 & 89 & $5.46 \mathrm{E}-04$ & $2.61 \mathrm{E}-05$ & 4.65E-02 & 1779 \\
\hline \multicolumn{8}{|c|}{ Stored Under DI Water } \\
\hline 1-Week Storage & 1 & 250 & 89 & $5.46 \mathrm{E}-04$ & 9.93E-05 & $3.98 \mathrm{E}-02$ & 401 \\
\hline 1-Week Storage Dup & 1 & 30 & 89 & $5.46 \mathrm{E}-04$ & $3.12 E-05$ & 4.58E-02 & 1468 \\
\hline 3-Week Storage & 3 & 250 & 92 & $5.46 \mathrm{E}-04$ & $7.46 \mathrm{E}-05$ & $4.35 \mathrm{E}-02$ & 583 \\
\hline 3-Week Storage Dup & 3 & 30 & 92 & $5.46 \mathrm{E}-04$ & 4.62E-05 & $4.59 \mathrm{E}-02$ & 994 \\
\hline 5-Week Storage & 5 & 250 & 88 & $5.46 \mathrm{E}-04$ & $6.88 \mathrm{E}-05$ & $4.18 \mathrm{E}-02$ & 607 \\
\hline 5-Week Storage Dup & 5 & 30 & 87 & $5.46 \mathrm{E}-04$ & NA & NA & NA \\
\hline 8-Week Storage & 8 & 250 & 89 & $5.46 \mathrm{E}-04$ & $8.13 \mathrm{E}-05$ & $4.15 \mathrm{E}-02$ & 510 \\
\hline 8-Week Storage Dup & 8 & 30 & 90 & $5.46 \mathrm{E}-04$ & $1.81 \mathrm{E}-05$ & 4.73E-02 & 2621 \\
\hline \multicolumn{8}{|c|}{ Stored Under N2 Gas } \\
\hline 1-Week Storage & 1 & 250 & 89 & $5.46 \mathrm{E}-04$ & $8.50 \mathrm{E}-05$ & 4.12E-02 & 484 \\
\hline 1-Week Storage Dup & 1 & 30 & 89 & $5.46 \mathrm{E}-04$ & $3.45 \mathrm{E}-05$ & 4.56E-02 & 1322 \\
\hline 3-Week Storage & 3 & 250 & 89 & $5.46 \mathrm{E}-04$ & $9.48 \mathrm{E}-05$ & 4.02E-02 & 424 \\
\hline 3-Week Storage Dup & 3 & 30 & 89 & $5.46 \mathrm{E}-04$ & $3.24 \mathrm{E}-05$ & $4.58 \mathrm{E}-02$ & 1413 \\
\hline 5-Week Storage & 5 & 250 & 89 & $5.46 \mathrm{E}-04$ & 6.69E-05 & 4.27E-02 & 638 \\
\hline 5-Week Storage Dup & 5 & 30 & 89 & $5.46 \mathrm{E}-04$ & $1.72 \mathrm{E}-05$ & $4.70 \mathrm{E}-02$ & 2741 \\
\hline 8-Week Storage & 8 & 250 & 89 & $5.46 \mathrm{E}-04$ & $7.98 \mathrm{E}-05$ & $4.15 \mathrm{E}-02$ & 520 \\
\hline 8-Week Storage Dup & 8 & 30 & 90 & $5.46 \mathrm{E}-04$ & 1.89E-05 & 4.72E-02 & 2498 \\
\hline
\end{tabular}




\section{Storage Conditions Experiments}

Air Storage

SL 644 One Gallon Batch

Simple Alkaline Simulant

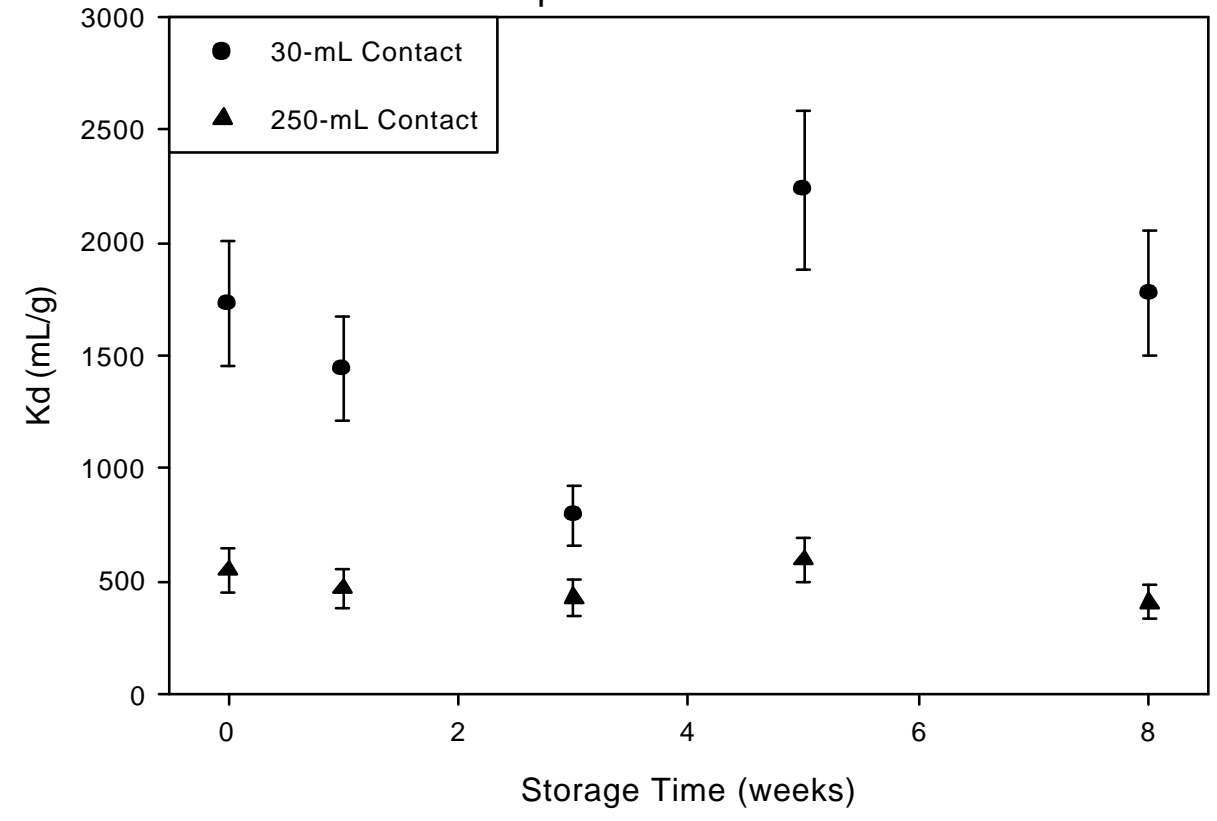

Figure 4-18 Cs $K_{d}$ versus storage duration in air 30 and $250 \mathrm{~mL}$ samples.

Storage Conditions Experiments

All $30 \mathrm{~mL}$ Samples: All StorageConditions

SL 644 One Gallon Batch

Simple Alkaline Simulant

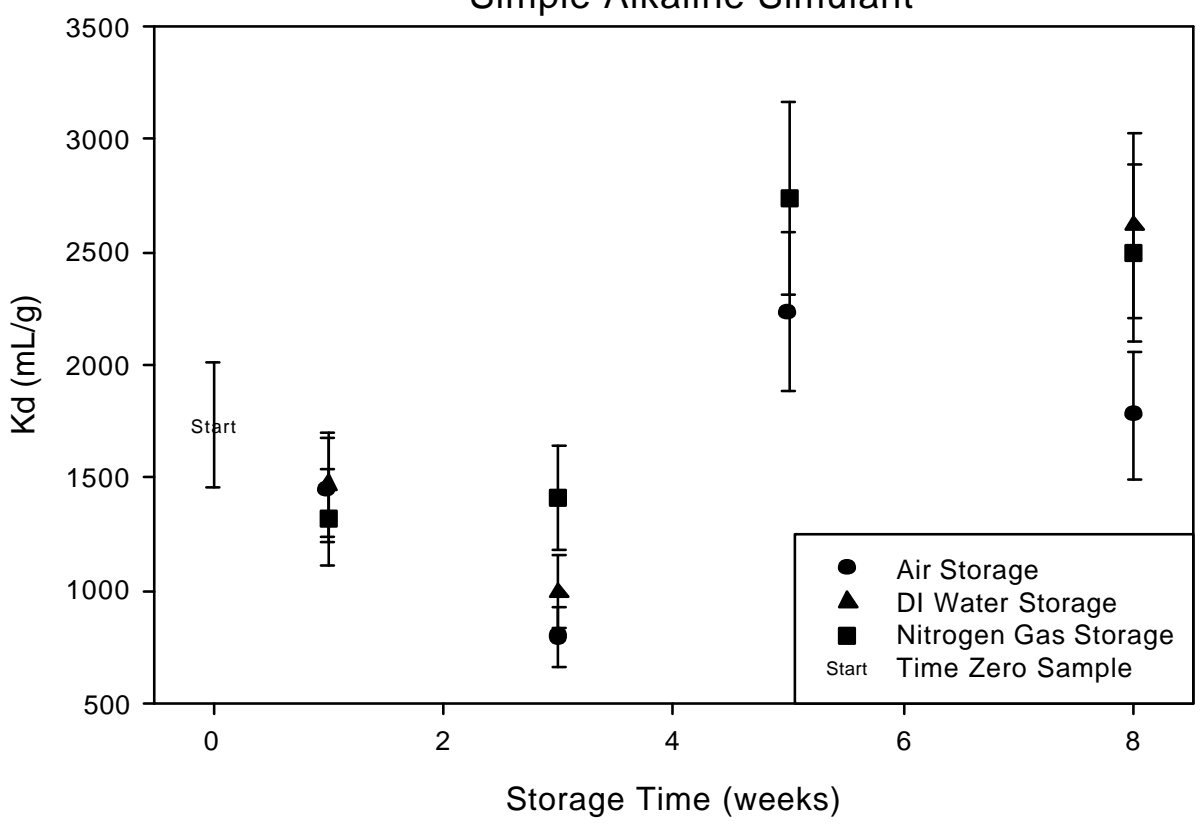

Figure 4-19 Cs $K_{d}$ versus storage duration in all storage conditions $30 \mathrm{~mL}$ samples. 


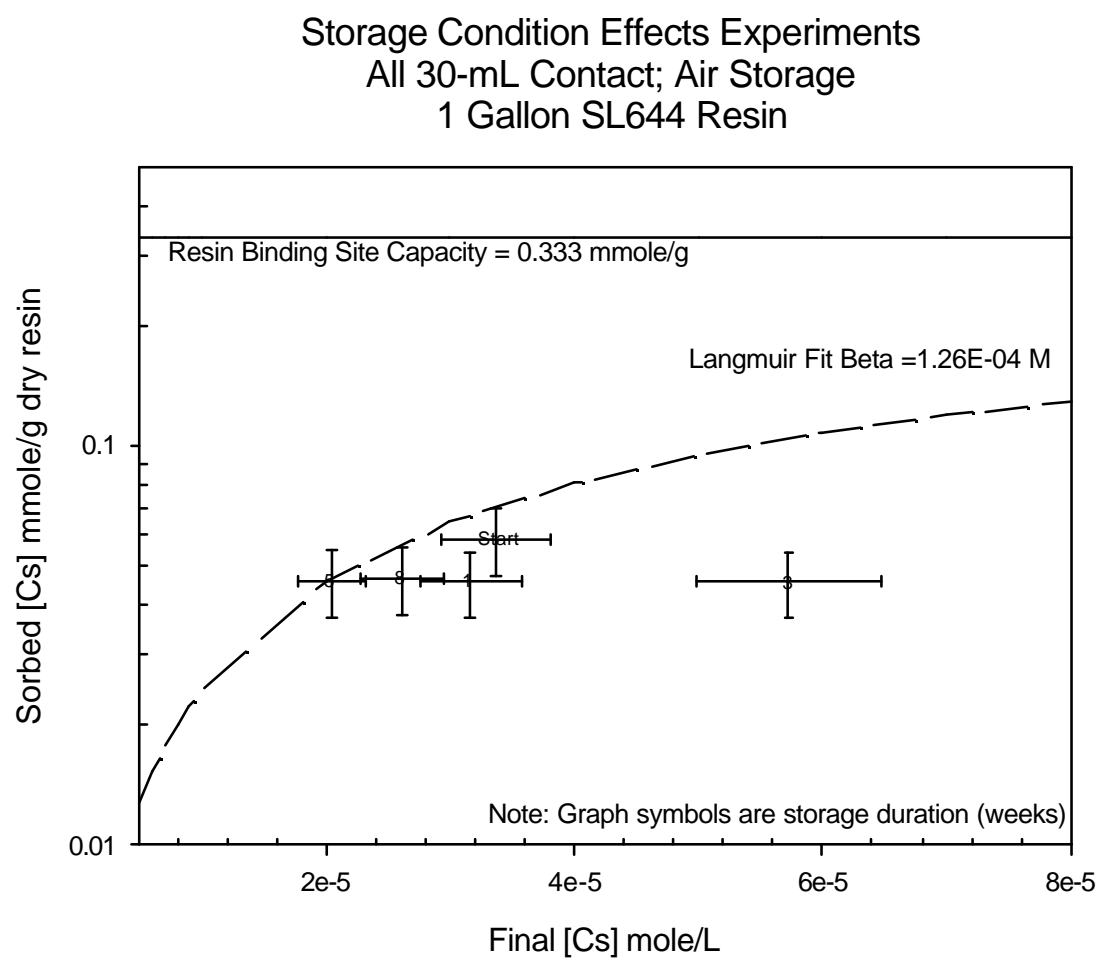

Figure 4-20 $[\mathrm{Cs}]_{\mathrm{aq}}$ versus $Q_{\mathrm{Cs}}$ air storage conditions $30 \mathrm{~mL}$ samples.

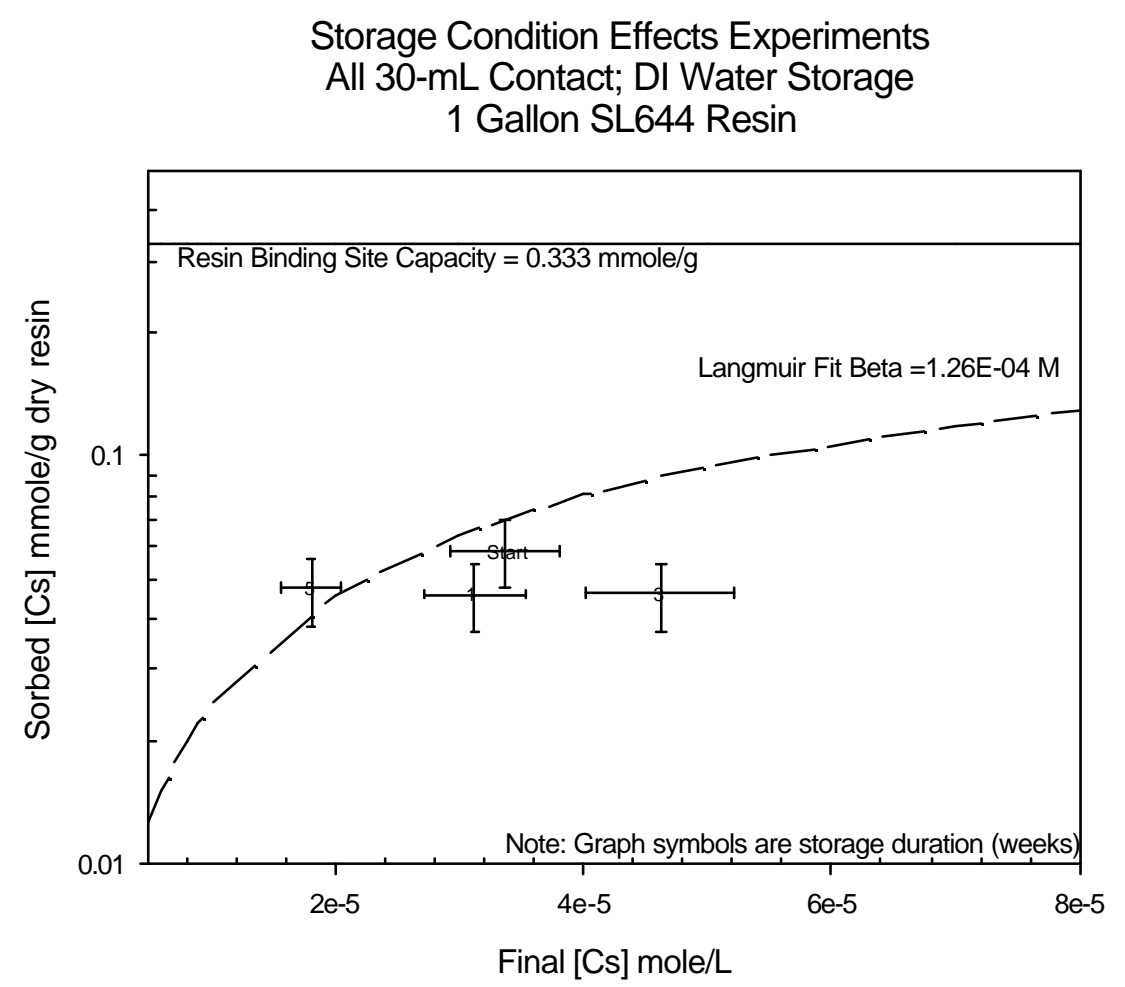

Figure 4-21 $[\mathrm{Cs}]_{\mathrm{aq}}$ versus $\mathbf{Q}_{\mathrm{Cs}}$ DI water storage conditions $30 \mathrm{~mL}$ samples. 


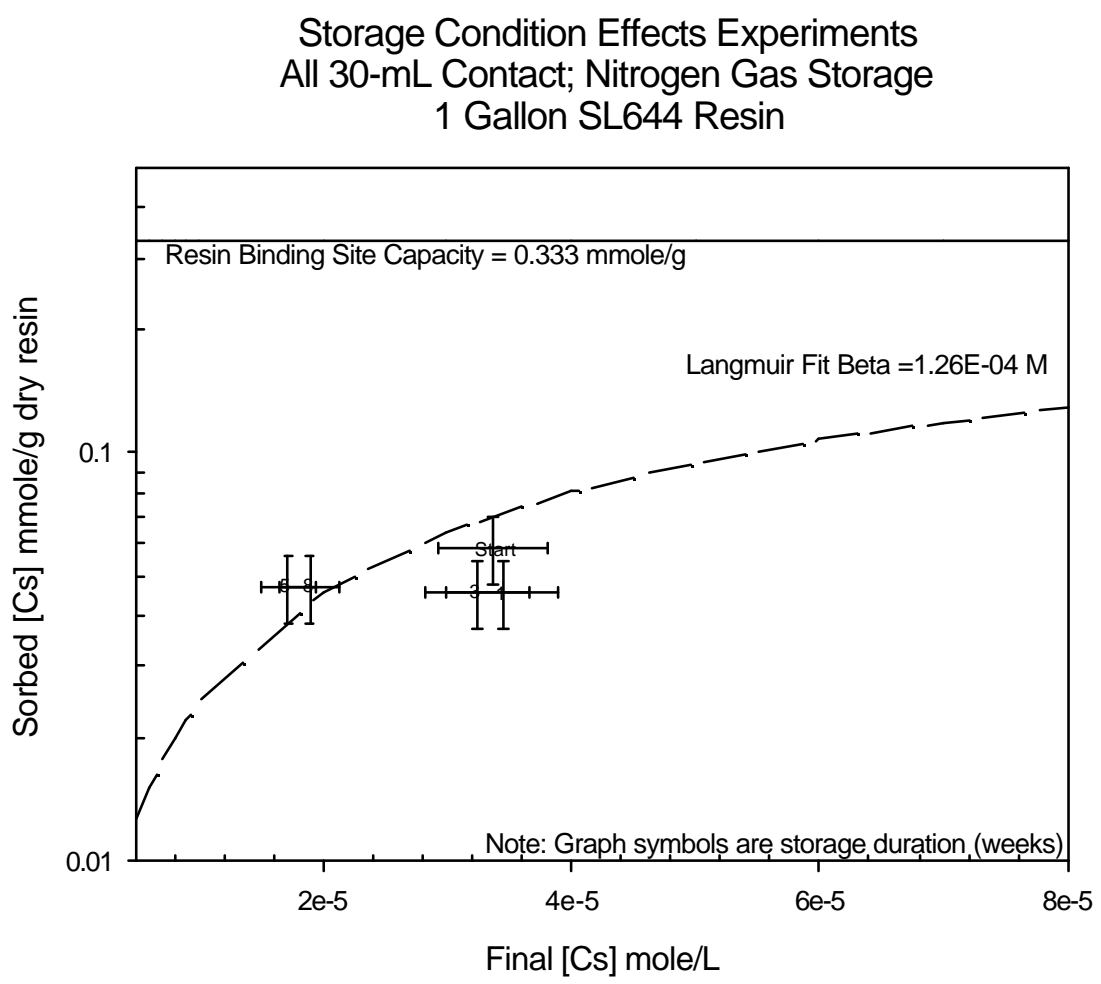

Figure 4-22 $[\mathrm{Cs}]_{\mathrm{aq}}$ versus $\mathrm{Q}_{\mathrm{Cs}}$ nitrogen gas storage conditions $30 \mathrm{~mL}$ samples.

\subsubsection{Resin Characterization}

\subsection{Optical Microscopy}

Qualitatively, no gross changes in particle-size distribution or physical appearance were observed for the SL644 resin exposed to the simple alkaline simulant under a variety of storage conditions including air, nitrogen, and water storage. As with the as received and pretreated resins, a variety of particle morphologies are present.

Resins were not stored in completely airtight containers prior to analysis. Consequently, some of the resins were damp at the time of analysis while others were no longer damp due to evaporation. This moisture effect on the optical appearance of the resin particles further complicates interpretation of small differences in resin appearance due to temporal and storage effects. A white precipitate was observed on a number of dry samples. When probed further using SEM and EDX techniques (see 4.5.1.2), this precipitate was determined to be sodium chloride presumably from evaporation of simulant.

Qualitatively, sharp edges appear to dull and more rounded resin morphologies are observed when comparing simulant exposed resins with the as received material (SL644 hydrogen form) or "pretreated" SL644 sodium form) ( 
Figure 4-2 and Figure 4-23). However, changes in morphologies due to duration of contact are more pronounced than comparing short-term storage ( 0 week) to longer storage ( 3 or 5 weeks). Differences in morphology due to different storage conditions (air, water, nitrogen) could not be distinguished under the optical microscope.

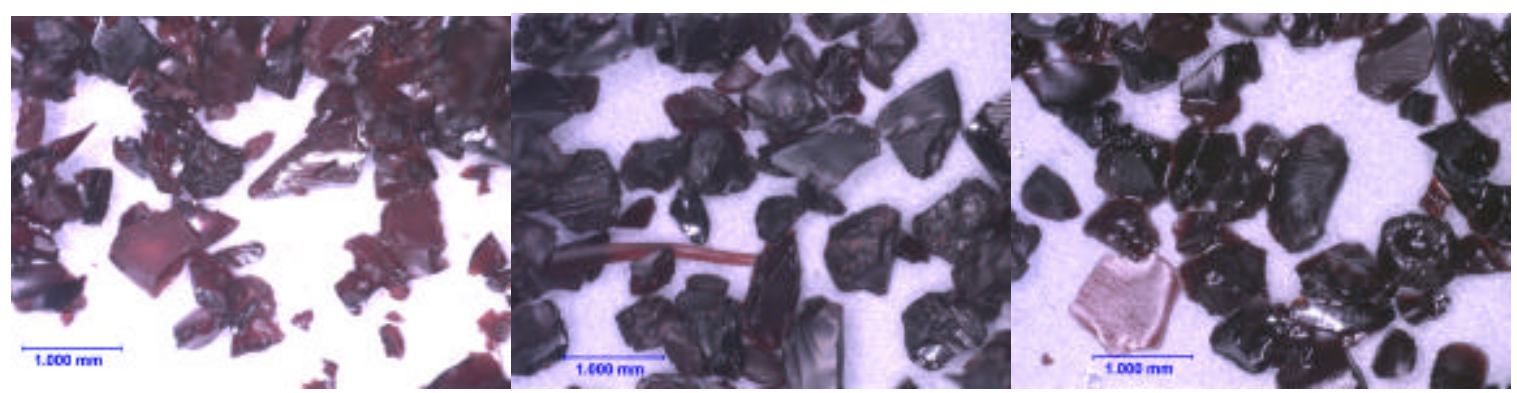

Figure 4-23 SL644 25 gallon Batch 1(left). NaCl-0 weeks storage (center). NaCl-5 weeks-Air (right).

\subsubsection{Scanning Electron Microscopy}

Figure 4-24 shows SEM images of resin exposed to the simple alkaline simulant in both secondary electron (left) and x-ray backscatter (right) modes. Irregular surface morphology is most evident in the $\mathrm{x}$-ray backscatter mode as large fissures in the resin material. Such fissures are also present in the "as received" resin (Figure 4-3). The backscatter image shows a surface precipitate (white spots) more clearly than the secondary electron image. The chemical composition of this surface precipitate was probed by EDX and determined to be sodium chloride (Figure 4-25).
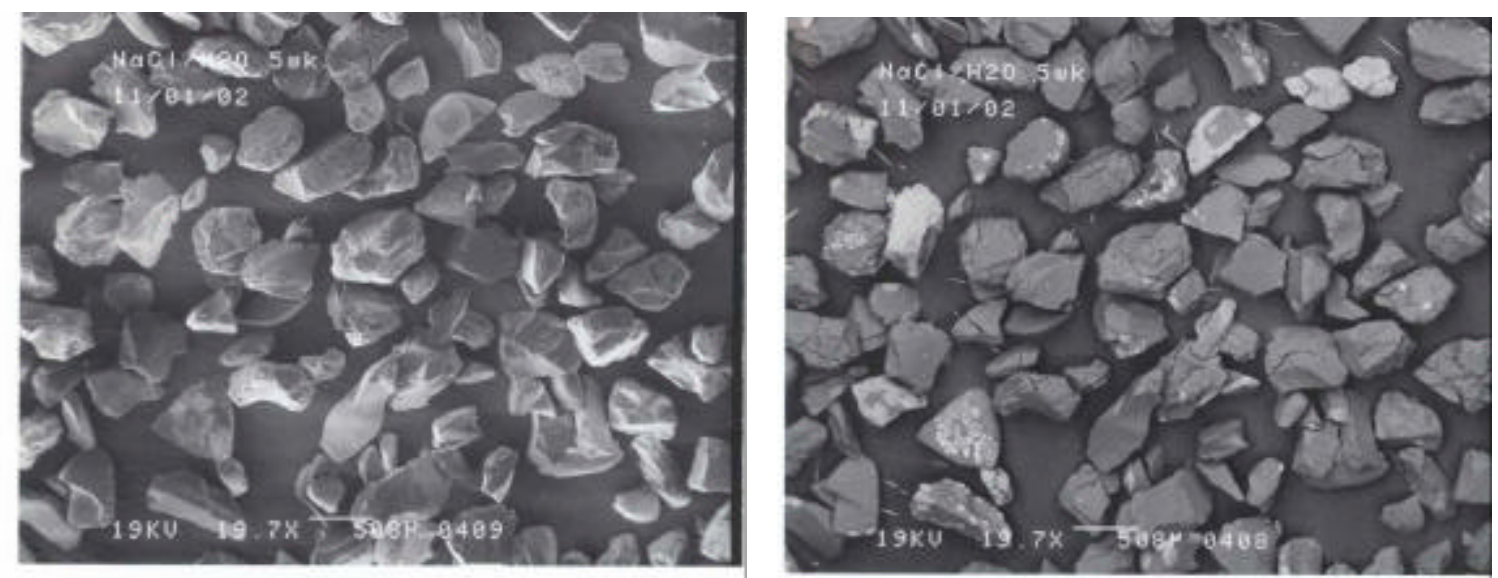

Figure 4-24 NaCl-5 weeks $-\mathrm{H}_{2} \mathrm{O}$. Secondary electron (left). Backscatter image (right) 


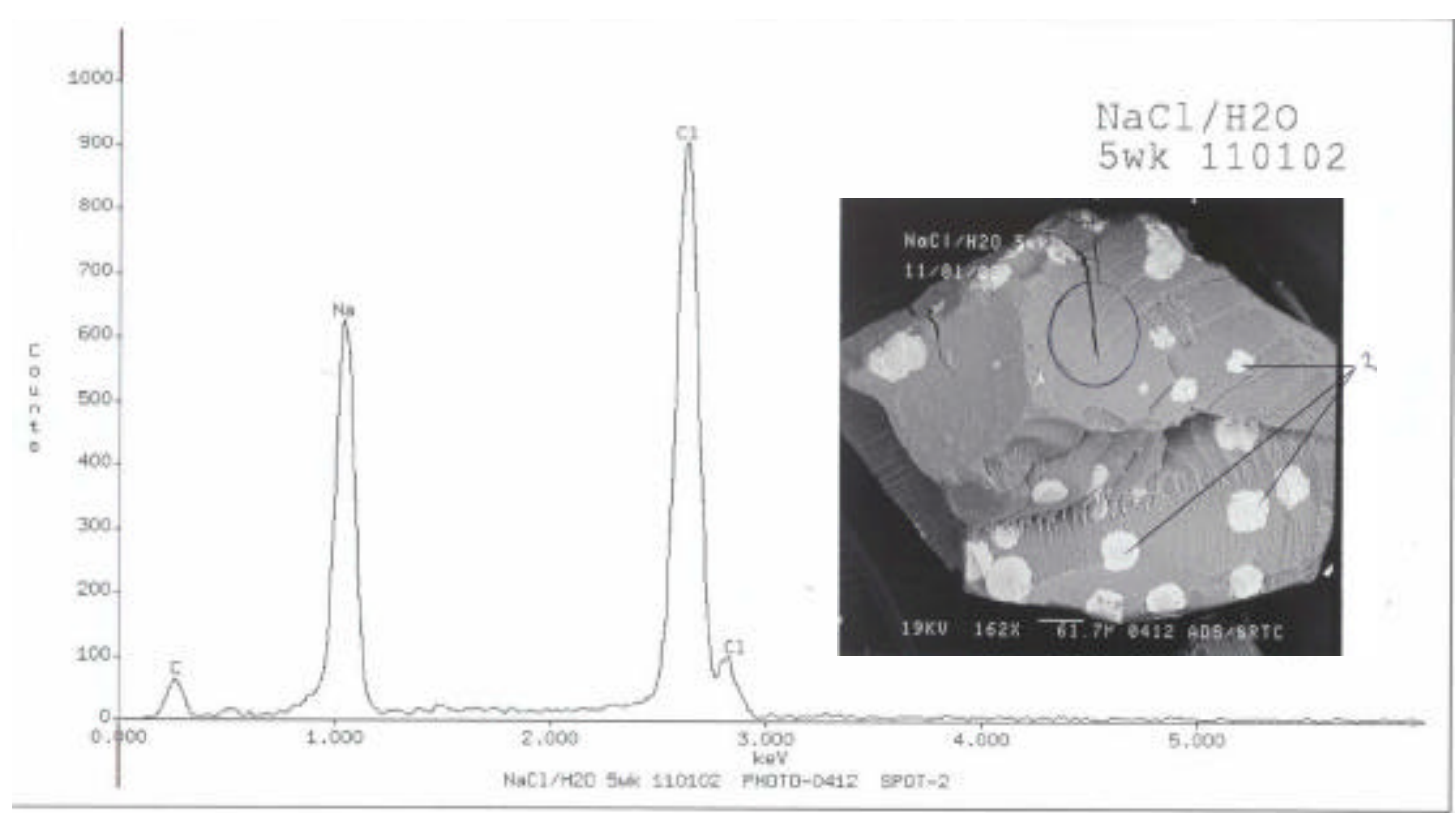

Figure 4-25 $\mathrm{NaCl}-5$ weeks $-\mathrm{H}_{2} \mathrm{O}$ (inset) and representative EDX spectrum for spot 2

\subsubsection{X-Ray Diffraction}

No diffractograms were collected on resin reacted with the simple alkaline simulant.

\subsubsection{Storage Conditions Summary}

No systematic trend in $\mathrm{K}_{\mathrm{d}}$ in terms of storage time were observed with any of the storage conditions. These data are complicated by large error bars associated with batch $\mathrm{K}_{\mathrm{d}}$ measurements made from solution-phase analysis and a probable analytical bias arising from different analysis dates.

The air-stored resin led to the lowest $\mathrm{K}_{\mathrm{d}}$ value and the DI-Water and nitrogen-gas stored $\mathrm{K}_{\mathrm{d}}$ values were virtually identical. Differences between $\mathrm{K}_{\mathrm{d}}$ values were up to about 25 percent, but only statistically different after eight weeks storage.

Resin contacted with the simple alkaline simulant showed a similar response to resin exposed to AN105 simulant. That is a gradual rounding of the particles with time. Small amounts of $\mathrm{NaCl}$ precipitates were also observed on the surface of the resin. 


\section{REFERENCES}

Abodishish, H. A. 2001. "Integrated Sr/TRU Precipitation and Cs Ion Exchange Process Validation Test Specifications," Bechtel River Protection Project document, 24590-WTP-TSP-RT-01-027, Rev. 0 (December, 2001).

Bray, L. A., J. E. Amonette, G. N. Brown, T. M. Kafka, and S. F. Yates, 1995. "Efficient Separations and Processing Crosscutting Program: Develop and Test Sorbents," a FY 1995 Annual Progress Report, PNL-10750 (UC-2030), Battelle PNL, September.

Brown, G. N., S. R. Adami, L. A. Bray, S. A. Bryan, C. D. Carlson, K. J. Carson, J. R. DesChane, R. J. Elovich, S. J. Forbes, J. A. Franz, J. C. Linehan, W. J. Shaw, P. K. Tanaka, and M. R. Telander, 1995a. "Chemical and Radiation Stability of SuperLig ${ }_{\circledast}$ 644, Resorcinol-Formaldehyde, and CS-100 Cesium Ion Exchange Materials,” PNL-10772 (UC-2030), Battelle PNL, September.

Brown, G. N., L. A. Bray, R. J. Elovich, R. L. Bruening, R. M. Decker, T. M. Kafka, and L. R. White, 1995b. "Evaluation and Comparison of SuperLig ${ }_{\circledast}$ 644, Resorcinol-Formaldehyde and CS-100 Ion Exchange Materials for the Removal of Cesium from Simulated Alkaline Supernate," PNL-10486 (UC-2030), Battelle PNL, March.

Brown, G. N., L. A. Bray, C. D. Carlson, K. J. Carson, J. R. DesChane, R. J. Elovich, F. V. Hoopes, D. E. Kurath, L. L. Nenninger, and P. K. Tanaka, 1996. "Comparison of Organic and Inorganic Ion Exchangers for Removal of Cesium and Strontium from Simulated and Actual Hanford 241-AW-101 DSSF Tank Waste," PNL-10920 (UC-2030), Battelle PNL, January.

Eibling, R.E., Nash, C.A., WSRC-TR-2000-00338, (SRT-RPP-2000-00017), Hanford Waste Simulants Created to Support the Research and Development on the River Protection Project - Waste Treatment Plant, February, 2001.

Freund, 1971. Mathematical Statistics, $2^{\text {nd }}$ Edition, Prentic-Hall, Inc., New Jersey (section 6.2 starting on page 195).

Hamm, L. L., F. G. Smith, III, and D. J. McCabe, 2000. "Preliminary Ion Exchange Modeling for Removal of Cesium from Hanford Waste Using SuperLig ${ }^{\circledR} 644$ Resin,” BNF-003-98-0220, June 16.

Helfferich, 1995. Ion Exchange, McGraw-Hill series in advanced chemistry, McGraw-Hill Book Company, Inc., New York.

King, W. D., D. J. McCabe, and N. M. Hassan, 2000. "Optimization of Cesium Removal from Hanford Envelope A Simulant with SuperLig ${ }_{\circledast} 644$ Ion Exchange Resin,” BNF-003-9800169, Rev. 0, April 13. 
Nash, C.A., Saito, H.H., WSRC-TR-2000-00506, (SRT-RPP-2001-00006, BNF-003-98-0317), Strontium-Transuranic Precipitation and Crossflow Filtration of 241-AN-102 Large C, April, 2001.

Serkiz, S. M. 2002. "Integrated Sr/TRU Precipitation and Cs Ion Exchange Process Validation Task Technical and QA plan(U)," Westinghouse Savannah River Co. document, WSRC-TR-2002-00132 (SRT-RPP-2002-00029), Rev. 0 (March 2002). 


\section{APPENDIX A. MICROSCOPY DATA}

Compact disc containing complete set of micrographs generated in this study (Table A-1)

Table A-1 Log of optical micrographs, SEM micrographs, EDX spectra, and XRD spectra included in Appendix A.

\begin{tabular}{|c|c|c|c|c|c|c|c|c|}
\hline \multirow[b]{2}{*}{ Resin } & \multirow{2}{*}{$\begin{array}{c}\text { sample } \\
\text { date }\end{array}$} & \multirow[b]{2}{*}{ duration } & \multirow[b]{2}{*}{ other } & \multirow{2}{*}{$\begin{array}{c}\text { optical } \\
7 X\end{array}$} & \multicolumn{3}{|c|}{ SEM } & \multirow[b]{2}{*}{ XRD } \\
\hline & & & & & upper & lower & EDX & \\
\hline $1 \mathrm{gal}$ & 11/11/2002 none & & baseline & 1 & 12 & & & 1 \\
\hline 25 gal Batch 1 & 11/11/2002 none & & baseline & 1 & 22 & 4 & & 1 \\
\hline 25 gal Batch 2 & $11 / 11 / 2002$ none & & baseline & 1 & & & & \\
\hline 25 gal Batch 3 & $11 / 11 / 2002$ none & & baseline & 1 & & & & \\
\hline $1 \mathrm{gal}$ & 8/15/2002 AN105 & $1 \mathrm{wk}$ & & 1 & & & & \\
\hline $1 \mathrm{gal}$ & 8/22/2002 AN105 & 2 wks & & 1 & & & & \\
\hline $1 \mathrm{gal}$ & 8/29/2002 AN105 & 3 wks & & 1 & & & & \\
\hline $1 \mathrm{gal}$ & 9/5/2002 AN105 & 4 wks & & 1 & & & & \\
\hline $1 \mathrm{gal}$ & 9/19/2002 AN105 & 6 wks & & 1 & & & & \\
\hline $1 \mathrm{gal}$ & 10/3/2002 AN105 & 8 wks & shaken & 1 & & & & \\
\hline $1 \mathrm{gal}$ & 10/3/2002 AN105 & 8 wks & Stagnant A & 1 & 8 & 8 & 3 & \\
\hline $1 \mathrm{gal}$ & 10/3/2002 AN105 & 8 wks & Stagnant B & 1 & & & & \\
\hline $1 \mathrm{gal}$ & 10/3/2002 AN105 & $8 \mathrm{wks}$ & Stagnant C & 1 & & & & \\
\hline $1 \mathrm{gal}$ & 7/23/2002 AN107 & 1day & supernate & 1 & & & & \\
\hline $1 \mathrm{gal}$ & 8/6/2002 AN107 & 2 wks & Table 3 & 1 & & & & \\
\hline $1 \mathrm{gal}$ & 8/13/2002 AN107 & $3 \mathrm{wks}$ & & 1 & & & & \\
\hline $1 \mathrm{gal}$ & 8/20/2002 AN107 & 4 wks & 24Rep & 1 & & & & \\
\hline $1 \mathrm{gal}$ & 9/3/2002 AN107 & 6 wks & & 1 & & & & \\
\hline $1 \mathrm{gal}$ & 9/17/2002 AN107 & 8 wks & & 1 & & & & \\
\hline $1 \mathrm{gal}$ & 9/17/2002 AN107 & $8 \mathrm{wks}$ & Stagnant $\mathrm{C}$ & 1 & 8 & 19 & 9 & 1 \\
\hline $1 \mathrm{gal}$ & 9/27/2002 NaCl & 0 wks & Storage & 1 & & & & \\
\hline $1 \mathrm{gal}$ & $10 / 4 / 2002 \mathrm{NaCl}$ & $1 \mathrm{wk}$ & Air & 1 & & & & \\
\hline $1 \mathrm{gal}$ & $10 / 4 / 2002 \mathrm{NaCl}$ & $1 \mathrm{wk}$ & $\mathrm{H} 2 \mathrm{O}$ & 1 & & & & \\
\hline $1 \mathrm{gal}$ & $10 / 4 / 2002 \mathrm{NaCl}$ & $1 \mathrm{wk}$ & $\mathrm{N} 2$ & 1 & & & & \\
\hline $1 \mathrm{gal}$ & $10 / 18 / 2002 \mathrm{NaCl}$ & 3 wks & Air & 1 & & & & \\
\hline $1 \mathrm{gal}$ & $10 / 18 / 2002 \mathrm{NaCl}$ & $3 \mathrm{wks}$ & $\mathrm{H} 2 \mathrm{O}$ & 1 & & & & \\
\hline $1 \mathrm{gal}$ & $10 / 18 / 2002 \mathrm{NaCl}$ & $3 \mathrm{wks}$ & N2 & 1 & & & & \\
\hline $1 \mathrm{gal}$ & $11 / 1 / 2002 \mathrm{NaCl}$ & $5 \mathrm{wks}$ & Air & 1 & & & & \\
\hline $1 \mathrm{gal}$ & $11 / 1 / 2002 \mathrm{NaCl}$ & $5 \mathrm{wks}$ & $\mathrm{H} 2 \mathrm{O}$ & 1 & 4 & 15 & 10 & \\
\hline $1 \mathrm{gal}$ & $11 / 1 / 2002 \mathrm{NaCl}$ & $5 \mathrm{wks}$ & N2 & 1 & & & & \\
\hline
\end{tabular}

